\title{
Stereochemical differences in fluorocyclopropyl amides enable tuning of Btk inhibition and off-target activity
}

James J. Crawford*, Wendy Lee*, Adam R. Johnson, Kelly J. Delatorre, Charles Eigenbrot, Julia Heidmann, Satoko Kakiuchi-Kiyota, Arna Katewa, Jim Kiefer, Lichuan Liu, Joseph W. Lubach, Dinah Misner, Hans Purkey, Karin Reif, Jennifer Vogt, Harvey Wong, Christine Yu, Wendy B. Young

Supporting Information

Table of contents:

Title page S1

Chemistry $\mathrm{S} 2-\mathrm{S} 30$

In vitro pharmacology

S31

In vitro ADME assays $\mathrm{S} 32-\mathrm{S} 33$

Solubility assay S33

hERG automatic patch clamp assay S34

iPSC-derived cardiomyocte multi-electrode array assay S34

Pharmacokinetics study protocols S35 - S37

Animal care and animal care statement S37

Table S1. Broad panel of 220 human kinases of $\mathbf{2 5}$ S38

Table S2. Comparison of kinome selectivity of $\mathbf{2 5}$ vs. $\mathbf{6}$ against the top kinase hits S39 Crystallography S41

Table S3: BTK crystallographic data collection and refinement statistics $\mathrm{S} 42$

SI References

S43 


\section{CHEMISTRY}

All chemicals were used directly as received from commercial suppliers. ${ }^{1} \mathrm{H}$ NMR spectra were recorded on Bruker Avance 400 or $500 \mathrm{MHz}$ spectrometers. Chemical shifts are expressed in $\delta$ ppm referenced to an internal standard, tetramethylsilane $(\delta=0 \mathrm{ppm})$. Abbreviations used in describing peak signals are: $\mathrm{br}=$ broad signal, $\mathrm{s}=$ singlet, $\mathrm{d}=$ doublet, $\mathrm{dd}=$ doublet of doublets, $\mathrm{t}=$ triplet, $\mathrm{q}=$ quartet, $\mathrm{m}=$ multiplet. All final compounds were purified to $>95 \%$ by reverse phase high performance liquid chromatography (HPLC), supercritical fluid chromatography (SFC) or normal phase silica gel flash chromatography. The purity was assessed by reverse phase HPLC with a gradient of 5-95\% acetonitrile in water (with either acid or base modifier) and monitored by absorption at $254 \mathrm{~nm}$. Low-resolution mass spectra were recorded on liquid chromatography-mass spectrometer in electrospray positive (ES+) mode. HRMS experiments were performed on Dionex LC Ultimate3000 coupled with ThermoScientific Q Exactive orbitrap mass spectrometer using ESI as ionization source and a Phenomenex XB-C18, 1.7mm, $50 \times 2.1 \mathrm{~mm}$ column with a $0.7 \mathrm{ml} /$ minute flow rate at $40{ }^{\circ} \mathrm{C}$ for LC separation. Solvent A is water with $0.1 \% \mathrm{FA}$ and solvent $\mathrm{B}$ is acetonitrile with $0.1 \%$ FA. The gradient consisted with $2-98 \%$ solvent B over 7 min and hold $98 \% \mathrm{~B}$ for $1.5 \mathrm{~min}$ following equilibration for $1.0 \mathrm{~min}$. The LC was monitored by absorption at $220 \mathrm{~nm}$ and $254 \mathrm{~nm}$. MS full scan with 10,000 resolution was applied to all experiments.

\section{Scheme S1. Preparation of 25. ${ }^{a}$}
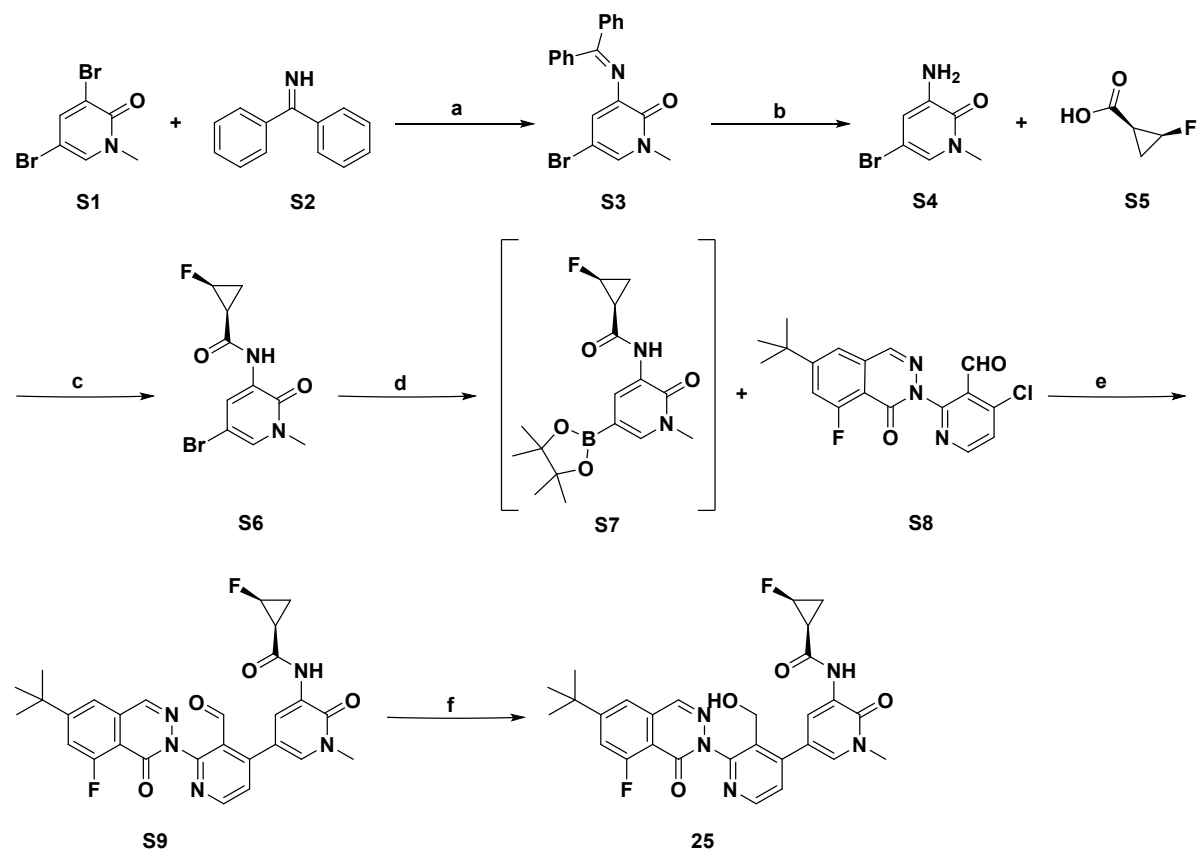

${ }^{a}$ Reagents and conditions: (a) $\mathrm{Pd}_{2}(\mathrm{dba})_{3}$, XantPhos, $\mathrm{Cs}_{2} \mathrm{CO}_{3}$, toluene, $120{ }^{\circ} \mathrm{C}, 18 \mathrm{~h}, 68.5 \%$ yield;

(b) $1 \mathrm{~N} \mathrm{HCl}$, THF, MeOH, RT, 2h, 70.6\% yield; (c) HATU, DIPEA, DMF, $60{ }^{\circ} \mathrm{C}, 83.2 \%$ yield; 
(d) $\mathrm{Pin}_{2} \mathrm{~B}_{2}$, KOAc, XPhos, $\mathrm{Pd}_{2}(\mathrm{dba})_{3}$, dioxane, microwave, $100{ }^{\circ} \mathrm{C}, 30 \min (\mathrm{e}) \mathrm{K}_{3} \mathrm{PO}_{4} \cdot 3 \mathrm{H}_{2} \mathrm{O}, 80$ ${ }^{\circ} \mathrm{C}$, microwave, $1 \mathrm{~h}, 38.6 \%$ yield over 2 steps; (f) $\mathrm{NaBH}_{4}, \mathrm{MeOH}, 68.5 \%$ yield.

(1S,2S)- $N$-(2'-(6-(tert-butyl)-8-fluoro-1-oxophthalazin-2(1H)-yl)-3'-(hydroxymethyl)-1-methyl6-oxo-1,6-dihydro-[3,4'-bipyridin]-5-yl)-2-fluorocyclopropane-1-carboxamide 25

Step 1: 5-bromo-3-((diphenylmethylene)amino)-1-methylpyridin-2(1H)-one $\mathbf{S 3}$

To a vessel with screwed cap charged with 3,5-dibromo-1-methyl-pyridin-2-one (4.0 g, 15.0 $\mathrm{mmol}), \mathrm{Cs}_{2} \mathrm{CO}_{3}$ (8.70 g, $45.1 \mathrm{mmol}, 3.0$ equiv.), tris(dibenzylideneacetone)dipalladium (0) (482 $\mathrm{mg}, 0.53 \mathrm{mmol}, 0.035$ equiv.), and XantPhos ( $870 \mathrm{mg}, 1.5 \mathrm{mmol}, 0.10$ equiv.) was added a solution of diphenylmethanimine ( $3.27 \mathrm{~g}, 18.0 \mathrm{mmol}, 1.2$ equiv.) in toluene $(50 \mathrm{~mL})$. The reaction mixture was degassed for $15 \mathrm{~min}$, vacuum purged and backfilled with $\mathrm{N}_{2}(3 \mathrm{x})$. The vessel was capped, and the reaction mixture was stirred at $140{ }^{\circ} \mathrm{C}$ for $16 \mathrm{~h}$. The reaction mixture was diluted with ethyl acetate and filtered through a pad of Celite. The filtrate was washed with water and brine, dried over $\mathrm{Na}_{2} \mathrm{SO}_{4}$, filtered, and concentrated under reduced pressure. The resulting residue was purified by flash column chromatography ( $\mathrm{SiO}_{2}$ : ethyl acetate / heptane) to afford $3.78 \mathrm{~g}$ of $\mathbf{S 3}$ as yellow solid. Yield: $68.5 \%$. ${ }^{1} \mathrm{H}$ NMR (400 MHz, Chloroform- $d$ ) $\delta 7.79-7.71(\mathrm{~m} \mathrm{2H}), 7.51-7.41(\mathrm{~m}$, 1H), $7.41-7.30(\mathrm{~m}, 6 \mathrm{H}), 7.28-7.20(\mathrm{~m}, 1 \mathrm{H}), 7.03(\mathrm{~d}, \mathrm{~J}=2.7 \mathrm{~Hz}, 1 \mathrm{H}), 6.64(\mathrm{~d}, \mathrm{~J}=2.5 \mathrm{~Hz}, 1 \mathrm{H})$, $3.45(\mathrm{~s}, 3 \mathrm{H})$. MS [ES-MS] (ESI+): $\mathrm{m} / \mathrm{z}$ calcd for $\mathrm{C}_{19} \mathrm{H}_{16} \mathrm{BrN}_{2} \mathrm{O}[\mathrm{M}+\mathrm{H}]^{+}, 367.2$; found, 367 .

Step 2: 3-amino-5-bromo-1-methylpyridin-2(1H)-one $\mathbf{S 4}$

To a stirred solution of 3-(benzhydrylideneamino)-5-bromo-1-methyl-pyridin-2-one $\mathbf{S 3}$ (1.0 g, $2.72 \mathrm{mmol})$ dissolved in tetrahydrofuran $(13.6 \mathrm{~mL})$ and methanol $(2.7 \mathrm{~mL})$ was added $1 \mathrm{M} \mathrm{HCl}$ ( $2.0 \mathrm{~mL}, 3.0$ equiv.), and the reaction mixture was stirred at room temperature for $2 \mathrm{~h}$. Volatile solvent was then evaporated under reduced pressure, and the crude reaction was basified with sat. $\mathrm{NaHCO}_{3}$ solution until neutral $\mathrm{pH}$ and extracted with ethyl acetate (3x). The combined organic layers were washed with water and brine, dried over $\mathrm{Na}_{2} \mathrm{SO}_{4}$, filtered, and concentrated under reduced pressure. The resulting residue was purified by flash column chromatography $\left(\mathrm{SiO}_{2}\right.$ : ethyl acetate / heptane) to afford $390.5 \mathrm{mg}$ of $\mathbf{S 4}$ as a white solid. Yield: $70.6 \%$. ${ }^{1} \mathrm{H}$ NMR (400 MHz, Chloroform- $d$ ) $\delta 6.82(\mathrm{~d}, \mathrm{~J}=2.3 \mathrm{~Hz}, 1 \mathrm{H}), 6.55(\mathrm{~d}, \mathrm{~J}=2.3 \mathrm{~Hz}, 1 \mathrm{H}), 4.34(\mathrm{br} \mathrm{s}, 2 \mathrm{H}), 3.54(\mathrm{~s}, 3 \mathrm{H})$. MS [ES-MS] (ESI+): $\mathrm{m} / \mathrm{z}$ calcd for $\mathrm{C}_{6} \mathrm{H}_{8} \mathrm{BrN}_{2} \mathrm{O}[\mathrm{M}+\mathrm{H}]^{+}, 203$; found, 203.

Step 3: (1S,2S)-N-(5-bromo-1-methyl-2-oxo-1,2-dihydropyridin-3-yl)-2-fluorocyclopropane-1carboxamide S6 
A mixture of 3-amino-5-bromo-1-methyl-pyridin-2-one S4 (389 mg, $1.92 \mathrm{mmol}$ ), (1S,2S)-2fluorocyclopropanecarboxylic acid S5 (300 mg, $2.88 \mathrm{mmol}, 1.5$ equiv.), HATU (1.24 g, 3.26 mmol, 1.7 equiv.), and DIPEA (992 mg, $7.67 \mathrm{mmol}, 4.0$ equiv.) in DMF (9.6 mL) was stirred at $60{ }^{\circ} \mathrm{C}$ under $\mathrm{N}_{2}$ for $16 \mathrm{~h}$. The reaction was quenched with water and extracted with $1: 1 \mathrm{v} / \mathrm{v}$ ether / ethyl acetate $(3 \mathrm{x})$. The combined organic layers were washed with water and brine, dried over $\mathrm{Na}_{2} \mathrm{SO}_{4}$, filtered, and concentrated under reduced pressure. The resulting residue was purified by flash column chromatography $\left(\mathrm{SiO}_{2}\right.$ : ethyl acetate / heptane) to afford $461 \mathrm{mg}$ of $\mathbf{S 6}$ as a white solid. Yield: $83.2 \%$. ${ }^{1} \mathrm{H}$ NMR (400 MHz, Chloroform- $d$ ) $\delta 8.63$ (br s, 1H), 8.51 (d, J = $2.5 \mathrm{~Hz}$, $1 \mathrm{H}), 7.13(\mathrm{~d}, \mathrm{~J}=2.5 \mathrm{~Hz}, 1 \mathrm{H}), 4.89-4.65(\mathrm{~m}, 1 \mathrm{H}), 3.58(\mathrm{~s}, 3 \mathrm{H}), 1.95-1.80(\mathrm{~m}, 2 \mathrm{H}), 1.28-1.15$ (m, 1H). MS [ES-MS] (ESI+): m/z calcd for $\mathrm{C}_{10} \mathrm{H}_{11} \mathrm{BrFN}_{2} \mathrm{O}_{2}[\mathrm{M}+\mathrm{H}]^{+}, 289$; found, 289.

Step 4: (1S,2S)-N-(2'-(6-(tert-butyl)-8-fluoro-1-oxophthalazin-2(1H)-yl)-3'-formyl-1-methyl-6oxo-1,6-dihydro-[3,4'-bipyridin]-5-yl)-2-fluorocyclopropane-1-carboxamide S9

A vial was charged with $(1 S, 2 S)-N$-(5-bromo-1-methyl-2-oxo-1,2-dihydropyridin-3-yl)-2fluorocyclopropane-1-carboxamide S6 (726 mg, $2.51 \mathrm{mmol}, 1.0$ equiv.), bis(pinacolato)diboron (829 mg, 3.26 mmol, 1.3 equiv.), KOAc (493 mg, 5.02 mmol, 2.0 equiv.), XPhos (122 mg, 0.25 mmol, 0.1 equiv.), and tris(dibenzylideneactone)dipalladium (0) (115 mg, $0.126 \mathrm{mmol}, 0.05$ equiv.). Degassed 1,4-dioxane (16 mL) was added, and the reaction mixture was vacuum purged / backfilled with $\mathrm{N}_{2}(3 \mathrm{x})$. The vial was capped and the reaction mixture was microwaved at $100{ }^{\circ} \mathrm{C}$ for $30 \mathrm{~min}$ and cooled to room temperature. To this was added 2-(6-tert-butyl-8-fluoro-1-oxophthalazin-2-yl)-4-chloro-pyridine-3-carbaldehyde S8 (904 mg, $2.51 \mathrm{mmol}, 1.0$ equiv.) followed by a solution of potassium phosphate tribasic (1.37 g, $6.28 \mathrm{mmol}, 2.5$ equiv.) in water $(2.5 \mathrm{~mL})$. The reaction mixture was vacuum purged/ back-filled with $\mathrm{N}_{2}(3 \mathrm{x})$, and the vial was capped. The reaction mixture was then microwaved at $80^{\circ} \mathrm{C}$ for $30 \mathrm{~min}$ and quenched with EtOAc and filtered. The organic layer was washed with water and brine, dried over $\mathrm{Na}_{2} \mathrm{SO}_{4}$, filtered, and concentrated under reduced pressure. The resulting residue was purified by flash column chromatography $\left(\mathrm{SiO}_{2}\right.$ : methanol / ethyl acetate) to afford $516.7 \mathrm{mg}$ of $\mathbf{S 9}$ as a foam. Yield: $38.6 \%$. ${ }^{1} \mathrm{H}$ NMR (400 MHz, Chloroform- $d$ ) $\delta 9.97(\mathrm{~s}, 1 \mathrm{H}), 8.76(\mathrm{~d}, \mathrm{~J}=5.1 \mathrm{~Hz}, 1 \mathrm{H}), 8.69(\mathrm{~s}, 1 \mathrm{H}), 8.60(\mathrm{~d}, \mathrm{~J}=2.4 \mathrm{~Hz}, 1 \mathrm{H}), 8.26$ $(\mathrm{d}, \mathrm{J}=2.5 \mathrm{~Hz}, 1 \mathrm{H}), 7.56-7.44(\mathrm{~m}, 3 \mathrm{H}), 7.10(\mathrm{~d}, \mathrm{~J}=2.4 \mathrm{~Hz}, 1 \mathrm{H}), 4.90-4.67(\mathrm{~m}, 1 \mathrm{H}), 3.65$ (s, $3 \mathrm{H}), 1.95-1.86(\mathrm{~m}, 2 \mathrm{H}), 1.40(\mathrm{~s}, 9 \mathrm{H}), 1.29-1.15(\mathrm{~m}, 1 \mathrm{H})$. MS [ES-MS] (ESI+): m/z calcd for $\mathrm{C}_{28} \mathrm{H}_{26} \mathrm{~F}_{2} \mathrm{~N}_{5} \mathrm{O}_{4}[\mathrm{M}+\mathrm{H}]^{+}$, 534.2; found, 534.2. 
Step 5: (1S,2S)- $N$-(2'-(6-(tert-butyl)-8-fluoro-1-oxophthalazin-2(1H)-yl)-3'-(hydroxymethyl)-1methyl-6-oxo-1,6-dihydro-[3,4'-bipyridin]-5-yl)-2-fluorocyclopropane-1-carboxamide 25

To $\quad((1 S, 2 S)-N$-(2'-(6-(tert-butyl)-8-fluoro-1-oxophthalazin-2(1H)-yl)-3'-formyl-1-methyl-6oxo-1,6-dihydro-[3,4'-bipyridin]-5-yl)-2-fluorocyclopropane-1-carboxamide S9 (1.04 g, 1.95 $\mathrm{mmol})$ in anhydrous $\mathrm{MeOH}(49 \mathrm{~mL})$ at $0{ }^{\circ} \mathrm{C}$ was added sodium borohydride $(185 \mathrm{mg}, 4.88 \mathrm{mmol}$, 2.500 equiv.) portionwise over $30 \mathrm{~min}$. The reaction mixture was stirred at $0{ }^{\circ} \mathrm{C}$ for $1 \mathrm{~h}$ and at $\mathrm{RT}$ for $2 \mathrm{~h}$, then quenched with water. Volatile solvent was removed under reduced pressure, and the crude reaction was diluted with ethyl acetate. The organic layer was washed with water and brine, dried over $\mathrm{Na}_{2} \mathrm{SO}_{4}$, filtered, and concentrated under reduced pressure. The resulting residue was purified by flash column chromatography $\left(\mathrm{SiO}_{2}: \mathrm{MeOH} / \mathrm{EtOAc}\right)$ followed by crystallization from EtOAc / hexane to obtain $716.9 \mathrm{mg}$ of the title compound 25 as a white solid. Yield: $68.5 \%$. ${ }^{1} \mathrm{H}$ NMR (400 MHz, DMSO- $\left.d_{6}\right) \delta 9.75(\mathrm{~s}, 1 \mathrm{H}), 8.56(\mathrm{~d}, \mathrm{~J}=5.2 \mathrm{~Hz}, 1 \mathrm{H}), 8.52(\mathrm{~d}, \mathrm{~J}=2.5 \mathrm{~Hz}, 1 \mathrm{H}), 8.41$ $(\mathrm{d}, \mathrm{J}=2.4 \mathrm{~Hz}, 1 \mathrm{H}), 7.89(\mathrm{~d}, \mathrm{~J}=2.0 \mathrm{~Hz}, 1 \mathrm{H}), 7.80-7.74(\mathrm{~m}, 2 \mathrm{H}), 7.49(\mathrm{~d}, \mathrm{~J}=5.0 \mathrm{~Hz}, 1 \mathrm{H}), 5.01-$ $4.78(\mathrm{~m}, 2 \mathrm{H}), 4.40(\mathrm{t}, \mathrm{J}=4.7 \mathrm{~Hz}, 2 \mathrm{H}), 3.60(\mathrm{~s}, 3 \mathrm{H}), 2.49-2.43(\mathrm{~m}, 1 \mathrm{H}), 1.67-1.53(\mathrm{~m}, 1 \mathrm{H}), 1.39$ (s, 9H), $1.20-1.09$ (m, 1H). ${ }^{13} \mathrm{C}$ NMR (101 MHz, DMSO) $\delta 166.29$ (d), 161.76, 160.02 (d), $159.15,156.34,155.59$ (d), 153.78, 148.22, 147.98, 137.68, 132.45, 131.98, 131.09, 128.22, 125.34, 123.51, 119.68, 117.00, 116.80, 114.91, 113.86 (d), 73.66, 56.37, 37.61, 35.58, 30.49, 21.40 (d), 10.78 (d). HRMS (ESI+) $\mathrm{m} / \mathrm{z}$ found $\mathrm{MH}^{+}$536.2099, $\mathrm{C}_{28} \mathrm{H}_{28} \mathrm{~F}_{2} \mathrm{~N}_{5} \mathrm{O}_{4}$ requires 536.2104. Chiral $\mathrm{t}_{\mathrm{R}}=1.091 \mathrm{~min}$ (Chiralpak IB-N, isocratic $45 \% \mathrm{MeOH} \mathrm{w} / 0.1 \% \mathrm{NH}_{4} \mathrm{OH} / \mathrm{CO}_{2}, 4 \mathrm{~mL} / \mathrm{min}$ flow, $2.5 \mathrm{~min}$ at $40{ }^{\circ} \mathrm{C}, 120$ bar). $[\alpha]_{\mathrm{D}}^{20}=-12.57(\mathrm{c}=1.67 \mathrm{mg} / \mathrm{mL}, \mathrm{MeOH})$.

Scheme S2. Preparation of 7. ${ }^{a}$

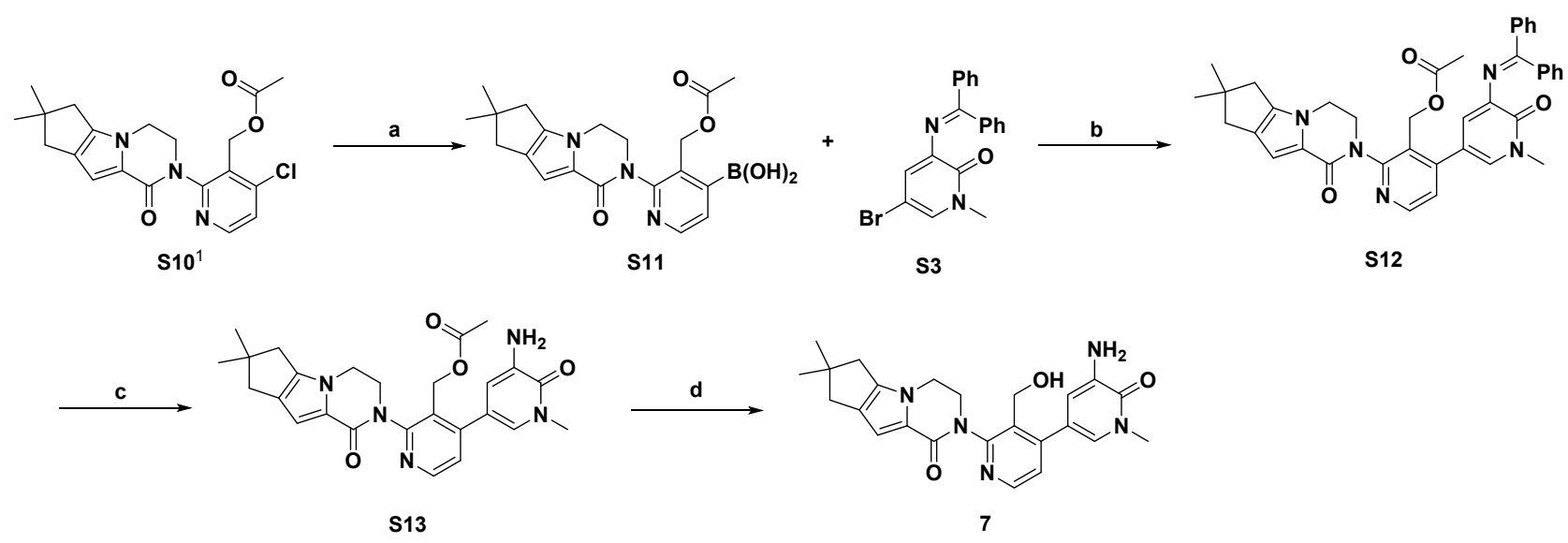


${ }^{a}$ Reagents and conditions: (a) $\mathrm{Pin}_{2} \mathrm{~B}_{2}, \mathrm{KOAc}, \mathrm{XPhos}, \mathrm{PdCl}_{2}$ (dppf), dioxane, $65^{\circ} \mathrm{C}, 4 \mathrm{~h}, 65 \%$ yield; (b) $\mathrm{PdCl}_{2}$ (dppf), $\mathrm{NaOAc}, \mathrm{K}_{3} \mathrm{PO}_{4} \cdot 3 \mathrm{H}_{2} \mathrm{O}, \mathrm{ACN}, \mathrm{H}_{2} \mathrm{O}, 80{ }^{\circ} \mathrm{C}, 1 \mathrm{~h}, 47 \%$ yield; (c) $\mathrm{HCl}$ in dioxane, $0{ }^{\circ} \mathrm{C}, 0.5 \mathrm{~h}, 60 \%$ yield; (d) $\mathrm{LiOH},{ }^{i} \mathrm{PrOH} / \mathrm{THF}, \mathrm{H}_{2} \mathrm{O}, 40^{\circ} \mathrm{C}, 0.5 \mathrm{~h}, 36 \%$ yield.

2-(5-amino-3'-(hydroxymethyl)-1-methyl-6-oxo-1,6-dihydro-[3,4'-bipyridin]-2'-yl)-7,7-dimethyl3,4,7,8-tetrahydro-2H-cyclopenta[4,5]pyrrolo[1,2-a]pyrazin-1(6H)-one 7

Step 1. Preparation of S11.

In a $250-\mathrm{mL}$ single-neck round-bottomed flask equipped with a magnetic stirrer and a reflux condenser was charged with $\mathbf{S 1 0}^{1}$ (4.5 g, $11.6 \mathrm{mmol}$ ) [1434051-95-2], bis(pinacolato)diboron (7.38 g, 29.0 mmol, 2.5 equiv,), $\mathrm{PdCl}_{2}$ (dppf) (473 mg, $0.58 \mathrm{mmol}, 0.05$ equiv.), Xphos (470 mg, $1.16 \mathrm{mmol}, 0.1$ equiv.), potassium acetate ( $3.41 \mathrm{~g} ., 34.8 \mathrm{mmol}, 3.0$ equiv.), and dioxane (100 mL). After three cycles of vacuum/argon flush, the reaction mixture was heated at $65^{\circ} \mathrm{C}$ for $4 \mathrm{~h}$, cooled to room temperature, and filtered. The filtrate was concentrated under reduced pressure to afford crude $\mathrm{S11}$ as a brown-red liquid (4.0 g, 86.8\%). MS (ESI+) m/z found $\mathrm{MH}^{+} 398.3, \mathrm{C}_{20} \mathrm{H}_{25} \mathrm{BN}_{3} \mathrm{O}_{5}$ requires 388.2.

Step 2. Preparation of $\mathbf{S 1 2}$.

A $100-\mathrm{mL}$ single-neck round-bottomed flask equipped with a magnetic stirrer and a reflux condenser was charged with $\mathbf{S 3}(1.0 \mathrm{~g}, 2.70 \mathrm{mmol})$, S11 (1.20 g, $3.00 \mathrm{mmol}, 1.1$ equiv.), $\mathrm{PdCl}_{2}$ (dppf) (122 mg, $0.15 \mathrm{mmol}, 0.056$ equiv.), NaOAc (460 mg, $5.4 \mathrm{mmol}, 2.0$ equiv.), $\mathrm{K}_{3} \mathrm{PO}_{4} \cdot 3 \mathrm{H}_{2} \mathrm{O}(1.27 \mathrm{~g}, 5.4 \mathrm{mmol}, 2.0$ equiv. $), \mathrm{H}_{2} \mathrm{O}(1 \mathrm{~mL})$, and $\mathrm{ACN}(30 \mathrm{~mL})$. After three cycles of vacuum/argon flush, the reaction mixture was heated at $80^{\circ} \mathrm{C}$ for $1 \mathrm{~h}$, cooled to room temperature, and filtered. The filtrate was concentrated under reduced pressure, and the crude was purified by column chromatography $\left(\mathrm{SiO}_{2}: 20: 1 \mathrm{DCM} / \mathrm{MeOH}\right)$ to afford $\mathbf{S 1 2}$ as a yellow solid (800 $\mathrm{mg}, 47 \%$ ). MS (ESI+) $\mathrm{m} / \mathrm{z}$ found $\mathrm{MH}^{+} 640.3, \mathrm{C}_{39} \mathrm{H}_{38} \mathrm{~N}_{5} \mathrm{O}_{4}$ requires 640.3 .

\section{Step 3. Preparation of $\mathbf{S 1 3}$.}

A mixture of $\mathbf{S 1 2}(800 \mathrm{mg}, 1.25 \mathrm{mmol}) \mathrm{in} \mathrm{HCl}$ in dioxane $(4 \mathrm{M}, 20 \mathrm{~mL})$ was stirred at $0^{\circ} \mathrm{C}$ for $0.5 \mathrm{~h}$. The reaction mixture was evaporated in vacuo, and the residue was purified by reversephase prep-HPLC to afford $\mathbf{S 1 3}$ as a pale yellow solid (350 mg, 60\%). ${ }^{1} \mathrm{H}$ NMR (500 MHz, DMSO- $\left.d_{6}\right) \delta 8.43(\mathrm{~d}, J=5.0 \mathrm{~Hz}, 1 \mathrm{H}), 7.09(\mathrm{~d}, J=5.0 \mathrm{~Hz}, 1 \mathrm{H}), 6.81(\mathrm{~d}, J=2.0 \mathrm{~Hz}, 1 \mathrm{H}), 6.77(\mathrm{~s}$, $1 \mathrm{H}), 6.57(\mathrm{~d}, J=2.0 \mathrm{~Hz}, 1 \mathrm{H}), 6.24-6.22(\mathrm{~m}, 1 \mathrm{H}), 5.13-5.11(\mathrm{~m}, 1 \mathrm{H}), 4.51-4.47(\mathrm{~m}, 1 \mathrm{H}), 4.36(\mathrm{~s}$, 2H), 4.24-4.20 (m, 1H), 4.14-4.11 (m, 1H), 4.01-3.98 (m, 1H), $3.62(\mathrm{~s}, 3 \mathrm{H}), 2.55-2.54(\mathrm{~m}, 2 \mathrm{H})$, 
$2.49(\mathrm{~s}, 2 \mathrm{H}), 1.81(\mathrm{~s}, 3 \mathrm{H}), 1.26(\mathrm{~s}, 6 \mathrm{H}) . \mathrm{MS}(\mathrm{ESI}+) \mathrm{m} / \mathrm{z}$ found $\mathrm{MH}^{+} 476.1, \mathrm{C}_{26} \mathrm{H}_{30} \mathrm{~N}_{5} \mathrm{O}_{4}$ requires 476.2 .

Step 4. Preparation of 7.

A mixture of $\mathbf{S 1 3}$ (1.1 g, $2.3 \mathrm{mmol}$ ) and $\mathrm{LiOH}\left(450 \mathrm{mg}, 11.0 \mathrm{mmol}, 4.8\right.$ equiv.) in ${ }^{\mathrm{P} r O H} / \mathrm{THF}$ $(1: 1,10 \mathrm{~mL})$ and $\mathrm{H}_{2} \mathrm{O}(2.5 \mathrm{~mL})$ was stirred at $40{ }^{\circ} \mathrm{C}$ for $0.5 \mathrm{~h}$. The mixture was evaporated in vacuo. The residue was partitioned between EtOAc and water. The combined EtOAc extract was concentrated under reduced pressure. The residue was purified by by column chromatography $\left(\mathrm{SiO}_{2}: 10: 1 \mathrm{DCM} / \mathrm{MeOH}\right)$ to afford the title compound 7 as a pale yellow solid (350 $\mathrm{mg}, 36 \%$ ). ${ }^{1} \mathrm{H} \mathrm{NMR}\left(500 \mathrm{MHz}, \mathrm{CDCl}_{3}\right) \delta 8.44(\mathrm{~d}, J=5.0 \mathrm{~Hz}, 1 \mathrm{H}), 7.59(\mathrm{~d}, J=2.0 \mathrm{~Hz}, 1 \mathrm{H}), 7.21(\mathrm{~d}, J=5.0$ $\mathrm{Hz}, 1 \mathrm{H}), 6.83(\mathrm{~s}, 1 \mathrm{H}), 6.82(\mathrm{~d}, J=2.0 \mathrm{~Hz}, 1 \mathrm{H}), 5.04-5.03(\mathrm{~m}, 1 \mathrm{H}), 4.63-4.62(\mathrm{~m}, 1 \mathrm{H}), 4.50-4.48$ (m, 1H), 4.30-4.28 (m, 1H), 4.16-4.10 (m, 3H), 3.87-3.85 (m, 1H), $3.65(\mathrm{~s}, 3 \mathrm{H}), 2.57-2.56(\mathrm{~m}, 2 \mathrm{H})$, $2.50(\mathrm{~s}, 2 \mathrm{H}), 1.26(\mathrm{~s}, 6 \mathrm{H})$. MS (ESI+) $\mathrm{m} / \mathrm{z}$ found $\mathrm{MH}^{+} 434.2, \mathrm{C}_{24} \mathrm{H}_{28} \mathrm{~N}_{5} \mathrm{O}_{3}$ requires 434.2.

Amides $9-12,14,15,18-21,23,24,26,30-32$ were prepared in a parallel fashion by HATU coupling of advanced intermediates $\mathbf{7}$ or $\mathbf{S 1 5}$ with the corresponding carboxylic acids (Scheme S3). Amides 8 and 13 were prepared from Suzuki coupling of bromide S16a or S16b with boronic acid $\mathbf{S 1 7}{ }^{1}$ to give the acetylated intermediates $\mathbf{S 1 8 a}$ or $\mathbf{S 1 8 b}$, respectively, which was then treated with lithium hydroxide in ${ }^{\mathrm{i} r O H} / \mathrm{THF} / \mathrm{H}_{2} \mathrm{O}$ to afford the desired alcohols 7 or 13, respectively (Scheme S4). For compounds 16, 33, and 34, we employed the one-pot borylation / Suzuki coupling methodology described for the synthesis of $\mathbf{2 5}$ starting from bromo intermediates S19, S6, and $\mathbf{S 2 1}{ }^{3}$ to generate the desired alcohols, respectively (Scheme $\mathbf{S 5}$ and S6).

Scheme S3. Preparation of $9-12,14,15,18-20,23,24,26,27,30-32 .{ }^{a}$
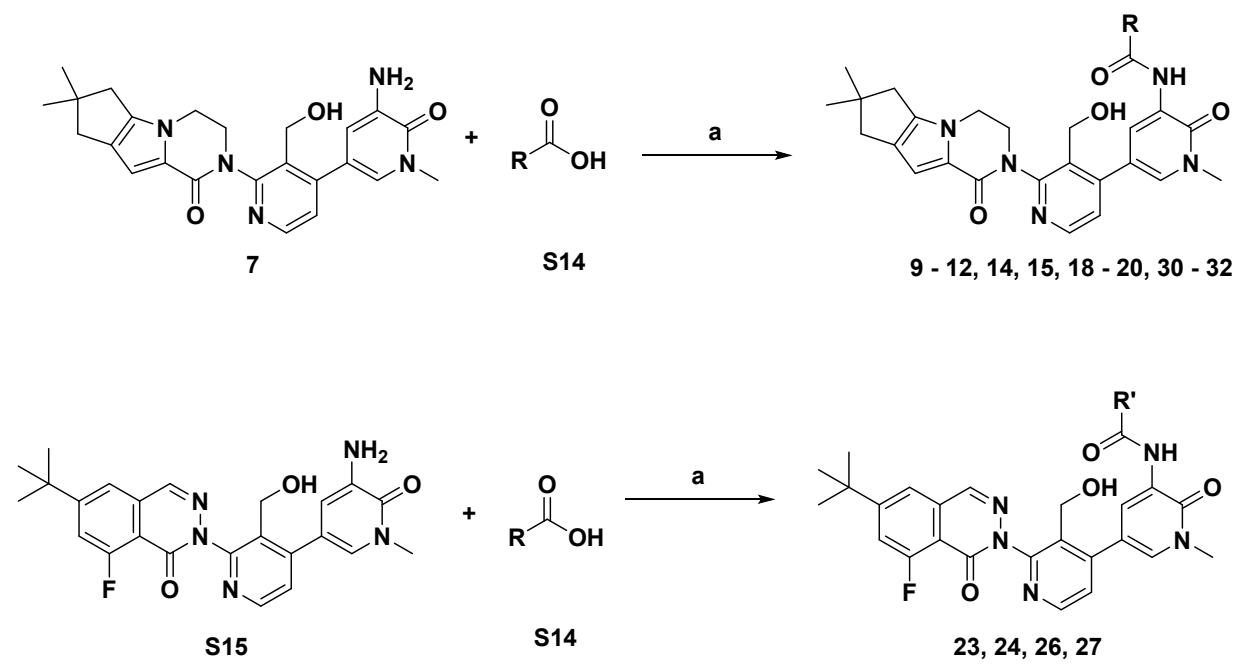
${ }^{a}$ Reagents and conditions: (a) HATU, DIPEA, DMF, $50{ }^{\circ} \mathrm{C}, 18 \mathrm{~h}, 11.5-54 \%$ yield. Representative library synthesis: Preparation of $9-12,14,15,17-20,23,24,26,27,30$ - 32. $N$-(2'-(7,7-dimethyl-1-oxo-1,3,4,6,7,8-hexahydro-2H-cyclopenta[4,5]pyrrolo[1,2-a]pyrazin-2yl)-3'-(hydroxymethyl)-1-methyl-6-oxo-1,6-dihydro-[3,4'-bipyridin]-5-yl)acetamide 9

A screw-capped vial was charged with 2-(5-amino-3'-(hydroxymethyl)-1-methyl-6-oxo-1,6dihydro-[3,4'-bipyridin]-2'-yl)-7,7-dimethyl-3,4,7,8-tetrahydro-2 $H$-cyclopenta[4,5]pyrrolo[1,2a]pyrazin-1(6H)-one 7 (50 mg, $0.115 \mathrm{mmol}$ ), acetic acid (9.0 mg, $0.345 \mathrm{mmol}, 1.3$ equiv.), HATU (66.5 mg, $0.173 \mathrm{mmol}, 1.5$ equiv.), DIPEA (45.2 mg, $0.346 \mathrm{mmol}, 3$ equiv.), and DMF (1 mL). The capped was sealed, and the reaction mixture was stirred at $50{ }^{\circ} \mathrm{C}$ for $18 \mathrm{~h}$. Solvent was concentrated under reduced pressure, and the crude was purified by reverse phase HPLC to give $15.4 \mathrm{mg}$ (28.1\% yield) of 9 as a white solid. ${ }^{1} \mathrm{H}$ NMR (400 MHz, DMSO- $\left.d_{6}\right) \delta 9.37(\mathrm{~s}, 1 \mathrm{H}), 8.47$ $(\mathrm{d}, \mathrm{J}=5.0 \mathrm{~Hz}, 1 \mathrm{H}), 8.43(\mathrm{~d}, \mathrm{~J}=2.4 \mathrm{~Hz}, 1 \mathrm{H}), 7.72(\mathrm{~d}, \mathrm{~J}=2.5 \mathrm{~Hz}, 1 \mathrm{H}), 7.29(\mathrm{~d}, \mathrm{~J}=5.1 \mathrm{~Hz}, 1 \mathrm{H})$, $6.55(\mathrm{~s}, 1 \mathrm{H}), 4.92(\mathrm{t}, \mathrm{J}=5.3 \mathrm{~Hz}, 1 \mathrm{H}), 4.42$ - $4.36(\mathrm{~m}, 2 \mathrm{H}), 4.29-4.14(\mathrm{~m}, 3 \mathrm{H}), 3.90$ - 3.80 (m, 1H), $3.58(\mathrm{~s}, 3 \mathrm{H}), 2.57(\mathrm{~d}, \mathrm{~J}=7.5 \mathrm{~Hz}, 2 \mathrm{H}), 2.43(\mathrm{~s}, 2 \mathrm{H}), 2.14(\mathrm{~s}, 3 \mathrm{H}), 1.22(\mathrm{~s}, 6 \mathrm{H})$. HRMS (ESI+) $\mathrm{m} / \mathrm{z}$ found $\mathrm{MH}^{+} 476.2290, \mathrm{C}_{26} \mathrm{H}_{30} \mathrm{~N}_{5} \mathrm{O}_{4}$ requires 476.2292 .

The following compounds were prepared using the procedure described for 9 and replacing acetic acid with the appropriate carboxylic acids:

$N$-(2'-(7,7-dimethyl-1-oxo-1,3,4,6,7,8-hexahydro-2H-cyclopenta[4,5]pyrrolo[1,2-a]pyrazin-2yl)-3'-(hydroxymethyl)-1-methyl-6-oxo-1,6-dihydro-[3,4'-bipyridin]-5-yl)propionamide $\quad \mathbf{1 0}$ Yield 40.7\%. ${ }^{1} \mathrm{H}$ NMR (400 MHz, DMSO- $\left.d_{6}\right) \delta 9.26(\mathrm{~s}, 1 \mathrm{H}), 8.47(\mathrm{~d}, \mathrm{~J}=5.0 \mathrm{~Hz}, 1 \mathrm{H}), 8.45(\mathrm{~d}, \mathrm{~J}=$ $2.4 \mathrm{~Hz}, 1 \mathrm{H}), 7.73$ (d, J = 2.4 Hz, 1H), 7.30 (d, J = 5.1 Hz, 1H), 6.56 (s, 1H), 4.96 - 4.89 (m, 1H), $4.47-4.33(\mathrm{~m}, 2 \mathrm{H}), 4.30-4.14(\mathrm{~m}, 3 \mathrm{H}), 3.90-3.81(\mathrm{~m}, 1 \mathrm{H}), 3.58(\mathrm{~s}, 3 \mathrm{H}), 2.57$ (d, J = 7.3 Hz, 2H), 2.48 (q, J = 7.5 Hz, 2H), $2.43(\mathrm{~s}, 2 \mathrm{H}), 1.22(\mathrm{~s}, 6 \mathrm{H}), 1.05$ (t, J = 7.5 Hz, 3H). HRMS (ESI+) $\mathrm{m} / \mathrm{z}$ found $\mathrm{MH}^{+} 490.2446, \mathrm{C}_{27} \mathrm{H}_{32} \mathrm{~N}_{5} \mathrm{O}_{4}$ requires 490.2449 .

$N$-(2'-(7,7-dimethyl-1-oxo-1,3,4,6,7,8-hexahydro-2H-cyclopenta[4,5]pyrrolo[1,2-a]pyrazin-2yl)-3'-(hydroxymethyl)-1-methyl-6-oxo-1,6-dihydro-[3,4'-bipyridin]-5-yl)butyramide 11: Yield 41.2\%. ${ }^{1} \mathrm{H}$ NMR (400 MHz, DMSO-d 6 ) $\delta 9.27(\mathrm{~s}, 1 \mathrm{H}), 8.47(\mathrm{~d}, \mathrm{~J}=5.0 \mathrm{~Hz}, 1 \mathrm{H}), 8.45$ (d, J = 2.3 $\mathrm{Hz}, 1 \mathrm{H}), 7.73(\mathrm{~d}, \mathrm{~J}=2.3 \mathrm{~Hz}, 1 \mathrm{H}), 7.30$ (d, J = 5.1 Hz, 1H), $6.56(\mathrm{~s}, 1 \mathrm{H}), 4.97-4.92(\mathrm{~m}, 1 \mathrm{H}), 4.47$ - $4.33(\mathrm{~m}, 2 \mathrm{H}), 4.30-4.12(\mathrm{~m}, 3 \mathrm{H}), 3.90-3.80(\mathrm{~m}, 1 \mathrm{H}), 3.58(\mathrm{~s}, 3 \mathrm{H}), 2.64-2.52(\mathrm{~m}, 2 \mathrm{H}), 2.45$ $(\mathrm{d}, \mathrm{J}=7.3 \mathrm{~Hz}, 1 \mathrm{H}), 2.42(\mathrm{~s}, 3 \mathrm{H}), 1.58$ (h, J = $7.3 \mathrm{~Hz}, 2 \mathrm{H}), 1.22(\mathrm{~s}, 6 \mathrm{H}), 0.89$ (t, J = $7.3 \mathrm{~Hz}, 3 \mathrm{H})$. 
${ }^{13} \mathrm{C}$ NMR (101 MHz, DMSO) $\delta 172.31,159.22,156.41,154.66,147.88,147.74,140.90,132.06$, 130.65, 128.04, 125.77, 125.56, 123.47, 123.41, 115.64, 108.86, 57.20, 47.79, 45.30, 41.95, 40.71, 38.96, 37.99, 37.59, 30.16, 30.05, 18.53, 13.54. HRMS (ESI+) m/z found $\mathrm{MH}^{+}$504.2601, $\mathrm{C}_{28} \mathrm{H}_{34} \mathrm{~N}_{5} \mathrm{O}_{4}$ requires 504.2605.

$N$-(2'-(7,7-dimethyl-1-oxo-1,3,4,6,7,8-hexahydro-2H-cyclopenta[4,5]pyrrolo[1,2-a]pyrazin-2yl)-3'-(hydroxymethyl)-1-methyl-6-oxo-1,6-dihydro-[3,4'-bipyridin]-5-yl)isobutyramide

Yield 11.5\%. ${ }^{1} \mathrm{H}$ NMR (400 MHz, DMSO-d $) \delta 9.23(\mathrm{~s}, 1 \mathrm{H}), 8.47(\mathrm{~d}, \mathrm{~J}=5.0 \mathrm{~Hz}, 1 \mathrm{H}), 8.44(\mathrm{~d}, \mathrm{~J}$ $=2.4 \mathrm{~Hz}, 1 \mathrm{H}), 7.74(\mathrm{~d}, \mathrm{~J}=2.4 \mathrm{~Hz}, 1 \mathrm{H}), 7.30(\mathrm{~d}, \mathrm{~J}=5.0 \mathrm{~Hz}, 1 \mathrm{H}), 6.56(\mathrm{~s}, 1 \mathrm{H}), 4.98-4.90(\mathrm{~m}, 1 \mathrm{H})$, $4.49-4.33(\mathrm{~m}, 2 \mathrm{H}), 4.30-4.11(\mathrm{~m}, 3 \mathrm{H}), 3.89-3.81(\mathrm{~m}, 1 \mathrm{H}), 3.58(\mathrm{~s}, 3 \mathrm{H}), 2.95-2.84(\mathrm{~m}, 1 \mathrm{H})$, $2.60-2.56(\mathrm{~m}, 2 \mathrm{H}), 2.43(\mathrm{~s}, 2 \mathrm{H}), 1.22(\mathrm{~s}, 6 \mathrm{H}), 1.08(\mathrm{~d}, \mathrm{~J}=6.8 \mathrm{~Hz}, 6 \mathrm{H})$. HRMS (ESI+) m/z found $\mathrm{MH}^{+}$504.2602, $\mathrm{C}_{28} \mathrm{H}_{34} \mathrm{~N}_{5} \mathrm{O}_{4}$ requires 504.2605.

2-Cyclopropyl- $N$-(2'-(7,7-dimethyl-1-oxo-1,3,4,6,7,8-hexahydro-2H-cyclopenta[4,5]pyrrolo[1,2a]pyrazin-2-yl)-3'-(hydroxymethyl)-1-methyl-6-oxo-1,6-dihydro-[3,4'-bipyridin]-5-yl)acetamide 14: Yield 29.4\%. ${ }^{1} \mathrm{H}$ NMR (400 MHz, DMSO- $\left.d_{6}\right) \delta 9.27(\mathrm{~s}, 1 \mathrm{H}), 8.51-8.44(\mathrm{~m}, 2 \mathrm{H}), 7.73(\mathrm{~d}, \mathrm{~J}=$ $2.4 \mathrm{~Hz}, 1 \mathrm{H}), 7.30(\mathrm{~d}, \mathrm{~J}=5.0 \mathrm{~Hz}, 1 \mathrm{H}), 6.56(\mathrm{~s}, 1 \mathrm{H}), 4.97-4.87(\mathrm{~m}, 1 \mathrm{H}), 4.47-4.33(\mathrm{~m}, 2 \mathrm{H}), 4.32$ - 4.13 (m, 3H), 3.85 - 3.65 (m, 1H), 3.59 (s, 3H), 2.57 (d, J = 7.5 Hz, 2H), 2.43 (s, 2H), 2.37 (d, J $=7.1 \mathrm{~Hz}, 2 \mathrm{H}), 1.22(\mathrm{~s}, 6 \mathrm{H}), 1.08-0.94(\mathrm{~m}, 1 \mathrm{H}), 0.56-0.46(\mathrm{~m}, 2 \mathrm{H}), 0.26-0.17(\mathrm{~m}, 2 \mathrm{H})$. HRMS (ESI+) $\mathrm{m} / \mathrm{z}$ found $\mathrm{MH}^{+} 516.2599, \mathrm{C}_{29} \mathrm{H}_{34} \mathrm{~N}_{5} \mathrm{O}_{4}$ requires 516.2605.

$N$-(2'-(7,7-dimethyl-1-oxo-1,3,4,6,7,8-hexahydro-2H-cyclopenta[4,5]pyrrolo[1,2-a]pyrazin-2yl)-3'-(hydroxymethyl)-1-methyl-6-oxo-1,6-dihydro-[3,4'-bipyridin]-5-yl)oxetane-3carboxamide 15: Yield 12.0\%. ${ }^{1} \mathrm{H}$ NMR (400 MHz, DMSO- $\left.d_{6}\right) \delta 9.52(\mathrm{~s}, 1 \mathrm{H}), 8.53(\mathrm{~d}, \mathrm{~J}=2.5 \mathrm{~Hz}$, 1H), $8.48(\mathrm{~d}, \mathrm{~J}=5.0 \mathrm{~Hz}, 1 \mathrm{H}), 7.76(\mathrm{~d}, \mathrm{~J}=2.5 \mathrm{~Hz}, 1 \mathrm{H}), 7.32(\mathrm{~d}, \mathrm{~J}=5.0 \mathrm{~Hz}, 1 \mathrm{H}), 6.60$ - $6.55(\mathrm{~m}$, 2H), $4.94(\mathrm{t}, \mathrm{J}=5.3 \mathrm{~Hz}, 1 \mathrm{H}), 4.70-4.62(\mathrm{~m}, 3 \mathrm{H}), 4.46-4.38(\mathrm{~m}, 2 \mathrm{H}), 4.30-4.16(\mathrm{~m}, 3 \mathrm{H}), 3.87$ (s, 1H), $3.58(\mathrm{~s}, 3 \mathrm{H}), 2.58(\mathrm{~d}, \mathrm{~J}=7.1 \mathrm{~Hz}, 2 \mathrm{H}), 2.43(\mathrm{~s}, 3 \mathrm{H}), 1.22(\mathrm{~s}, 6 \mathrm{H})$. HRMS (ESI+) m/z found $\mathrm{MH}^{+}$518.2395, $\mathrm{C}_{28} \mathrm{H}_{32} \mathrm{~N}_{5} \mathrm{O}_{5}$ requires 518.2398.

(S)- $N$-(2'-(7,7-dimethyl-1-oxo-1,3,4,6,7,8-hexahydro-2H-cyclopenta[4,5]pyrrolo[1,2-a]pyrazin2-yl)-3'-(hydroxymethyl)-1-methyl-6-oxo-1,6-dihydro-[3,4'-bipyridin]-5-yl)tetrahydrofuran-2carboxamide 17: Yield 35.0\%. ${ }^{1} \mathrm{H}$ NMR (400 MHz, DMSO-d $) \delta 9.39$ (s, 1H), 8.48 (d, J = 5.0 Hz, $1 \mathrm{H}), 8.46(\mathrm{~d}, \mathrm{~J}=2.5 \mathrm{~Hz}, 1 \mathrm{H}), 7.76(\mathrm{~d}, \mathrm{~J}=2.5 \mathrm{~Hz}, 1 \mathrm{H}), 7.31(\mathrm{~d}, \mathrm{~J}=5.0 \mathrm{~Hz}, 1 \mathrm{H}), 6.56(\mathrm{~s}, 1 \mathrm{H}), 4.95$ $(\mathrm{t}, \mathrm{J}=5.3 \mathrm{~Hz}, 1 \mathrm{H}), 4.47(\mathrm{dd}, \mathrm{J}=8.5,5.6 \mathrm{~Hz}, 1 \mathrm{H}), 4.34-4.33(\mathrm{~m}, 2 \mathrm{H}), 4.31-4.14(\mathrm{~m}, 3 \mathrm{H}), 4.00$ $-3.81(\mathrm{~m}, 3 \mathrm{H}), 3.59(\mathrm{~s}, 3 \mathrm{H}), 2.57(\mathrm{~d}, \mathrm{~J}=7.6 \mathrm{~Hz}, 2 \mathrm{H}), 2.42(\mathrm{~s}, 2 \mathrm{H}), 2.29-2.18(\mathrm{~m}, 1 \mathrm{H}), 2.04-$ 
$1.77(\mathrm{~m}, 3 \mathrm{H}), 1.22(\mathrm{~s}, 6 \mathrm{H}) .{ }^{13} \mathrm{C}$ NMR (101 MHz, DMSO) $\delta 171.82,159.23,156.28,154.62,147.93$, $147.54,140.92,132.46,130.71,126.85,125.74,125.58,123.51,122.36,115.87,108.88,77.97$, 69.05, 57.17, 47.79, 45.31, 41.97, 40.72, 38.97, 37.57, 30.16, 30.06, 29.69, 25.09. HRMS (ESI+) $\mathrm{m} / \mathrm{z}$ found $\mathrm{MH}^{+} 532.2550, \mathrm{C}_{29} \mathrm{H}_{34} \mathrm{~N}_{5} \mathrm{O}_{5}$ requires 532.2554

$N$-(2'-(7,7-dimethyl-1-oxo-1,3,4,6,7,8-hexahydro-2H-cyclopenta[4,5]pyrrolo[1,2-a]pyrazin-2yl)-3'-(hydroxymethyl)-1-methyl-6-oxo-1,6-dihydro-[3,4'-bipyridin]-5-yl)-1-fluorocyclopropane1-carboxamide 18: Yield 46.9\%. ${ }^{1} \mathrm{H}$ NMR (400 MHz, DMSO- $\left.d_{6}\right) \delta 9.24(\mathrm{~d}, \mathrm{~J}=3.9 \mathrm{~Hz}, 1 \mathrm{H}), 8.48$ $(\mathrm{d}, \mathrm{J}=5.0 \mathrm{~Hz}, 1 \mathrm{H}), 8.42(\mathrm{~d}, \mathrm{~J}=2.4 \mathrm{~Hz}, 1 \mathrm{H}), 7.82(\mathrm{~d}, \mathrm{~J}=2.4 \mathrm{~Hz}, 1 \mathrm{H}), 7.32(\mathrm{~d}, \mathrm{~J}=5.0 \mathrm{~Hz}, 1 \mathrm{H})$, $6.55(\mathrm{~s}, 1 \mathrm{H}), 4.94(\mathrm{t}, \mathrm{J}=5.3 \mathrm{~Hz}, 1 \mathrm{H}), 4.46-4.34(\mathrm{~m}, 2 \mathrm{H}), 4.30-4.14(\mathrm{~m}, 3 \mathrm{H}), 3.85(\mathrm{~d}, \mathrm{~J}=11.1$ $\mathrm{Hz}, 1 \mathrm{H}), 3.62(\mathrm{~s}, 3 \mathrm{H}), 2.57(\mathrm{~d}, \mathrm{~J}=7.3 \mathrm{~Hz}, 2 \mathrm{H}), 2.43(\mathrm{~s}, 2 \mathrm{H}), 1.56-1.45(\mathrm{~m}, 2 \mathrm{H}), 1.39-1.31(\mathrm{~m}$, $2 \mathrm{H}), 1.22(\mathrm{~s}, 6 \mathrm{H})$. HRMS (ESI+) $\mathrm{m} / \mathrm{z}$ found $\mathrm{MH}^{+}$520.2351, $\mathrm{C}_{28} \mathrm{H}_{31} \mathrm{FN}_{5} \mathrm{O}_{4}$ requires 520.2360.

$(1 S, 2 S)-N$-(2'-(7,7-dimethyl-1-oxo-1,3,4,6,7,8-hexahydro-2H-cyclopenta[4,5]pyrrolo[1,2a]pyrazin-2-yl)-3'-(hydroxymethyl)-1-methyl-6-oxo-1,6-dihydro-[3,4'-bipyridin]-5-yl)-2fluorocyclopropane-1-carboxamide 19: Yield 53.9\%. ${ }^{1} \mathrm{H}$ NMR (400 MHz, DMSO- $\left.d_{6}\right) \delta 9.70(\mathrm{~s}$, $1 \mathrm{H}), 8.47(\mathrm{~d}, \mathrm{~J}=5.0 \mathrm{~Hz}, 1 \mathrm{H}), 8.43(\mathrm{~d}, \mathrm{~J}=2.4 \mathrm{~Hz}, 1 \mathrm{H}), 7.74(\mathrm{~d}, \mathrm{~J}=2.4 \mathrm{~Hz}, 1 \mathrm{H}), 7.30(\mathrm{~d}, \mathrm{~J}=5.1$ $\mathrm{Hz}, 1 \mathrm{H}), 6.56(\mathrm{~s}, 1 \mathrm{H}), 4.93(\mathrm{t}, \mathrm{J}=5.3 \mathrm{~Hz}, 2 \mathrm{H}), 5.01-4.72(\mathrm{~m}, 1 \mathrm{H}), 4.48-4.36(\mathrm{~m}, 2 \mathrm{H}), 4.25-$ $4.14(\mathrm{~m}, 3 \mathrm{H}), 3.85(\mathrm{~d}, \mathrm{~J}=10.1 \mathrm{~Hz}, 1 \mathrm{H}), 3.60$ (s, 3H), 2.57 (d, J = 7.2 Hz, 2H), 2.43 (s, 2H), 1.67 $1.52(\mathrm{~m}, 1 \mathrm{H}), 1.22(\mathrm{~s}, 6 \mathrm{H}), 1.20-1.08(\mathrm{~m}, 1 \mathrm{H}) . \mathrm{MS}(\mathrm{ESI}+) \mathrm{m} / \mathrm{z}$ found $\mathrm{MH}^{+}$found 520.2, $\mathrm{C}_{28} \mathrm{H}_{31} \mathrm{FN}_{5} \mathrm{O}_{4}$ requires 520.2. Chiral $\mathrm{t}_{\mathrm{R}}=0.579$ min (Chiralpak IB-N, isocratic $45 \% \mathrm{MeOH}$ w/ $0.1 \% \mathrm{NH}_{4} \mathrm{OH} / \mathrm{CO}_{2}, 4 \mathrm{~mL} / \mathrm{min}$ flow, $2.5 \mathrm{~min}$ at $40{ }^{\circ} \mathrm{C}, 120$ bar).

$(1 R, 2 R)-\mathrm{N}-(2$ '-(7,7-dimethyl-1-oxo-1,3,4,6,7,8-hexahydro-2H-cyclopenta[4,5]pyrrolo[1,2a]pyrazin-2-yl)-3'-(hydroxymethyl)-1-methyl-6-oxo-1,6-dihydro-[3,4'-bipyridin]-5-yl)-2fluorocyclopropane-1-carboxamide 20: Yield 48.1\%. ${ }^{1} \mathrm{H}$ NMR (400 MHz, DMSO- $\left.d_{6}\right) \delta 9.70(\mathrm{~s}$, $1 \mathrm{H}), 8.47(\mathrm{~d}, \mathrm{~J}=5.1 \mathrm{~Hz}, 1 \mathrm{H}), 8.43(\mathrm{~d}, \mathrm{~J}=2.4 \mathrm{~Hz}, 1 \mathrm{H}), 7.74(\mathrm{~d}, \mathrm{~J}=2.4 \mathrm{~Hz}, 1 \mathrm{H}), 7.30(\mathrm{~d}, \mathrm{~J}=5.0$ $\mathrm{Hz}, 1 \mathrm{H}), 6.56(\mathrm{~s}, 1 \mathrm{H}), 4.93(\mathrm{t}, \mathrm{J}=5.3 \mathrm{~Hz}, 2 \mathrm{H}), 5.04-4.71(\mathrm{~m}, 1 \mathrm{H}), 4.45-4.36(\mathrm{~m}, 2 \mathrm{H}), 4.25-$ $4.15(\mathrm{~m}, 3 \mathrm{H}), 3.85(\mathrm{~d}, \mathrm{~J}=10.5 \mathrm{~Hz}, 1 \mathrm{H}), 3.60$ (s, 3H), 2.57 (d, J = 7.2 Hz, 2H), 2.43 (s, 2H), 1.66 $1.54(\mathrm{~m}, 1 \mathrm{H}), 1.22(\mathrm{~s}, 6 \mathrm{H}), 1.21-1.08(\mathrm{~m}, 1 \mathrm{H})$. HRMS (ESI+) m/z found $\mathrm{MH}^{+}$520.2348, $\mathrm{C}_{28} \mathrm{H}_{31} \mathrm{FN}_{5} \mathrm{O}_{4}$ requires 520.2355. Chiral $\mathrm{t}_{\mathrm{R}}=0.704 \mathrm{~min}$ (Chiralpak IB-N, isocratic $45 \% \mathrm{MeOH}$ w/ $0.1 \% \mathrm{NH}_{4} \mathrm{OH} / \mathrm{CO}_{2}, 4 \mathrm{~mL} / \mathrm{min}$ flow, $2.5 \mathrm{~min}$ at $40{ }^{\circ} \mathrm{C}, 120$ bar).

$N$-(2'-(7,7-dimethyl-1-oxo-1,3,4,6,7,8-hexahydro-2H-cyclopenta[4,5]pyrrolo[1,2-a]pyrazin-2yl)-3'-(hydroxymethyl)-1-methyl-6-oxo-1,6-dihydro-[3,4'-bipyridin]-5-yl)-1- 
hydroxycyclopropane-1-carboxamide 30: Yield 4.1\% ${ }^{1} \mathrm{H}$ NMR (400 MHz, DMSO- $\left.d_{6}\right) \delta 9.76(\mathrm{~s}$, 1H), $8.49-8.45(\mathrm{~m}, 2 \mathrm{H}), 7.75(\mathrm{~d}, \mathrm{~J}=2.4 \mathrm{~Hz}, 1 \mathrm{H}), 7.31(\mathrm{~d}, \mathrm{~J}=5.1 \mathrm{~Hz}, 1 \mathrm{H}), 6.86(\mathrm{~s}, 1 \mathrm{H}), 6.55(\mathrm{~s}$, 1H), $4.94-4.89(\mathrm{~m}, 1 \mathrm{H}), 4.45-4.36(\mathrm{~m}, 2 \mathrm{H}), 4.22$ - $4.15(\mathrm{~m}, 2 \mathrm{H}), 3.89-3.82(\mathrm{~m}, 1 \mathrm{H}), 3.61(\mathrm{~s}$, $3 \mathrm{H}), 2.57(\mathrm{~d}, \mathrm{~J}=7.2 \mathrm{~Hz}, 1 \mathrm{H}), 2.43(\mathrm{~s}, 2 \mathrm{H}), 1.24(\mathrm{~s}, 1 \mathrm{H}), 1.22(\mathrm{~s}, 6 \mathrm{H}), 1.16(\mathrm{q}, \mathrm{J}=3.9,3.5 \mathrm{~Hz}, 2 \mathrm{H})$, $1.02(\mathrm{~d}, \mathrm{~J}=3.4 \mathrm{~Hz}, 2 \mathrm{H}), 0.95(\mathrm{~d}, \mathrm{~J}=6.5 \mathrm{~Hz}, 1 \mathrm{H}) . \mathrm{MS}(\mathrm{ESI}+) \mathrm{m} / \mathrm{z}$ found $\mathrm{MH}^{+} 518.2, \mathrm{C}_{28} \mathrm{H}_{32} \mathrm{~N}_{5} \mathrm{O}_{5}$ requires 518.2 .

$N$-(2'-(7,7-dimethyl-1-oxo-1,3,4,6,7,8-hexahydro-2H-cyclopenta[4,5]pyrrolo[1,2-a]pyrazin-2yl)-3'-(hydroxymethyl)-1-methyl-6-oxo-1,6-dihydro-[3,4'-bipyridin]-5-yl)-2-

morpholinoacetamide 31: Yield 32.2\%. ${ }^{1} \mathrm{H}$ NMR (400 MHz, DMSO- $\left.d_{6}\right) \delta 9.96(\mathrm{~s}, 1 \mathrm{H}), 8.48(\mathrm{~d}, \mathrm{~J}$ $=5.0 \mathrm{~Hz}, 1 \mathrm{H}), 8.45(\mathrm{~d}, \mathrm{~J}=2.4 \mathrm{~Hz}, 1 \mathrm{H}), 7.74(\mathrm{~d}, \mathrm{~J}=2.4 \mathrm{~Hz}, 1 \mathrm{H}), 7.30(\mathrm{~d}, \mathrm{~J}=5.1 \mathrm{~Hz}, 1 \mathrm{H}), 6.55(\mathrm{~s}$, 1H), 4.93 (br s, 1H), 4.46 - 4.34 (m, 2H), $4.28-4.15$ (m, 3H), $3.89-3.81$ (m, 1H), $3.69-3.63$ (m, 4H), $3.60(\mathrm{~s}, 3 \mathrm{H}), 3.27(\mathrm{~s}, 2 \mathrm{H}), 3.17(\mathrm{~s}, 2 \mathrm{H}), 2.61-2.52(\mathrm{~m}, 6 \mathrm{H}), 1.22(\mathrm{~s}, 6 \mathrm{H})$. HRMS (ESI+) $\mathrm{m} / \mathrm{z}$ found $\mathrm{MH}^{+}$561.2817, $\mathrm{C}_{30} \mathrm{H}_{37} \mathrm{~N}_{6} \mathrm{O}_{5}$ requires 561.2820.

$N$-(2'-(7,7-dimethyl-1-oxo-1,3,4,6,7,8-hexahydro-2H-cyclopenta[4,5]pyrrolo[1,2-a]pyrazin-2yl)-3'-(hydroxymethyl)-1-methyl-6-oxo-1,6-dihydro-[3,4'-bipyridin]-5-yl)nicotinamide 32: Yield 37.7\%. ${ }^{1} \mathrm{H}$ NMR (400 MHz, DMSO-d $) \delta 9.72(\mathrm{~s}, 1 \mathrm{H}), 9.08(\mathrm{dd}, \mathrm{J}=2.4,0.9 \mathrm{~Hz}, 1 \mathrm{H}), 8.77$ (dd, J $=4.8,1.6 \mathrm{~Hz}, 1 \mathrm{H}), 8.52-8.49(\mathrm{~m}, 2 \mathrm{H}), 8.31-8.26(\mathrm{~m}, 1 \mathrm{H}), 7.86(\mathrm{~d}, \mathrm{~J}=2.4 \mathrm{~Hz}, 1 \mathrm{H}), 7.60-7.55$ (m 1H), $7.36(\mathrm{~d}, \mathrm{~J}=5.1 \mathrm{~Hz}, 1 \mathrm{H}), 6.56(\mathrm{~s}, 1 \mathrm{H}), 4.99(\mathrm{br} \mathrm{s}, 1 \mathrm{H}), 4.51-4.37(\mathrm{~m}, 2 \mathrm{H}), 4.31$ - 4.16 (m, 3H), $3.91-3.83(\mathrm{~m}, 1 \mathrm{H}), 3.63(\mathrm{~s}, 3 \mathrm{H}), 2.58$ (d, J = $7.4 \mathrm{~Hz}, 2 \mathrm{H}), 2.43$ (s, 2H), 1.22 (s, 6H). HRMS (ESI+) m/z found $\mathrm{MH}+539.2399, \mathrm{C}_{30} \mathrm{H}_{31} \mathrm{~N}_{6} \mathrm{O}_{4}$ requires 539.2401.

The following compounds were prepared using the procedure described for 9 and replacing acetic acid with the appropriate carboxylic acids and substituting intermediate 7 with 2 -(5-amino3'-(hydroxymethyl)-1-methyl-6-oxo-1,6-dihydro-[3,4'-bipyridin]-2'-yl)-6-(tert-butyl)-8fluorophthalazin-1(2H)-one S15.

$N$-(2'-(6-(tert-butyl)-8-fluoro-1-oxophthalazin-2(1H)-yl)-3'-(hydroxymethyl)-1-methyl-6-oxo1,6-dihydro-[3,4'-bipyridin]-5-yl)cyclopropanecarboxamide 23: Yield 69.1\%. ${ }^{1} \mathrm{H}$ NMR (400 MHz, DMSO-d $)_{6} \delta 9.70(\mathrm{~s}, 1 \mathrm{H}), 8.55(\mathrm{~d}, \mathrm{~J}=5.0 \mathrm{~Hz}, 1 \mathrm{H}), 8.52(\mathrm{~d}, \mathrm{~J}=2.5 \mathrm{~Hz}, 1 \mathrm{H}), 8.38(\mathrm{~d}, \mathrm{~J}=2.4$ $\mathrm{Hz}, 1 \mathrm{H}), 7.89$ (d, J = 1.8 Hz, 1H), $7.80-7.71(\mathrm{~m}, 2 \mathrm{H}), 7.47$ (d, J = 5.0 Hz, 1H), 4.89 (t, J = 5.0 $\mathrm{Hz}, 1 \mathrm{H}), 4.43-4.35(\mathrm{~m}, 2 \mathrm{H}), 3.60(\mathrm{~s}, 3 \mathrm{H}), 2.31-2.20(\mathrm{~m}, 1 \mathrm{H}), 1.39(\mathrm{~s}, 9 \mathrm{H}), 0.85-0.72(\mathrm{~m}, 4 \mathrm{H})$. MS (ESI+) $\mathrm{m} / \mathrm{z}$ found $\mathrm{MH}^{+}$518.2, $\mathrm{C}_{28} \mathrm{H}_{29} \mathrm{FN}_{5} \mathrm{O}_{4}$ requires 518.2. 
$(1 R, 2 R)-N-(2 '-(6-(t e r t-b u t y l)-8$-fluoro-1-oxophthalazin-2(1H)-yl)-3'-(hydroxymethyl)-1-methyl6-oxo-1,6-dihydro-[3,4'-bipyridin]-5-yl)-2-fluorocyclopropane-1-carboxamide 24: Yield 64.4\%. ${ }^{1} \mathrm{H}$ NMR (400 MHz, DMSO- $\left.d_{6}\right) \delta 9.72(\mathrm{~s}, 1 \mathrm{H}), 8.56(\mathrm{~d}, \mathrm{~J}=5.0 \mathrm{~Hz}, 1 \mathrm{H}), 8.52(\mathrm{~d}, \mathrm{~J}=2.6 \mathrm{~Hz}, 1 \mathrm{H})$, $8.40(\mathrm{~d}, \mathrm{~J}=2.4 \mathrm{~Hz}, 1 \mathrm{H}), 7.89(\mathrm{~d}, \mathrm{~J}=1.8 \mathrm{~Hz}, 1 \mathrm{H}), 7.80-7.72(\mathrm{~m}, 2 \mathrm{H}), 7.48(\mathrm{~d}, \mathrm{~J}=5.0 \mathrm{~Hz}, 1 \mathrm{H})$, $5.01-4.78(\mathrm{~m}, 2 \mathrm{H}), 4.43-4.36(\mathrm{~m}, 2 \mathrm{H}), 3.60(\mathrm{~s}, 3 \mathrm{H}), 2.49-2.42(\mathrm{~m}, 1 \mathrm{H}), 1.66-1.53(\mathrm{~m}, 1 \mathrm{H})$, $1.39(\mathrm{~s}, 9 \mathrm{H}), 1.20-1.09(\mathrm{~m}, 1 \mathrm{H})$. HRMS (ESI + ) m/z found $\mathrm{MH}^{+} 536.2097, \mathrm{C}_{28} \mathrm{H}_{28} \mathrm{~F}_{2} \mathrm{~N}_{5} \mathrm{O}_{4}$ requires 536.2104. Chiral $t_{\mathrm{R}}=1.403 \mathrm{~min}\left(\right.$ Chiralpak IB-N, isocratic $45 \% \mathrm{MeOH}$ w $/ 0.1 \% \mathrm{NH}_{4} \mathrm{OH} / \mathrm{CO}_{2}, 4$ $\mathrm{mL} / \mathrm{min}$ flow, $2.5 \mathrm{~min}$ at $\left.40{ }^{\circ} \mathrm{C}, 120 \mathrm{bar}\right)$.

$(1 R, 2 S)$ - $N$-(2'-(6-(tert-butyl)-8-fluoro-1-oxophthalazin-2(1H)-yl)-3'-(hydroxymethyl)-1-methyl6-oxo-1,6-dihydro-[3,4'-bipyridin]-5-yl)-2-fluorocyclopropane-1-carboxamide 26: Yield 35.6\%. ${ }^{1} \mathrm{H}$ NMR $\left(400 \mathrm{MHz}\right.$, DMSO- $\left.d_{6}\right) \delta 10.02(\mathrm{~s}, 1 \mathrm{H}), 8.55(\mathrm{~d}, \mathrm{~J}=5.1 \mathrm{~Hz}, 1 \mathrm{H}), 8.52(\mathrm{~d}, \mathrm{~J}=2.6 \mathrm{~Hz}, 1 \mathrm{H})$, $8.35(\mathrm{~d}, \mathrm{~J}=2.4 \mathrm{~Hz}, 1 \mathrm{H}), 7.89$ (d, J = $1.7 \mathrm{~Hz}, 1 \mathrm{H}), 7.79-7.74(\mathrm{~m}, 2 \mathrm{H}), 7.47(\mathrm{~d}, \mathrm{~J}=5.0 \mathrm{~Hz}, 1 \mathrm{H})$, $4.96-4.73(\mathrm{~m}, 2 \mathrm{H}), 4.44-4.33(\mathrm{~m}, 2 \mathrm{H}), 3.60(\mathrm{~s}, 3 \mathrm{H}), 2.98-2.85(\mathrm{~m}, 1 \mathrm{H}), 1.56-1.40(\mathrm{~m}, 1 \mathrm{H})$, 1.39 (s, 9H), $1.25-1.14(\mathrm{~m}, 1 \mathrm{H}) .{ }^{13} \mathrm{C}$ NMR (101 MHz, DMSO) $\delta 169.63,161.77,160.05$ (d), 159.16, 156.36, 155.60 (d), 153.77, 148.15, 148.01, 137.70, 132.75, 131.98, 131.11, 127.91, 125.31, 124.11, 119.71, 117.02, 116.82, 114.83, 113.85 (d), 74.97, 72.75, 56.38, 37.62, 30.49, 20.94 (d), 18.45 (d). HRMS (ESI+) m/z found $\mathrm{MH}^{+}$536.2102, $\mathrm{C}_{28} \mathrm{H}_{28} \mathrm{~F}_{2} \mathrm{~N}_{5} \mathrm{O}_{4}$ requires 536.2104. Chiral $t_{\mathrm{R}}=0.586 \mathrm{~min}\left(\right.$ Chiralpak AD, isocratic $40 \% \mathrm{IPA}$ w $/ 0.1 \% \mathrm{NH}_{4} \mathrm{OH} / \mathrm{CO}_{2}, 4 \mathrm{~mL} / \mathrm{min}$ flow, $2.5 \mathrm{~min}$ at $\left.40^{\circ} \mathrm{C}, 120 \mathrm{bar}\right)$.

$(1 S, 2 R)-N$-(2'-(6-(tert-butyl)-8-fluoro-1-oxophthalazin-2(1H)-yl)-3'-(hydroxymethyl)-1-methyl6-oxo-1,6-dihydro-[3,4'-bipyridin]-5-yl)-2-fluorocyclopropane-1-carboxamide 27: Yield 33.6\%. ${ }^{1} \mathrm{H}$ NMR (400 MHz, DMSO- $\left.d_{6}\right) \delta 10.02(\mathrm{~s}, 1 \mathrm{H}), 8.55(\mathrm{~d}, \mathrm{~J}=5.0 \mathrm{~Hz}, 1 \mathrm{H}), 8.52(\mathrm{~d}, \mathrm{~J}=2.5 \mathrm{~Hz}, 1 \mathrm{H})$, $8.35(\mathrm{~d}, \mathrm{~J}=2.5 \mathrm{~Hz}, 1 \mathrm{H}), 7.89(\mathrm{~d}, \mathrm{~J}=1.9 \mathrm{~Hz}, 1 \mathrm{H}), 7.79-7.74(\mathrm{~m}, 2 \mathrm{H}), 7.47(\mathrm{~d}, \mathrm{~J}=5.0 \mathrm{~Hz}, 1 \mathrm{H})$, $4.94-4.74(\mathrm{~m}, 2 \mathrm{H}), 4.38(\mathrm{t}, \mathrm{J}=5.2 \mathrm{~Hz}, 2 \mathrm{H}), 3.60(\mathrm{~s}, 3 \mathrm{H}), 2.98-2.85(\mathrm{~m}, 1 \mathrm{H}), 1.56-1.40(\mathrm{~m}$, 1H), 1.39 (s, 9H), $1.25-1.14$ (m, 1H). ${ }^{13} \mathrm{C}$ NMR (101 MHz, DMSO) $\delta 169.62,161.77,160.05$ (d), 159.16, 156.36, 155.60 (d), 153.77, 148.15, 148.01, 137.70, 132.75, 131.97, 131.11, 127.89, 125.31, 124.11, 119.71, 117.02, 116.81, 114.83, 113.85 (d), 74.97, 72.75, 56.38, 37.62, 30.49, 20.94 (d), 18.45 (d). HRMS (ESI+) m/z found $\mathrm{MH}^{+}$536.2103; $\mathrm{C}_{28} \mathrm{H}_{28} \mathrm{~F}_{2} \mathrm{~N}_{5} \mathrm{O}_{4}$ requires 536.2104. Chiral $\mathrm{t}_{\mathrm{R}}=0.685 \mathrm{~min}$ (Chiralpak AD, isocratic $40 \% \mathrm{IPA} \mathrm{w} / 0.1 \% \mathrm{NH}_{4} \mathrm{OH} / \mathrm{CO}_{2}, 4 \mathrm{~mL} / \mathrm{min}$ flow, $2.5 \mathrm{~min}$ at $40^{\circ} \mathrm{C}, 120$ bar). 
Scheme S4. Preparation of 8 and 13. ${ }^{a}$

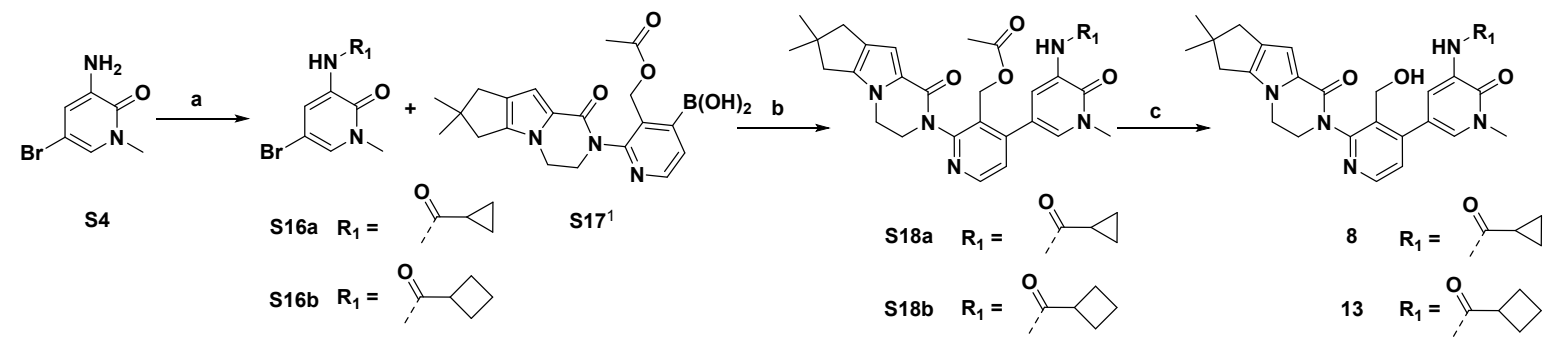

${ }^{a}$ Reagents and conditions: (a) Cyclopropanecarboxylic acid or cyclobutanecarboxylic acid, HATU, DIPEA, DCM, $60{ }^{\circ} \mathrm{C}, 56-72 \%$ yield; (b) $\mathrm{Pd}$ (dppf) $\mathrm{Cl}_{2}, \mathrm{NaOAc}_{3} \mathrm{~K}_{3} \mathrm{PO}_{4} \cdot 3 \mathrm{H}_{2} \mathrm{O}, \mathrm{ACN}, \mathrm{H}_{2} \mathrm{O}$, $100{ }^{\circ} \mathrm{C}, 33-56 \%$ yield; (c) $\mathrm{LiOH},{ }^{\mathrm{i}} \mathrm{PrOH} / \mathrm{THF} / \mathrm{H}_{2} \mathrm{O}, 40{ }^{\circ} \mathrm{C}, 47-65 \%$ yield.

$N$-(2'-(7,7-dimethyl-1-oxo-1,3,4,6,7,8-hexahydro-2 $H$-cyclopenta[4,5]pyrrolo[1,2-a]pyrazin-2yl)-3'-(hydroxymethyl)-1-methyl-6-oxo-1,6-dihydro-[3,4'-bipyridin]-5yl)cyclopropanecarboxamide $\mathbf{8}$

Step 1: N-(5-bromo-1-methyl-2-oxo-1,2-dihydropyridin-3-yl)cyclopropanecarboxamide S16a

To a mixture of cyclopropanecarboxylic acid (180 mg, $2.0 \mathrm{mmol}$ ), HATU (570 mg, $1.5 \mathrm{mmol}$ ) and DIPEA (390 mg, $3.0 \mathrm{mmol})$ in DCM ( $8 \mathrm{~mL}$ ) was added 3-amino-5-bromo-1-methylpyridin$2(1 \mathrm{H})$-one $\mathbf{S 4}$ ( $230 \mathrm{mg}, 1.12 \mathrm{mmol}$ ). The reaction mixture was stirred at $25^{\circ} \mathrm{C}$ for $5 \mathrm{~h}$. The resulting mixture was evaporated under reduced pressure. The resulting residue was purified by flash column chromatography $\left(\mathrm{SiO}_{2}: \mathrm{MeOH} / \mathrm{DCM}\right)$ to afford $220 \mathrm{mg}$ of S16a. Yield 72\%. MS [ESMS] (ESI+): $\mathrm{m} / \mathrm{z}$ calcd for $\mathrm{C}_{10} \mathrm{H}_{12} \mathrm{BrN}_{2} \mathrm{O}_{2}[\mathrm{M}+\mathrm{H}]^{+}, 270.0$; found, 270 .

Step 2: [4-(5-cyclopropaneamido-1-methyl-6-oxo-1,6-dihydropyridin-3-yl)-2-\{4,4-dimethyl-9oxo-1,10-diazatricyclo[6.4.0.02,6]dodeca-2(6),7-dien-10-yl\}pyridin-3-yl]methyl acetate S18a

A 50-mL round-bottomed flask equipped with a magnetic stirrer and a reflux condenser was charged with S16a (220 mg, $0.80 \mathrm{mmol})$, \{3-[(acetyloxy)methyl]-2-\{4,4-dimethyl-9-oxo-1,10diazatricyclo[6.4.0.02,6]dodeca-2(6),7-dien-10-yl\} pyridin-4-yl\} boronic acid $\mathbf{S 1 7}{ }^{1}$ (320 mg, 0.80 mmol), $\mathrm{Pd}(\mathrm{dppf}) \mathrm{Cl}_{2}\left(42 \mathrm{mg}, 0.05 \mathrm{mmol}\right.$ ), $\mathrm{NaOAc}(82 \mathrm{mg}, 1.0 \mathrm{mmol}), \mathrm{K}_{3} \mathrm{PO}_{4} \cdot 3 \mathrm{H}_{2} \mathrm{O}(266 \mathrm{mg}, 1.0$ $\mathrm{mmol})$, water (6 drops), and $\mathrm{ACN}(6 \mathrm{~mL})$. After three cycles of vacuum/argon purge, the mixture was heated at $100^{\circ} \mathrm{C}$ for $1 \mathrm{~h}$. The reaction mixture was filtered, and the filtrate was evaporated under reduced pressure. The residue was purified by flash column chromatography $\left(\mathrm{SiO}_{2}: \mathrm{MeOH}\right.$ 
/ DCM) to afford $150 \mathrm{mg}$ of $\mathbf{S 1 8 a}$ as a solid. Yield 33\%. MS [ES-MS] (ESI+): m/z calcd for $\mathrm{C}_{30} \mathrm{H}_{34} \mathrm{~N}_{5} \mathrm{O}_{5}[\mathrm{M}+\mathrm{H}]^{+}$544.3; found, 544.3.

Step 3: Preparation of $\mathbf{8}$

A mixture of S18a (150 mg, $0.27 \mathrm{mmol})$ and lithium hydroxide (34 mg, $1.4 \mathrm{mmol})$ in ${ }^{\mathrm{P} O \mathrm{PH}} /$ THF $(1: 1,4 \mathrm{~mL})$ and $\mathrm{H}_{2} \mathrm{O}(1 \mathrm{~mL})$ was stirred at $40{ }^{\circ} \mathrm{C}$ for $0.5 \mathrm{~h}$. The mixture was evaporated under reduced pressure and the residue was partitioned between ethyl acetate and water. The organic layer was concentrated under reduced pressure and the residue was purified by reverse-phase prepHPLC to afford $65 \mathrm{mg}$ of the title compound 8 as a pale yellow solid. Yield $65 \%$. ${ }^{1} \mathrm{H}$ NMR (400 MHz, DMSO-d $\left.d_{6}\right)=9.69(\mathrm{~s}, 1 \mathrm{H}), 8.46(\mathrm{~d}, \mathrm{~J}=5.0 \mathrm{~Hz}, 1 \mathrm{H}), 8.41(\mathrm{~d}, \mathrm{~J}=2.2 \mathrm{~Hz}, 1 \mathrm{H}), 7.73(\mathrm{~d}, \mathrm{~J}=2.4$ $\mathrm{Hz}, 1 \mathrm{H}), 7.29$ (d, J = 5.0 Hz, 1H), $6.55(\mathrm{~s}, 1 \mathrm{H}), 4.97-4.89$ (m, 1H), 4.48 - 4.32 (m, 2H), 4.29 4.13 (m, 3H), $3.89-3.79$ (m, 1H), 3.59 (s, 3H), 2.57 (d, J = 7.4 Hz, 2H), 2.42 (s, 2H), 2.30 -2.20 $(\mathrm{m}, 1 \mathrm{H}), 1.22(\mathrm{~s}, 6 \mathrm{H}), 0.82-0.72(\mathrm{~m}, 4 \mathrm{H}) .{ }^{13} \mathrm{C}$ NMR (101 MHz, DMSO) $\delta 172.87,159.20,156.40$, 154.64, 147.86, 147.71, 140.89, 132.05, 130.63, 128.13, 125.77, 125.57, 123.70, 123.44, 115.64, $108.85,57.21,47.79,45.30,41.96,40.72,37.60,30.16,30.06,14.18,7.67$. HRMS (ESI+) m/z found $\mathrm{MH}^{+}$502.2447, $\mathrm{C}_{28} \mathrm{H}_{32} \mathrm{~N}_{5} \mathrm{O}_{4}$ requires 502.2449.

$N$-(2'-(7,7-dimethyl-1-oxo-1,3,4,6,7,8-hexahydro-2H-cyclopenta[4,5]pyrrolo[1,2-a]pyrazin-2yl)-3'-(hydroxymethyl)-1-methyl-6-oxo-1,6-dihydro-[3,4'-bipyridin]-5-

yl)cyclobutanecarboxamide 13:

Compound 13 was prepared in a similar manner to 8, replacing cyclopropanecarboxylic acid with cyclobutanecarboxylic acid. Yield $14.7 \%$ over three steps. ${ }^{1} \mathrm{H}$ NMR (400 MHz, DMSO- $\left.d_{6}\right) \delta$ $9.08(\mathrm{~s}, 1 \mathrm{H}), 8.50-8.45(\mathrm{~m}, 2 \mathrm{H}), 7.73(\mathrm{~d}, \mathrm{~J}=2.5 \mathrm{~Hz}, 1 \mathrm{H}), 7.31$ (d, J = 5.0 Hz, 1H), $6.56(\mathrm{~s}, 1 \mathrm{H})$, $4.95(\mathrm{t}, \mathrm{J}=5.3 \mathrm{~Hz}, 1 \mathrm{H}), 4.47-4.34(\mathrm{~m}, 2 \mathrm{H}), 4.31-4.14(\mathrm{~m}, 3 \mathrm{H}), 3.90-3.81(\mathrm{~m}, 1 \mathrm{H}), 3.57(\mathrm{~s}$, $3 \mathrm{H}), 3.57-3.46(\mathrm{~m}, 1 \mathrm{H}), 2.57$ (d, J = $7.4 \mathrm{~Hz}, 2 \mathrm{H}), 2.43$ (s, 2H), $2.25-2.04(\mathrm{~m}, 4 \mathrm{H}), 1.98-1.85$ (m, 1H), $1.85-1.73(\mathrm{~m}, 1 \mathrm{H}), 1.22$ (s, 6H). ${ }^{13} \mathrm{C}$ NMR (101 MHz, DMSO) $\delta 173.96,159.21,156.41$, $154.65,147.88,147.71,140.90,132.04,130.64,127.99,125.77,125.57,123.47,123.36,115.71$, 108.86, 57.22, 47.80, 45.31, 41.97, 40.72, 39.24, 38.97, 37.58, 30.16, 30.06, 24.61, 17.61. HRMS (ESI+) $\mathrm{m} / \mathrm{z}$ found $\mathrm{MH}^{+} 516.2604, \mathrm{C}_{29} \mathrm{H}_{34} \mathrm{~N}_{5} \mathrm{O}_{4}$ requires 516.2605. 
Scheme S5. Preparation of $\mathbf{1 6} .^{a}$

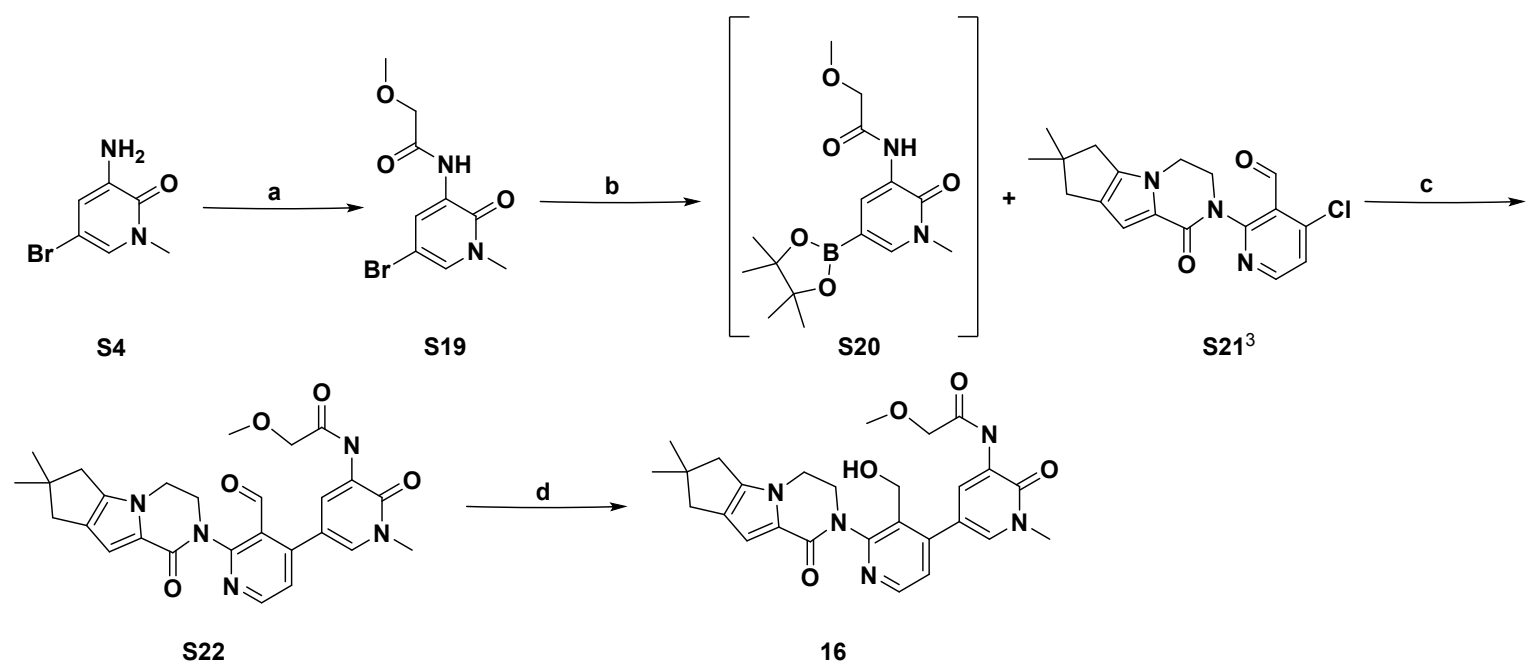

${ }^{a}$ Reagents and conditions: (a) HATU, DIPEA, DMF, $60{ }^{\circ} \mathrm{C}, 78.4 \%$ yield; (b) $\operatorname{Pin}_{2} \mathrm{~B}_{2}$, KOAc, XPhos, $\mathrm{Pd}_{2}(\mathrm{dba})_{3}$, dioxane, microwave, $100{ }^{\circ} \mathrm{C}, 30$ min.; (c) $\mathrm{K}_{3} \mathrm{PO}_{4} \cdot 3 \mathrm{H}_{2} \mathrm{O}, 80{ }^{\circ} \mathrm{C}$, microwave, $1 \mathrm{~h}$, $62.5 \%$ yield over 2 steps; (d) $\mathrm{NaBH}_{4}, \mathrm{MeOH}, 77.2 \%$ yield.

$N$-(2'-(7,7-dimethyl-1-oxo-1,3,4,6,7,8-hexahydro-2 $H$-cyclopenta[4,5]pyrrolo[1,2-a]pyrazin-2yl)-3'-(hydroxymethyl)-1-methyl-6-oxo-1,6-dihydro-[3,4'-bipyridin]-5-yl)-2-methoxyacetamide

\section{6}

Step 1: $N$-(5-bromo-1-methyl-2-oxo-1,2-dihydropyridin-3-yl)-2-methoxyacetamide $\mathbf{S 1 9}$

A mixture of 3-amino-5-bromo-1-methylpyridin-2(1H)-one S4 (1014 mg, $4.99 \mathrm{mmol}), 2$ methoxyacetic acid (540 mg, $5.99 \mathrm{mmol}, 1.2$ equiv.), HATU (3230 mg, $8.49 \mathrm{mmol} .1 .7$ equiv.) and DIPEA (2.6 mL, $1936 \mathrm{mg}, 15.0 \mathrm{mmol}, 3$ equiv.) in DMF (10 mL) was stirred at $60^{\circ} \mathrm{C}$ for $16 \mathrm{~h}$. The resulting mixture was diluted with water and then extracted with $1: 1 \mathrm{v} / \mathrm{v}$ ethyl acetate/ether $(3 \mathrm{x})$. The combined organic layers were washed with brine, dried over $\mathrm{Na}_{2} \mathrm{SO}_{4}$, filtered, and concentrated under reduced pressure. The resulting residue was purified by flash column chromatography ( $\mathrm{SiO}_{2}$ : ethyl acetate / heptane) to afford $1077 \mathrm{mg}$ of $\mathbf{S 1 9}$. Yield $78 \%$. MS [ESMS] (ESI+): $\mathrm{m} / \mathrm{z}$ calcd for $\mathrm{C}_{9} \mathrm{H}_{12} \mathrm{BrN}_{2} \mathrm{O}_{3}[\mathrm{M}+\mathrm{H}]^{+}, 274.9$; found, 274.9 .

\section{Step 2: Preparation of 16}

Compound 16 was prepared in a similar manner to 25, using $N$-(5-bromo-1-methyl-2-oxo-1,2dihydropyridin-3-yl)-2-methoxyacetamide S19 and 4-chloro-2-(7,7-dimethyl-1-oxo-1,3,4,6,7,8hexahydro-2 $H$-cyclopenta[4,5]pyrrolo[1,2-a]pyrazin-2-yl)nicotinaldehyde $\quad \mathbf{S 2 1}^{3}$ as starting materials. Yield 37.8\%. ${ }^{1} \mathrm{H}$ NMR (400 MHz, DMSO- $\left.d_{6}\right) \delta 9.26(\mathrm{~s}, 1 \mathrm{H}), 8.50-8.46(\mathrm{~m}, 2 \mathrm{H}), 7.77$ 
$(\mathrm{d}, \mathrm{J}=2.5 \mathrm{~Hz}, 1 \mathrm{H}), 7.31(\mathrm{~d}, \mathrm{~J}=5.1 \mathrm{~Hz}, 1 \mathrm{H}), 6.56(\mathrm{~s}, 1 \mathrm{H}), 4.97-4.92(\mathrm{~m}, 1 \mathrm{H}), 4.46-4.33(\mathrm{~m}$, $2 \mathrm{H}), 4.29-4.16(\mathrm{~m}, 3 \mathrm{H}), 4.06(\mathrm{~s}, 2 \mathrm{H}), 3.90-3.80(\mathrm{~m}, 1 \mathrm{H}), 3.60(\mathrm{~s}, 3 \mathrm{H}), 3.43(\mathrm{~s}, 3 \mathrm{H}), 2.57(\mathrm{~d}, \mathrm{~J}=$ $7.8 \mathrm{~Hz}, 2 \mathrm{H}), 2.42$ (s, 2H), 1.22 (s, 6H). 13C NMR (101 MHz, DMSO) $\delta 168.34,159.22,156.24$, 154.64, 147.94, 147.53, 140.91, 132.49, 130.71, 126.86, 125.74, 125.58, 123.51, 122.56, 115.86, 108.87, 71.50, 58.81, 57.15, 47.78, 45.30, 41.96, 40.71, 38.96, 37.56, 30.16, 30.04. HRMS (ESI+) $\mathrm{m} / \mathrm{z}$ found $\mathrm{MH}^{+}$506.2396, $\mathrm{C}_{27} \mathrm{H}_{32} \mathrm{~N}_{5} \mathrm{O}_{5}$ requires 506.2398.

Scheme S6. Preparation of $\mathbf{3 3}$ and 34. ${ }^{a}$

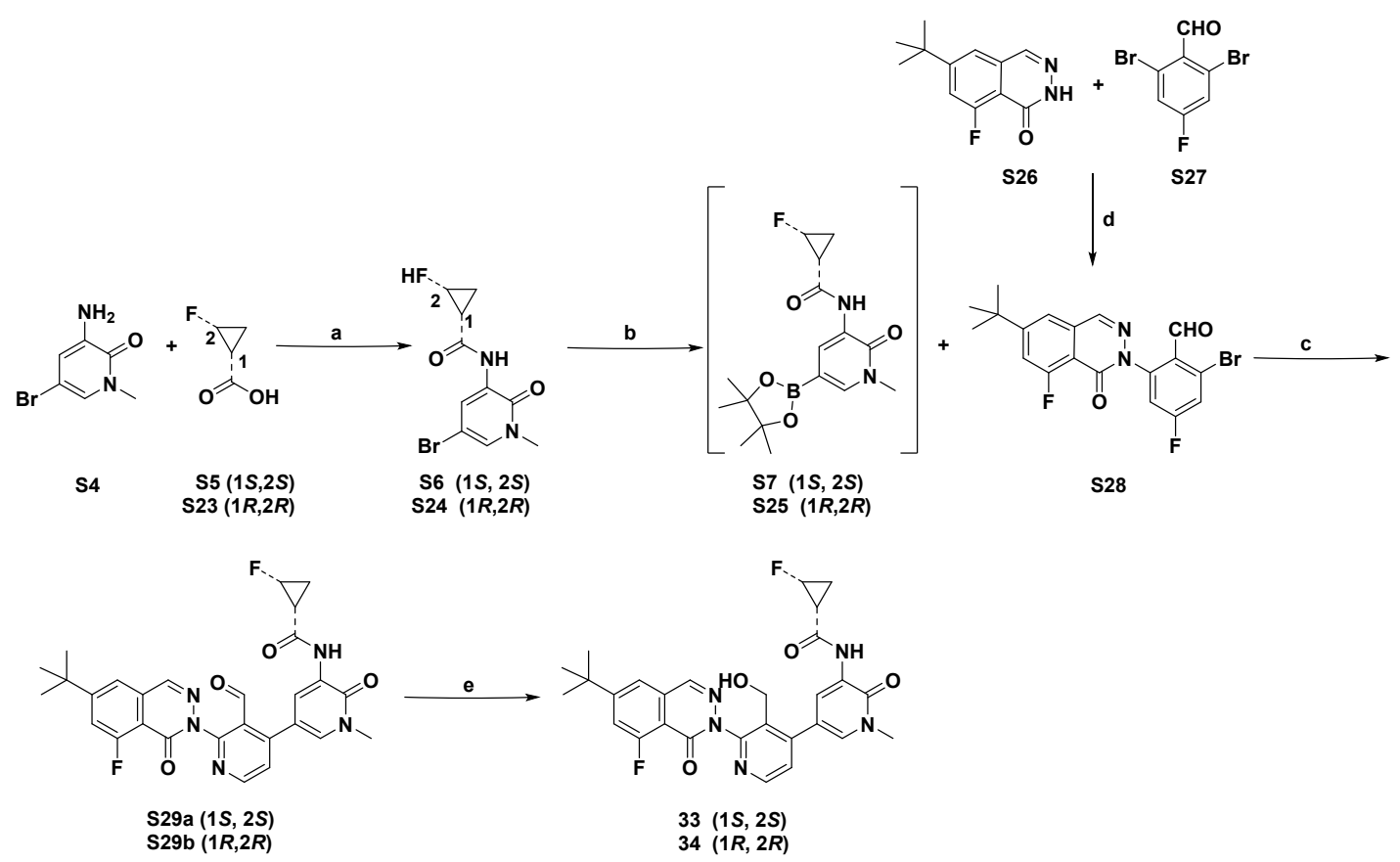

${ }^{a}$ Reagents and conditions: (a) HATU, DIPEA, DCM, $60{ }^{\circ} \mathrm{C}, 54-74.4 \%$ yield; (b) $\mathrm{Pin}_{2} \mathrm{~B}_{2}$, KOAc, XPhos, $\mathrm{Pd}_{2}(\mathrm{dba})_{3}$, dioxane, microwave, $100^{\circ} \mathrm{C}, 30 \mathrm{~min}(\mathrm{c}) \mathrm{K}_{3} \mathrm{PO}_{4} \cdot 3 \mathrm{H}_{2} \mathrm{O}, 80{ }^{\circ} \mathrm{C}$, microwave, $1 \mathrm{~h}$, 17.6 - 25.1\% yield over 2 steps; (d) XantPhos, $\mathrm{Cs}_{2} \mathrm{CO}_{3}, \mathrm{Pd}_{2}(\mathrm{dba})_{3}, 1$,4-dioxane, $90^{\circ} \mathrm{C}, 19 \mathrm{~h}, 24.8 \%$ yield; (e) $\mathrm{NaBH}_{4}, \mathrm{MeOH}, 63.2-69.8 \%$ yield.

$(1 S, 2 S)-N$-(2'-(6-(tert-butyl)-8-fluoro-1-oxophthalazin-2(1H)-yl)-3'-(hydroxymethyl)-1-methyl6-oxo-1,6-dihydro-[3,4'-bipyridin]-5-yl)-2-fluorocyclopropane-1-carboxamide 33

Step 1: Preparation of 2-bromo-6-(6-(tert-butyl)-8-fluoro-1-oxophthalazin-2(1H)-yl)-4fluorobenzaldehyde S28.

In a 5-mL vial was placed 6-tert-butyl-8-fluoro-2H-phthalazin-1-one S26 (331 mg, $1.50 \mathrm{mmol}$ ), 2,6-dibromo-4-fluoro-benzaldehyde $\mathbf{S 2 7}$ (508 mg, $1.80 \mathrm{mmol}, 1.2$ equiv.), cesium carbonate (867 mg, 4.51 mmol, 3.0 equiv.), Xantphos (174 mg, 0.3006 mmol, 0.2 equiv.), $\mathrm{Pd}_{2}(\mathrm{dba})_{3}(69 \mathrm{mg}, 0.08$ 
mmol, 0.05 equiv.), and dioxane $(10.7 \mathrm{~mL})$, and the reaction mixture was degassed for $15 \mathrm{~min}$. The vial was vacuum purged / filled with $\mathrm{N}_{2}(3 \mathrm{x})$ and capped. The reaction mixture was stirred at $90{ }^{\circ} \mathrm{C}$ for $19 \mathrm{~h}$. The reaction was quenched with ethyl acetate / water and filtered. The organic phase from the filtrate was washed with water and brine, dried over $\mathrm{Na}_{2} \mathrm{SO}_{4}$, filtered, and concentrated under reduced pressure. The crude residue was purified by flash column chromatography $\left(\mathrm{SiO}_{2}\right.$ : Ethyl acetate / heptane) to afford $157 \mathrm{mg}$ of $\mathbf{S 2 8}$ as a solid. Yield 24.8\%. ${ }^{1} \mathrm{H}$ NMR (400 MHz, Chloroform- $d$ ) $\delta 10.20(\mathrm{~d}, \mathrm{~J}=0.9 \mathrm{~Hz}, 1 \mathrm{H}), 8.19$ (d, J = 2.5 Hz, 1H), $7.52-7.49$ (m, 2H), 7.48 (dd, $\mathrm{J}=4.4,2.1 \mathrm{~Hz}, 1 \mathrm{H}), 7.27-7.23(\mathrm{~m}, 1 \mathrm{H}), 1.41(\mathrm{~s}, 9 \mathrm{H}) . \mathrm{MS}(\mathrm{ESI}+) \mathrm{m} / \mathrm{z}$ found $\mathrm{MH}^{+} 421.1$, $\mathrm{C}_{19} \mathrm{H}_{16} \mathrm{BrF}_{2} \mathrm{~N}_{2} \mathrm{O}_{2}$ requires 421.1 .

Step 2: Preparation of $\mathbf{3 3}$

Following the procedures described for 25, replacing 2-(6-tert-butyl-8-fluoro-1-oxophthalazin-2-yl)-4-chloro-pyridine-3-carbaldehyde S8 with 2-bromo-6-(6-(tert-butyl)-8-fluoro-1oxophthalazin-2(1H)-yl)-4-fluorobenzaldehyde S28, the title compound $\mathbf{3 3}$ was prepared. Yield 17.5\%. ${ }^{1} \mathrm{H}$ NMR (400 MHz, DMSO- $\left.d_{6}\right) \delta 9.70(\mathrm{~s}, 1 \mathrm{H}), 8.51(\mathrm{~d}, \mathrm{~J}=2.5 \mathrm{~Hz}, 1 \mathrm{H}), 8.34(\mathrm{~d}, \mathrm{~J}=2.4$ $\mathrm{Hz}, 1 \mathrm{H}), 7.88(\mathrm{~d}, \mathrm{~J}=1.8 \mathrm{~Hz}, 1 \mathrm{H}), 7.75(\mathrm{dd}, \mathrm{J}=13.3,1.7 \mathrm{~Hz}, 1 \mathrm{H}), 7.65(\mathrm{~d}, \mathrm{~J}=2.4 \mathrm{~Hz}, 1 \mathrm{H}), 7.38$ $(\mathrm{dd}, \mathrm{J}=9.0,2.8 \mathrm{~Hz}, 1 \mathrm{H}), 7.28(\mathrm{dd}, \mathrm{J}=9.3,2.8 \mathrm{~Hz}, 1 \mathrm{H}), 5.00-4.78(\mathrm{~m}, 1 \mathrm{H}), 4.66(\mathrm{t}, \mathrm{J}=5.2 \mathrm{~Hz}$, $1 \mathrm{H}), 4.30(\mathrm{~d}, \mathrm{~J}=5.3 \mathrm{~Hz}, 2 \mathrm{H}), 3.58(\mathrm{~s}, 3 \mathrm{H}), 2.48-2.42(\mathrm{~m}, 1 \mathrm{H}), 1.66-1.53(\mathrm{~m}, 1 \mathrm{H}), 1.38(\mathrm{~s}, 9 \mathrm{H})$, 1.20 - $1.09(\mathrm{~m}, 1 \mathrm{H}) .{ }^{13} \mathrm{C}$ NMR (101 MHz, DMSO) $\delta 166.18$ (d), 161.74, 159.86 (d), 159.31, $159.12,156.23,155.63$ (d), 143.28 (d), 140.78 (d), 137.85, 132.86 (d), 131.96, 127.85, 124.28, 119.57 (d), 116.90 (d), 116.68, 116.42, 115.34, 115.12, 113.98 (d), 73.64, 71.38, 56.49, 37.49, 35.54, 30.48, 21.38 (d), 10.75 (d). HRMS (ESI+) m/z found $\mathrm{MH}^{+} 553.2050, \mathrm{C}_{29} \mathrm{H}_{28} \mathrm{~F}_{3} \mathrm{~N}_{4} \mathrm{O}_{4}$ requires 553.2057. Chiral $\mathrm{t}_{\mathrm{R}}=0.743 \mathrm{~min}$ (Chiralcel OX, isocratic 50\% $\mathrm{MeOH}$ w/ 0.1\% NH $\mathrm{NH}_{4} \mathrm{OH}$ $\mathrm{CO}_{2}, 4 \mathrm{~mL} / \mathrm{min}$ flow, $2.5 \mathrm{~min}$ at $40{ }^{\circ} \mathrm{C}, 120 \mathrm{bar}$ ).

$(1 R, 2 R)-N-(2 '-(6-($ tert-butyl)-8-fluoro-1-oxophthalazin-2(1H)-yl)-3'-(hydroxymethyl)-1-methyl6-oxo-1,6-dihydro-[3,4'-bipyridin]-5-yl)-2-fluorocyclopropane-1-carboxamide 34

Step 1: Preparation of $(1 R, 2 R)-N$-(5-bromo-1-methyl-2-oxo-1,2-dihydropyridin-3-yl)-2fluorocyclopropane-1-carboxamide S24

Following a similar procedure described for $\mathbf{S 6}$ as previously described, replacing $(1 S, 2 S)$-2fluorocyclopropanecarboxylic acid S5 with $(1 R, 2 R)$-2-fluorocyclopropanecarboxylic acid S23, (1R,2R)-N-(5-bromo-1-methyl-2-oxo-1,2-dihydropyridin-3-yl)-2-fluorocyclopropane-1-

carboxamide $\mathbf{S 2 4}$ was prepared. Yield 74\%. ${ }^{1} \mathrm{H}$ NMR (400 MHz, $\left.\mathrm{CDCl}_{3}\right) \delta 8.61$ (br s, $\left.1 \mathrm{H}\right), 8.51$ 
$(\mathrm{d}, \mathrm{J}=2.5 \mathrm{~Hz}, 1 \mathrm{H}), 7.13(\mathrm{~d}, \mathrm{~J}=2.6 \mathrm{~Hz}, 1 \mathrm{H}), 4.89-4.67(\mathrm{~m}, 1 \mathrm{H}), 3.59(\mathrm{~s}, 3 \mathrm{H}), 1.95-1.83(\mathrm{~m}$, $2 \mathrm{H}), 1.27-1.18(\mathrm{~m}, 1 \mathrm{H})$. MS (ESI+) m/z found $\mathrm{MH}^{+} 289, \mathrm{C}_{10} \mathrm{H}_{11} \mathrm{BrFN}_{2} \mathrm{O}_{2}$ requires 288.99.

\section{Step 2: Preparation of $\mathbf{3 4}$}

Following the procedures described for 33, replacing (1S,2S)- $N$-(5-bromo-1-methyl-2-oxo-1,2dihydropyridin-3-yl)-2-fluorocyclopropane-1-carboxamide $\mathbf{S 6}$ with $\quad(1 R, 2 R)-N$-(5-bromo-1methyl-2-oxo-1,2-dihydropyridin-3-yl)-2-fluorocyclopropane-1-carboxamide $\mathbf{S 2 4}$, the title compound 34 was prepared. Yield 11.1\%. ${ }^{1} \mathrm{H}$ NMR (400 MHz, DMSO- $\left.d_{6}\right) \delta 9.70(\mathrm{~s}, 1 \mathrm{H}), 8.51$ (d, $\mathrm{J}=2.5 \mathrm{~Hz}, 1 \mathrm{H}), 8.34(\mathrm{~d}, \mathrm{~J}=2.4 \mathrm{~Hz}, 1 \mathrm{H}), 7.88(\mathrm{~d}, \mathrm{~J}=1.7 \mathrm{~Hz}, 1 \mathrm{H}), 7.75(\mathrm{dd}, \mathrm{J}=13.2,1.7 \mathrm{~Hz}, 1 \mathrm{H})$, $7.65(\mathrm{~d}, \mathrm{~J}=2.4 \mathrm{~Hz}, 1 \mathrm{H}), 7.38(\mathrm{dd}, \mathrm{J}=9.0,2.8 \mathrm{~Hz}, 1 \mathrm{H}), 7.28(\mathrm{dd}, \mathrm{J}=9.3,2.8 \mathrm{~Hz}, 1 \mathrm{H}), 5.00$ - 4.78 $(\mathrm{m}, 1 \mathrm{H}), 4.66(\mathrm{t}, \mathrm{J}=5.2 \mathrm{~Hz}, 1 \mathrm{H}), 4.30(\mathrm{~d}, \mathrm{~J}=5.2 \mathrm{~Hz}, 2 \mathrm{H}), 3.58(\mathrm{~s}, 3 \mathrm{H}), 2.52-2.42(\mathrm{~m}, 1 \mathrm{H}), 1.66$ - $1.53(\mathrm{~m}, 1 \mathrm{H}), 1.38(\mathrm{~s}, 9 \mathrm{H}), 1.20-1.09(\mathrm{~m}, 1 \mathrm{H})$. HRMS (ESI+) m/z found $\mathrm{MH}^{+} 553.2051$. $\mathrm{C}_{29} \mathrm{H}_{28} \mathrm{~F}_{3} \mathrm{~N}_{4} \mathrm{O}_{4}$ requires 553.2057. Chiral $\mathrm{t}_{\mathrm{R}}=1.053 \mathrm{~min}$ (Chiralcel OX, isocratic $50 \% \mathrm{MeOH} \mathrm{w} /$ $0.1 \% \mathrm{NH}_{4} \mathrm{OH} / \mathrm{CO}_{2}, 4 \mathrm{~mL} / \mathrm{min}$ flow, $2.5 \mathrm{~min}$ at $40{ }^{\circ} \mathrm{C}, 120$ bar).

Scheme S7. Preparation of 22. ${ }^{a}$

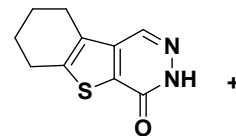

S30

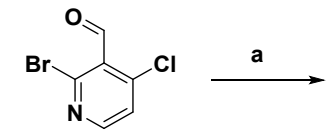

S31

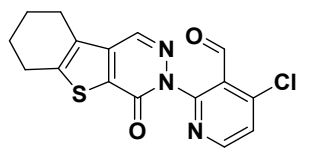

S32
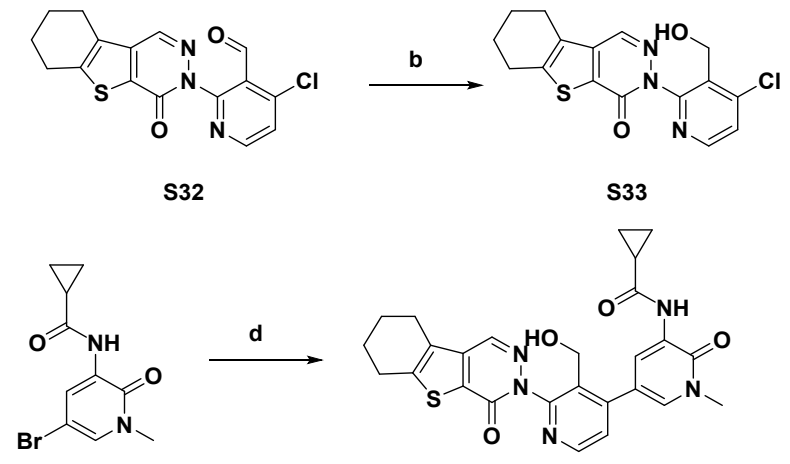

S16a
S33

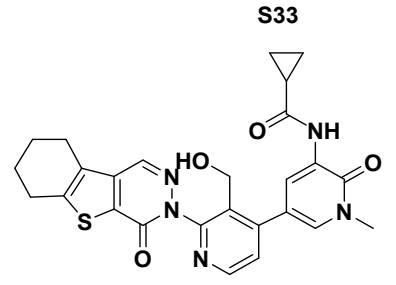

22

${ }^{a}$ Reagents: (a) CuI, sarcosine, $\mathrm{K}_{2} \mathrm{CO}_{3}$, dioxane, $80{ }^{\circ} \mathrm{C}, 16 \mathrm{~h}, 60 \%$ yield; (b) $\mathrm{NaBH}_{4}, \mathrm{MeOH}, \mathrm{DMA}$, dioxane, $10{ }^{\circ} \mathrm{C}$, 1h, 59\% yield; (c) $\mathrm{B}_{2}(\mathrm{OH})_{4}$, XPhos-Pd-G2, XPhos, KOAc, EtOH, $80{ }^{\circ} \mathrm{C}, 1 \mathrm{~h}, 56 \%$ yield; (d) $\mathrm{Pd}(\mathrm{dppf}) \mathrm{Cl}_{2}, \mathrm{Na}_{2} \mathrm{CO}_{3}$, $\mathrm{LiCl}$, dioxane $/ \mathrm{H}_{2} \mathrm{O}(10 \mathrm{~mL}, 3 / 1, \mathrm{v} / \mathrm{v}) 50{ }^{\circ} \mathrm{C}, 2 \mathrm{~h}, 10.5 \%$ yield.

$N$-(3'-(hydroxymethyl)-1-methyl-6-oxo-2'-(4-oxo-6,7,8,9-tetrahydrobenzo[4,5]thieno[2,3d]pyridazin-3(4H)-yl)-1,6-dihydro-[3,4'-bipyridin]-5-yl)cyclopropanecarboxamide 22 Step 1: 4-chloro-2-(4-oxo-6,7,8,9-tetrahydrobenzo[4,5]thieno[2,3- $d]$ pyridazin-3(4H)yl)nicotinaldehyde S32

A mixture of 6,7,8,9-tetrahydrobenzo[4,5]thieno[2,3-d]pyridazin-4(3H)-one (500 mg, 2.42 mmol), 2-bromo-4-chloronicotinaldehyde (1.59 g, $7.26 \mathrm{mmol})$ and $\mathrm{K}_{2} \mathrm{CO}_{3}(1.0 \mathrm{~g}, 7.26 \mathrm{mmol})$ in 
1,4-dioxane $(50 \mathrm{~mL})$ was treated with $\mathrm{CuI}(462 \mathrm{mg}, 2.42 \mathrm{mmol})$ and sarcosine $(237 \mathrm{mg}, 2.66$ $\mathrm{mmol}$ ), and the reaction mixture was stirred at $110{ }^{\circ} \mathrm{C}$ for $16 \mathrm{~h}$. The reaction mixture was filtered and the filtrate was concentrated. The residue was purified by flash column chromatography $\left(\mathrm{SiO}_{2}\right.$ : ethyl acetate / DCM) to afford $0.5 \mathrm{~g}$ of $\mathbf{S 3 2}$ as a solid. Yield $60 \%$.

Step 2: 3-(4-chloro-3-(hydroxymethyl)pyridin-2-yl)-6,7,8,9-tetrahydrobenzo[4,5]thieno[2,3d]pyridazin-4(3H)-one $\mathbf{S 3 3}$

To a mixture of 4-chloro-2-(4-oxo-6,7,8,9-tetrahydrobenzo[4,5]thieno[2,3-d]pyridazin-3(4H)yl)nicotinaldehyde (500 mg, $1.45 \mathrm{mmol})$ in 1,4-dioxane $(10 \mathrm{~mL})$ were added $\mathrm{NaBH}_{4}(27 \mathrm{mg}, 0.725$ mmol) in DMA (252 mg, $2.9 \mathrm{mmol})$ and $\mathrm{MeOH}(139 \mathrm{mg}, 4.35 \mathrm{mmol})$ in one portion at $10^{\circ} \mathrm{C}$. The reaction mixture was stirred at $10^{\circ} \mathrm{C}$ for $1 \mathrm{~h}$, quenched with ice-water $(10 \mathrm{~mL})$, and stirred for 20 min. Volatile solvent was concentrated under reduced pressure at $50{ }^{\circ} \mathrm{C}$, and the mixture was extracted with ethyl acetate $(50 \mathrm{~mL} \times 3)$. The combined organic layers were washed with brine $(20$ $\mathrm{mL} \times 2$ ), dried over $\mathrm{Na}_{2} \mathrm{SO}_{4}$, and concentrated under reduced pressure. The residue was purified purified by flash column chromatography $\left(\mathrm{SiO}_{2}\right.$ : Ethyl acetate / petroleum ether) to afford $300 \mathrm{mg}$ of $\mathbf{S 3 3}$ as a solid. Yield $59 \%$.

Step 3: 3-(1-hydroxy-1,3-dihydro-[1,2] $\quad 3$ oxaborolo[4,3-c]pyridin-4-yl)-6,7,8,9tetrahydrobenzo[4,5]thieno[2,3- $d]$ pyridazin-4(3H)-one $\mathbf{S 3 4}$

A mixture of 3-(4-chloro-3-(hydroxymethyl)pyridin-2-yl)-6,7,8,9tetrahydrobenzo[4,5]thieno[2,3- $d]$ pyridazin-4(3H)-one $\quad\left(\begin{array}{lllll}360 & \mathrm{mg}, & 1.04 & \mathrm{mmol}\end{array}\right)$ and tetrahydroxydiborane $(281 \mathrm{mg}, 3.12 \mathrm{mmol})$ in EtOH $(10 \mathrm{~mL})$ was treated with Xphos-Pd-G2 (78 $\mathrm{mg}, 0.1 \mathrm{~mol}$ ) and Xphos (95 mg, $0.2 \mathrm{mmol})$. The resulting mixture was heated to $80{ }^{\circ} \mathrm{C}$ for $1 \mathrm{~h}$ under nitrogen. The mixture was quenched with water $(20 \mathrm{~mL})$ and extracted with ethyl acetate $(20 \mathrm{~mL} \times 3)$. The combined organic layers were dried over $\mathrm{Na}_{2} \mathrm{SO}_{4}$ and concentrated under reduced pressure. The residue was triturated with toluene ( $3 \mathrm{~mL}$ ) to afford $200 \mathrm{mg}$ of $\mathbf{S 3 4}$ as a brown solid. Yield 56\%.

Step 4: Preparation of 22

A mixture of 3-(1-hydroxy-1,3-dihydro-[1,2]oxaborolo[4,3-c]pyridin-4-yl)-6,7,8,9tetrahydrobenzo[4,5]thieno[2,3- $d$ ] pyridazin-4(3H)-one $\mathbf{S 3 4}$ (136 mg, $0.5 \mathrm{mmol}$ ), $N$-(5-bromo-1methyl-2-oxo-1,2-dihydropyridin-3-yl)cyclopropanecarboxamide $\mathbf{S 1 6 a}(170 \mathrm{mg} 0.5 \mathrm{mmol}$ ), $\mathrm{Pd}(\mathrm{dppf}) \mathrm{Cl}_{2}$ (24 mg, $\left.0.032 \mathrm{mmol}\right), \mathrm{Na}_{2} \mathrm{CO}_{3}(291 \mathrm{mg}, 2.75 \mathrm{mmol})$ and $\mathrm{LiCl}(74 \mathrm{mg}, 1.75 \mathrm{mmol})$ in dioxane $/ \mathrm{H}_{2} \mathrm{O}(10 \mathrm{~mL}, 3 / 1, \mathrm{v} / \mathrm{v})$ was stirred at $50{ }^{\circ} \mathrm{C}$ for $2 \mathrm{~h}$. The mixture was concentrated under 
reduced pressure and purified by prep-HPLC to give $26.5 \mathrm{mg}$ of title compound 22 as a white solid. Yield 10.5\%. ${ }^{1} \mathrm{H}$ NMR (400 MHz, DMSO- $\left.d_{6}\right) \delta 9.72(\mathrm{~s}, 1 \mathrm{H}), 8.55(\mathrm{~d}, \mathrm{~J}=5.0 \mathrm{~Hz}, 1 \mathrm{H}), 8.46$ $(\mathrm{s}, 1 \mathrm{H}), 8.40(\mathrm{~d}, \mathrm{~J}=2.5 \mathrm{~Hz}, 1 \mathrm{H}), 7.75(\mathrm{~d}, \mathrm{~J}=2.5 \mathrm{~Hz}, 1 \mathrm{H}), 7.49(\mathrm{~d}, \mathrm{~J}=5.0 \mathrm{~Hz}, 1 \mathrm{H}), 4.86(\mathrm{t}, \mathrm{J}=5.0$ $\mathrm{Hz}, 1 \mathrm{H}), 4.41-4.28(\mathrm{~m}, 2 \mathrm{H}), 3.59$ (s, 3H), $2.98-2.90(\mathrm{~m}, 2 \mathrm{H}), 2.89-2.81(\mathrm{~m}, 2 \mathrm{H}), 2.31-2.21$ $(\mathrm{m}, 1 \mathrm{H}), 1.96-1.79(\mathrm{~m}, 4 \mathrm{H}), 0.81-0.74(\mathrm{~m}, 4 \mathrm{H}) .{ }^{13} \mathrm{C}$ NMR (101 MHz, DMSO) $\delta 172.95,156.41$, 156.34, 153.69, 148.37, 148.00, 146.76, 138.70, 133.38, 132.29 (doublet), 131.77, 130.95, 128.21, $125.51,123.57,114.90,56.33,37.61,25.20,23.11,22.54,21.28,14.18,7.70$. HRMS (ESI+) m/z found $\mathrm{MH}^{+}$504.1696, $\mathrm{C}_{26} \mathrm{H}_{26} \mathrm{~N}_{5} \mathrm{O}_{4} \mathrm{~S}$ requires 504.1700.

Scheme S8. Preparation of 21 via Buchwald amidation. ${ }^{a}$

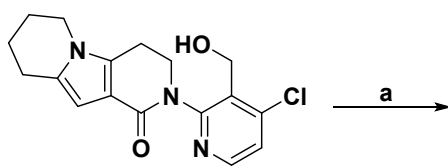

S35

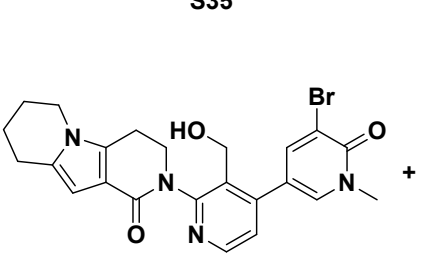

S38

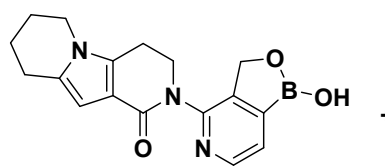

S36
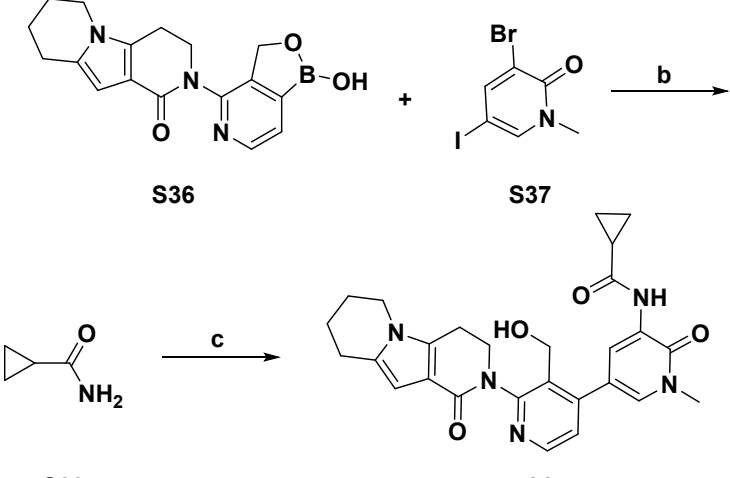

S39
S37

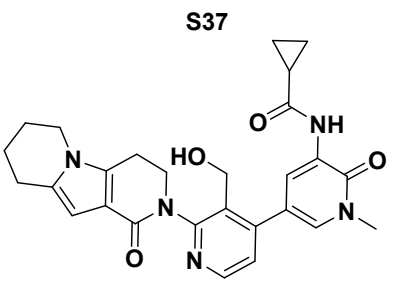

21

${ }^{a}$ Reagents: (a) $\mathrm{B}_{2}(\mathrm{OH})_{4}$, XPhos-Pd-G2, XPhos, KOAc, EtOH, $80{ }^{\circ} \mathrm{C}, 1 \mathrm{~h}, 70 \%$ yield; (b) $\mathrm{Pd}(\mathrm{dppf}) \mathrm{Cl}_{2}, \mathrm{Na}_{2} \mathrm{CO}_{3}, \mathrm{LiCl}$, dioxane $/ \mathrm{H}_{2} \mathrm{O}(10 \mathrm{~mL}, 3 / 1, \mathrm{v} / \mathrm{v}) 50{ }^{\circ} \mathrm{C}, 2 \mathrm{~h}, 33 \%$ yield; (c) XantPhos, $\mathrm{Cs}_{2} \mathrm{CO}_{3}, \mathrm{Pd}_{2}(\mathrm{dba})_{3}, 1,4$-dioxane, $100{ }^{\circ} \mathrm{C}, 1 \mathrm{~h}, 24.5 \%$ yield.

$N$-(3'-(hydroxymethyl)-1-methyl-6-oxo-2'-(1-oxo-3,4,6,7,8,9-hexahydropyrazino[1,2-a]indol2(1H)-yl)-1,6-dihydro-[3,4'-bipyridin]-5-yl)cyclopropanecarboxamide 21

Step 1: Preparation of 2-(1-hydroxy-1,3-dihydro-[1,2] oxaborolo[4,3-c]pyridin-4-yl)-3,4,6,7,8,9hexahydropyrido[3,4- $b]$ indolizin-1(2H)-one $\mathbf{S 3 6}$

Following the procedure described for 22, step 3, replacing 3-(4-chloro-3(hydroxymethyl)pyridin-2-yl)-6,7,8,9-tetrahydrobenzo[4,5]thieno[2,3- $d]$ pyridazin-4(3H)-one S33 with 2-(4-chloro-3-(hydroxymethyl)pyridin-2-yl)-3,4,6,7,8,9-hexahydropyrido[3,4b]indolizin-1(2H)-one S35, compound $\mathbf{S 3 6}$ was prepared. Yield 70\%.

Step 2: Preparation of 2-(5-bromo-3'-(hydroxymethyl)-1-methyl-6-oxo-1,6-dihydro-[3,4'bipyridin]-2'-yl)-3,4,6,7,8,9-hexahydropyrido[3,4-b]indolizin-1(2H)-one S38 
Following the procedure decribed for 22, step 4, replacing 3-(1-hydroxy-1,3-dihydro[1,2] oxaborolo[4,3-c]pyridin-4-yl)-6,7,8,9-tetrahydrobenzo[4,5]thieno[2,3-d]pyridazin-4(3H)one S34 and $N$-(5-bromo-1-methyl-2-oxo-1,2-dihydropyridin-3-yl)cyclopropanecarboxamide S16a with 2-(1-hydroxy-1,3-dihydro-[1,2] oxaborolo[4,3-c]pyridin-4-yl)-3,4,6,7,8,9hexahydropyrido[3,4-b]indolizin-1(2H)-one $\mathbf{S 3 6}$ and 3-bromo-5-iodo-1-methylpyridin-2(1H)-one $\mathbf{S 3 7}$, respectively, $\mathbf{S 3 8}$ was prepared. Yield 33\%.

Step 3: Preparation of 21

To a mixture of 2-(5-bromo-3'-(hydroxymethyl)-1-methyl-6-oxo-1,6-dihydro-[3,4'-bipyridin]2'-yl)-3,4,6,7,8,9-hexahydropyrido[3,4-b]indolizin-1(2H)-one (100 $\mathrm{mg}, \quad 0.21 \mathrm{mmol})$ and cyclopropanecarboxamide $(53.5 \mathrm{mg}, 0.63 \mathrm{mmol})$ in 1,4-dioxane $(4 \mathrm{~mL})$ were added Xantphos (12.2 $\mathrm{mg}, 0.02 \mathrm{mmol}), \mathrm{Cs}_{2} \mathrm{CO}_{3}(205 \mathrm{mg}, 0.63 \mathrm{mmol})$, followed by $\mathrm{Pd}_{2}(\mathrm{dba})_{3}(10 \mathrm{mg}, 0.0105$ mmol). The resulting mixture was stirred at $100{ }^{\circ} \mathrm{C}$ for $1 \mathrm{~h}$. The reaction mixture was diluted in water and filtered. The filtrate was extracted with ethyl acetate $(20 \mathrm{~mL} \times 3)$. The combined organic layers were dried over $\mathrm{Na}_{2} \mathrm{SO}_{4}$ and concentrated under reduced pressure. The residue was purified by flash column chromatography $\left(\mathrm{SiO}_{2}\right.$ : methanol / ethyl acetate) to give $25 \mathrm{mg}$ of the title compound as a white solid. Yield 24.5\%. ${ }^{1} \mathrm{H}$ NMR (400 MHz, DMSO- $\left.d_{6}\right) \delta 9.68(\mathrm{~s}, 1 \mathrm{H}), 8.47-$ $8.38(\mathrm{~m}, 2 \mathrm{H}), 7.75$ (d, J = 2.4 Hz, 1H), 7.25 (d, J = 5.0 Hz, 1H), 6.03 (s, 1H), 4.84 (s, 1H), $4.43-$ $4.26(\mathrm{~m}, 2 \mathrm{H}), 4.19-4.08(\mathrm{~m}, 1 \mathrm{H}), 3.99-3.89(\mathrm{~m}, 1 \mathrm{H}), 3.83-3.74(\mathrm{~m}, 2 \mathrm{H}), 3.59(\mathrm{~s}, 3 \mathrm{H}), 3.06-$ $2.88(\mathrm{~m}, 2 \mathrm{H}), 2.71(\mathrm{t}, \mathrm{J}=6.4 \mathrm{~Hz}, 2 \mathrm{H}), 2.31-2.20(\mathrm{~m}, 1 \mathrm{H}), 1.96-1.86(\mathrm{~m}, 2 \mathrm{H}), 1.83-1.67(\mathrm{~m}$, $2 \mathrm{H}), 0.81-0.73(\mathrm{~m} \mathrm{4H}) .{ }^{13} \mathrm{C}$ NMR (101 MHz, DMSO) $\delta 172.84,166.4,164.90,156.40,155.72$, $147.80,147.58,135.79,132.01,130.57,129.91,128.12$, 123.75, 123.09, 115.83, 112. 31, 102.03, $57.32,48.78,42.51,37.60,23.07,22.66,20.69,20.40,14.18,7.66$. HRMS (ESI + ) m/z found $\mathrm{MH}^{+}$ 488.2287, $\mathrm{C}_{27} \mathrm{H}_{30} \mathrm{~N}_{5} \mathrm{O}_{4}$ requires 488.2292 . 
Scheme S9. Preparation of $\mathbf{2 8}$ and $\mathbf{2 9} .^{a}$

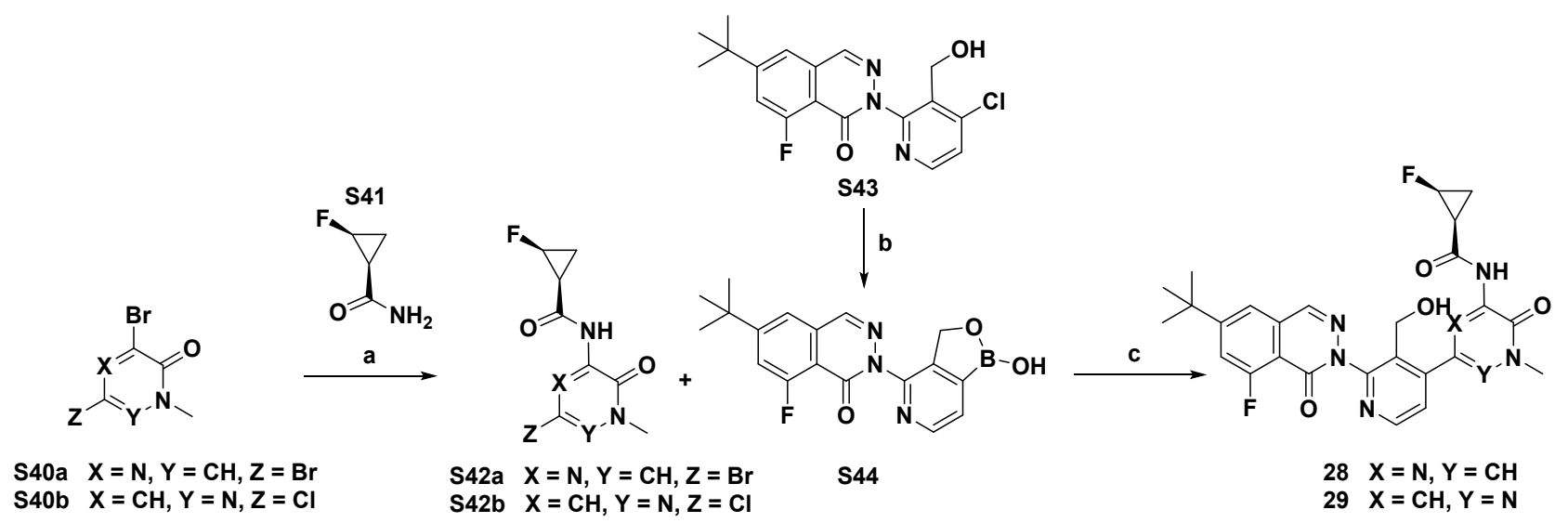

${ }^{a}$ Reagents: (a) $\mathrm{Pd}_{2}(\mathrm{dba})_{3}$, Xantphos, $\mathrm{Cs}_{2} \mathrm{CO}_{3}, 1,4$-dioxane, $110^{\circ} \mathrm{C}, 1 \mathrm{~h}, 30-76 \%$ yield; (b) $\mathrm{B}_{2}(\mathrm{OH})_{4}$, XPhos-Pd-G2, XPhos, KOAc, EtOH, $80{ }^{\circ} \mathrm{C}, 1 \mathrm{~h}, 92 \%$ yield; (c) $\mathrm{Pd}(\mathrm{dppf}) \mathrm{Cl}_{2}, \mathrm{Na}_{2} \mathrm{CO}_{3}, \mathrm{LiCl}, 1,4-$ dioxane, $\mathrm{H}_{2} \mathrm{O}, 80^{\circ} \mathrm{C}$, microwave, $1 \mathrm{~h}, 13-20 \%$ yield.

(1S,2S)-N-(6-(2-(6-(tert-butyl)-8-fluoro-1-oxophthalazin-2(1H)-yl)-3-(hydroxymethyl)pyridin-4yl)-4-methyl-3-oxo-3,4-dihydropyrazin-2-yl)-2-fluorocyclopropanecarboxamide $\mathbf{2 8}$

Step 1: (1S,2S)-N-(6-bromo-4-methyl-3-oxo-3,4-dihydropyrazin-2-yl)-2fluorocyclopropanecarboxamide $\mathbf{S 4 2 a}$

To a mixture of 3,5-dibromo-1-methylpyrazin-2(1H)-one S40a (200 $\mathrm{mg}, 0.7 \mathrm{mmol}$ ) and (1S,2S)-2-fluorocyclopropanecarboxamide $\mathbf{S 4 1}(72 \mathrm{mg}, 0.7 \mathrm{mmol})$ in 1,4-dioxane $(20 \mathrm{ml})$ were added Xantphos (41 mg, $0.07 \mathrm{mmol}$ ), cesium carbonate $(456 \mathrm{mg}, 1.4 \mathrm{mmol}$ ), followed by tris(dibenzylideneacetone)dipalladium( 0 ) (32 $\mathrm{mg}, 0.035 \mathrm{mmol}$ ). The resulting mixture was stirred at $110{ }^{\circ} \mathrm{C}$ for $1 \mathrm{~h}$ under nitrogen and then diluted with water and filtered. The filtrate was extracted with ethyl acetate $(20 \mathrm{~mL} \times 3)$. The combined organic layers were dried over anhydrous sodium sulfate and concentrated under reduced pressure. The residue was purified by flash column chromatography ( $\mathrm{SiO}_{2}: \mathrm{MeOH} / \mathrm{DCM}$ ) to afford $80 \mathrm{mg}$ of $\mathbf{S 4 2 a}$ as a yellow solid. Yield $30 \%$. MS (ESI+) $\mathrm{m} / \mathrm{z}$ found $\mathrm{MH}^{+} 290, \mathrm{C}_{9} \mathrm{H}_{10} \mathrm{BrFN}_{3} \mathrm{O}_{2}$ requires 289.99 .

Step 2: Preparation of 6-(tert-butyl)-8-fluoro-2-(1-hydroxy-1,3-dihydro-[1,2]oxaborolo[4,3c]pyridin-4-yl)phthalazin-1(2H)-one $\mathbf{S 4 4}$

Following the procedure described for 22, step 3, replacing 3-(4-chloro-3(hydroxymethyl)pyridin-2-yl)-6,7,8,9-tetrahydrobenzo[4,5]thieno[2,3- $d]$ pyridazin-4(3H)-one 
S33 with 6-(tert-butyl)-2-(4-chloro-3-(hydroxymethyl)pyridin-2-yl)-8-fluorophthalazin-1(2H)one S43, compound S44 was prepared. Yield 92\%.

Step 3: Preparation of title compound 28

To a mixture of (1S,2S)- $N$-(6-bromo-4-methyl-3-oxo-3,4-dihydropyrazin-2-yl)-2fluorocyclopropanecarboxamide S42a (70 mg, $0.24 \mathrm{mmol}$ ) and 6-(tert-butyl)-8-fluoro-2-(1hydroxy-1,3-dihydro-[1,2]oxaborolo[4,3-c]pyridin-4-yl)phthalazin-1(2H)-one S44 (85 mg, 0.24 $\mathrm{mmol})$ in 1,4-dioxane $(10 \mathrm{~mL})$ and water $(2 \mathrm{~mL})$ were added sodium carbonate $(127 \mathrm{mg}, 1.2 \mathrm{mmol})$, lithium chloride (30 mg, $0.72 \mathrm{mmol}$ ) and 1,1'-bis(diphenylphosphino)ferrocene palladium dichloride dichloromethane $(9.8 \mathrm{mg}, 0.012 \mathrm{mmol})$. The mixture was stirred at $80{ }^{\circ} \mathrm{C}$ for $1 \mathrm{~h}$ under nitrogen. The resulting mixture was diluted with water, and extracted with ethyl acetate $(20 \mathrm{~mL} \times 3)$. The organic layers were dried over anhydrous sodium sulfate and concentrated under reduced pressure. The crude residue was purified by flash column chromatography $\left(\mathrm{SiO}_{2}: \mathrm{MeOH} / \mathrm{DCM}\right)$ to afford $17 \mathrm{mg}$ of the title compound 28 as a white solid. 13\% Yield. ${ }^{1} \mathrm{H}$ NMR (400 MHz, DMSO$\left.d_{6}\right) \delta 10.59(\mathrm{~d}, \mathrm{~J}=6.7 \mathrm{~Hz}, 1 \mathrm{H}), 8.57(\mathrm{~d}, \mathrm{~J}=5.0 \mathrm{~Hz}, 1 \mathrm{H}), 8.54(\mathrm{~d}, \mathrm{~J}=2.6 \mathrm{~Hz}, 1 \mathrm{H}), 8.07$ (s, 1H), 7.91 $(\mathrm{d}, \mathrm{J}=1.8 \mathrm{~Hz}, 1 \mathrm{H}), 7.78(\mathrm{dd}, \mathrm{J}=13.2,1.7 \mathrm{~Hz}, 1 \mathrm{H}), 7.65(\mathrm{~d}, \mathrm{~J}=5.0 \mathrm{~Hz}, 1 \mathrm{H}), 5.30-5.19(\mathrm{~m}, 1 \mathrm{H})$, $5.04-4.80(\mathrm{~m}, 1 \mathrm{H}), 4.42-4.30(\mathrm{~m}, 1 \mathrm{H}), 4.28-4.18(\mathrm{~m}, 1 \mathrm{H}), 3.60(\mathrm{~s}, 3 \mathrm{H}), 2.63-2.53(\mathrm{~m}, 1 \mathrm{H})$, $1.65-1.52(\mathrm{~m}, 1 \mathrm{H}), 1.39(\mathrm{~s}, 9 \mathrm{H}), 1.24-1.12(\mathrm{~m}, 1 \mathrm{H}) .{ }^{13} \mathrm{C}$ NMR (101 MHz, DMSO) $\delta 165.78(\mathrm{~d})$, $161.70,160.16$ (d), 159.09, 155.61 (d), 154.05, 150.35, 148.17, 147.15, 144.09, 137.70, 131.91, $131.37,127.63,126.86,124.17,119.78$ (d), 117.13, 116.92, 73.89, 71.63, 56.31, 37.23, 35.60, 30.48, 21.77 (d), 11.14 (d). HRMS (ESI+) m/z found $\mathrm{MH}^{+} 537.2050, \mathrm{C}_{27} \mathrm{H}_{27} \mathrm{~F}_{2} \mathrm{~N}_{6} \mathrm{O}_{4}$ requires 537.2056 .

(1S,2S)- $N$-(6-(2-(6-(tert-butyl)-8-fluoro-1-oxophthalazin-2(1H)-yl)-3-(hydroxymethyl)pyridin-4yl)-2-methyl-3-oxo-2,3-dihydropyridazin-4-yl)-2-fluorocyclopropane-1-carboxamide 29

Compound 29 was prepare in a similar manner to 28, replacing 3,5-dibromo-1-methylpyrazin2(1H)-one S42a with 4-bromo-6-chloro-2-methylpyridazin-3(2H)-one $\mathbf{S 4 2 b}$. Yield 15.2\% over two-steps. ${ }^{1} \mathrm{H}$ NMR (400 MHz, DMSO-d $)_{6} \delta 10.42(\mathrm{~s}, 1 \mathrm{H}), 8.63(\mathrm{~d}, \mathrm{~J}=5.0 \mathrm{~Hz}, 1 \mathrm{H}), 8.54(\mathrm{~d}, \mathrm{~J}=$ $2.5 \mathrm{~Hz}, 1 \mathrm{H}), 8.31(\mathrm{~s}, 1 \mathrm{H}), 7.90(\mathrm{~d}, \mathrm{~J}=1.8 \mathrm{~Hz}, 1 \mathrm{H}), 7.77(\mathrm{dd}, \mathrm{J}=13.1,1.8 \mathrm{~Hz}, 1 \mathrm{H}), 7.60(\mathrm{~d}, \mathrm{~J}=5.0$ $\mathrm{Hz}, 1 \mathrm{H}), 5.07-4.83(\mathrm{~m}, 2 \mathrm{H}), 4.46-4.34(\mathrm{~m}, 2 \mathrm{H}), 3.80(\mathrm{~s}, 3 \mathrm{H}), 2.69-2.58(\mathrm{~m}, 1 \mathrm{H}), 1.72-1.57$ $(\mathrm{m}, 1 \mathrm{H}), 1.39$ (s, 9H), $1.28-1.16(\mathrm{~m}, 1 \mathrm{H}) .{ }^{13} \mathrm{C}$ NMR (101 MHz, DMSO) $\delta 167.80$ (d), 161.77, 160.18 (d), 155.57 (d), 154.61, 153.03, 148.25, 146.46, 144.43, 137.95, 135.75, 135.70, 131.96 
(d), 124.92, 119.78, 117.14, 116.93, 113.71 (d), 113.06, 73.97, 71.70, 56.20, 40.37, 35.60, 30.47, 21.52 (d), 11.33 (d). HRMS (ESI+) m/z found $\mathrm{MH}^{+}$537.2049, $\mathrm{C}_{27} \mathrm{H}_{27} \mathrm{~F}_{2} \mathrm{~N}_{6} \mathrm{O}_{4}$ requires 537.2056.

Scheme S10. Preparation of $\mathbf{S 8}$ and $\mathbf{S 4 3}{ }^{a}$

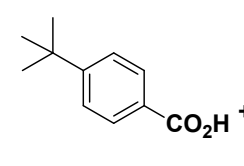

S45

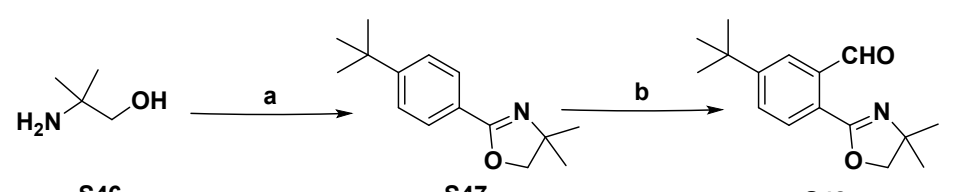

S46

S47

S48

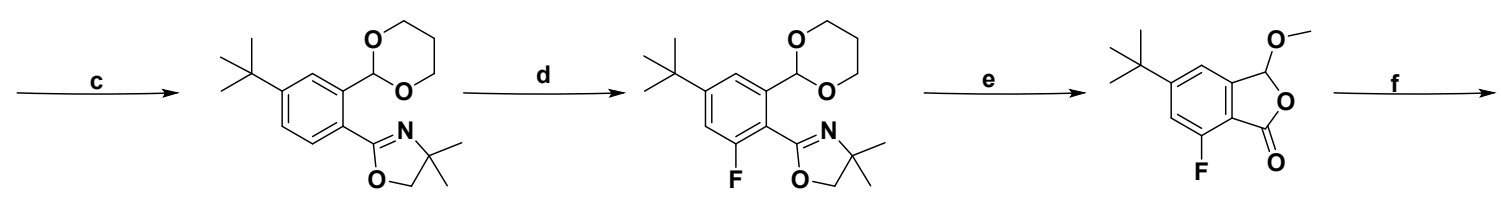

S49

S50

S51

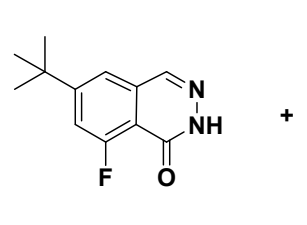

S26

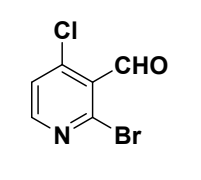

S52

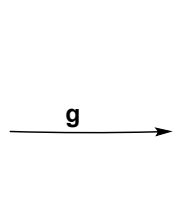

(cl一

S8

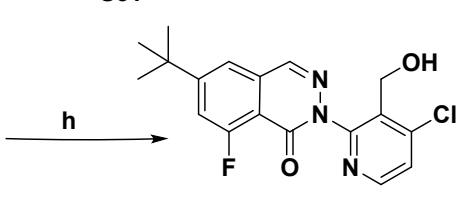

S43

${ }^{a}$ Reagents and conditions: (a) (i) $\mathrm{SO}_{2} \mathrm{Cl}_{2}$, reflux, $3 \mathrm{~h}$; (ii) DCM, $0{ }^{\circ} \mathrm{C}$ to RT, overnight; (iii) $\mathrm{SOCl}_{2}$, reflux, $1 \mathrm{~h}, 41 \%$ yield; (b) (i) $n \mathrm{BuLi}\left(2.4 \mathrm{M}\right.$ in hexane), THF, $78{ }^{\circ} \mathrm{C}$ to $-20^{\circ} \mathrm{C} 4 \mathrm{~h}$; (ii) $\mathrm{DMF},-78^{\circ} \mathrm{C}$ to RT, $2 \mathrm{~h} 15$ min, 62\% yield; (c) 1,3-propanediol, PPTS, toluene, reflux, overnight, 22\% yield; (d) $50 \%$ aq. $\mathrm{H}_{2} \mathrm{SO}_{4}, \mathrm{MeOH}$, reflux, overnight; (e) (i) $n \mathrm{BuLi}\left(2.4 \mathrm{M}\right.$ in hexane), $\mathrm{THF},-78^{\circ} \mathrm{C}$ to $-17^{\circ} \mathrm{C}$, 3h; (ii) NFSI, THF, $-78{ }^{\circ} \mathrm{C}$ to $-20{ }^{\circ} \mathrm{C}$ to $\mathrm{RT}, 1 \mathrm{~h}$ (f) $\mathrm{NH}_{2} \mathrm{NH}_{2} \cdot \mathrm{H}_{2} \mathrm{O}$, glacial $\mathrm{AcOH}, 0$ to $50{ }^{\circ} \mathrm{C}, 1.5 \mathrm{~h}$, $38 \%$ yield over 2 steps; (g) CuI, 4,7-dimethoxy-1,10-phenanthroline, KOAc, dioxane, $90{ }^{\circ} \mathrm{C}, 10 \mathrm{~h}$, $25 \%$ yield; (h) $\mathrm{NaBH}_{4}, \mathrm{MeOH}, \mathrm{RT}, 1 \mathrm{~h}, 90 \%$ yield.

2-(6-(tert-Butyl)-8-fluoro-1-oxophthalazin-2(1H)-yl)-4-chloronicotinaldehyde $\mathbf{S 8}$

Step 1: 2-(4-(tert-butyl)phenyl)-4,4-dimethyl-4,5-dihydrooxazole $\mathbf{S 4 7}$

A mixture of 4-(tert-butyl)benzoic acid $(1000 \mathrm{~g}, 5.6 \mathrm{~mol})$ in $\mathrm{SO}_{2} \mathrm{Cl}_{2}(1.5 \mathrm{~L})$ was refluxed for 3 hours. The solvent was then concentrated under reduced pressure to give crude 4-(tertbutyl)benzoyl chloride and DCM $(200 \mathrm{~mL})$ was added. To this reaction mixture at $0{ }^{\circ} \mathrm{C}$ was added dropwise a solution of 2-amino-2-methylpropan-1-ol (1000 g, $10.5 \mathrm{~mol})$ in DCM (2000 mL), while keeping the internal temperature between 0 to $10^{\circ} \mathrm{C}$. A white precipitate formed 5 minutes after 
the initial addition. The slurry was stirred at room temperature overnight, and the resulting white precipitate was filtered and rinsed with DCM $(1000 \mathrm{~mL})$. The filtrate was concentrated under reduced pressure to give 4-(tert-butyl)- $N$-(1-hydroxy-2-methylpropan-2-yl)benzamide as a light yellow solid which was used in the next step without further purification. A stirred mixture of crude 4-(tert-butyl)- $N$-(1-hydroxy-2-methylpropan-2-yl)benzamide (1000 g, $4 \mathrm{mmol}$ ) in $\mathrm{SOCl}_{2}$ $(1.5 \mathrm{~L})$ was refluxed for 1 hour. The reaction mixture was cooled to room temperature and slowly added to stirred ether $(500 \mathrm{~mL})$, during which time a white precipitate formed. The precipitate was collected by filtration and washed with additional ether. The solid was then dissolved in water (500 $\mathrm{mL}$ ) and neutralized with $25 \%$ aq. $\mathrm{NaOH}$ solution. The aqueous solution was extracted with EtOAC ( $3 \times 500 \mathrm{~mL})$, and the combined organic layers were washed with brine $(500 \mathrm{~mL})$, dried over $\mathrm{Na}_{2} \mathrm{SO}_{4}$, filtered, and concentrated under reduced pressure to afford $530 \mathrm{~g}$ of $\mathbf{S 4 7}$ as a white solid. Yield: 41\%. ${ }^{1} \mathrm{HNMR}(300 \mathrm{MHz}$, Chloroform- $d$ ) $\delta 7.87$ (d, J = $8.4 \mathrm{~Hz}, 2 \mathrm{H}$ ), 7.41 (d, J = 8.4 $\mathrm{Hz}, 2 \mathrm{H}), 4.08$ (s, 2H), 1.37 (s, 6H), 1.33 (s, 9H).

Step 2: 5-(tert-Butyl)-2-(4,4-dimethyl-4,5-dihydrooxazol-2-yl)benzaldehyde $\mathbf{S 4 8}$

To a solution of 2-(4-(tert-butyl)phenyl)-4,4-dimethyl-4,5-dihydrooxazole $\mathbf{S 4 7}$ (50 g, $0.22 \mathrm{~mol}$ ) in anhydrous THF $(750 \mathrm{~mL})$ under $\mathrm{N}_{2}$ was added $n$-butyllithium $(230 \mathrm{~mL}, 0.55 \mathrm{~mol}, 2.5$ equiv., $2.4 \mathrm{M}$ in hexane) at $-78{ }^{\circ} \mathrm{C}$. The amber solution was warmed to $-20{ }^{\circ} \mathrm{C}$ and stirred for $4 \mathrm{~h}$. The reaction mixture became cloudy and has a dark red amber color. The mixture was re-cooled to -78 ${ }^{\circ} \mathrm{C}$ and stirred rapidly before DMF ( $72 \mathrm{~mL}, 0.95 \mathrm{~mol}, 4.3$ equiv.) was added dropwise at such a rate that the temperature was controlled below $-60^{\circ} \mathrm{C}$. After the addition, the reaction mixture was stirred at $-78{ }^{\circ} \mathrm{C}$ for $15 \mathrm{~min}$, at $-20^{\circ} \mathrm{C}$ for $1 \mathrm{~h}$, and at $\mathrm{RT}$ for $1 \mathrm{~h}$ more. The reaction mixture was quenched with $0.5 \mathrm{M} \mathrm{KHSO}_{4}(200 \mathrm{~mL})$. Additionl $0.5 \mathrm{M} \mathrm{KHSO}_{4}$ was added to the reaction mixture until the $\mathrm{pH}$ was adjusted to 4-5. The aqueous phase was extracted with EtOAc ( $3 \times 500 \mathrm{~mL})$, and the combined organic layers were washed with brine $(400 \mathrm{~mL})$, dried over $\mathrm{Na}_{2} \mathrm{SO}_{4}$, filtered, and concentrated under reduced pressure to give $35 \mathrm{~g}$ of $\mathbf{S 4 8}$ as a yellow solid. Yield: $62 \%$. MS [ESMS] (ESI+) m/z found $\mathrm{MH}^{+} 260, \mathrm{C}_{16} \mathrm{H}_{22} \mathrm{NO}_{2}$ requires 260 .

Step 3: 2-(4-(tert-Butyl)-2-(1,3-dioxan-2-yl)phenyl)-4,4-dimethyl-4,5-dihydrooxazole $\mathbf{S 4 9}$

A mixture of 5-(tert-butyl)-2-(4,4-dimethyl-4,5-dihydrooxazol-2-yl)benzaldehyde $\mathbf{S 4 8}$ (60 g, $0.23 \mathrm{~mol})$, PPTS ( $4 \mathrm{~g}, 0.02 \mathrm{~mol})$ and 1,3-propanediol ( $60 \mathrm{~mL}, 0.83 \mathrm{~mol}, 3.6$ equiv.) in toluene (500 $\mathrm{mL}$ ) was heated to reflux overnight and then cooled to room temperature. The reaction mixture 
was quenched with $50 \%$ aq. $\mathrm{NaHCO}_{3}$ solution $(200 \mathrm{~mL})$, and the organic layer was washed with water $(200 \mathrm{~mL})$, brine $(200 \mathrm{~mL})$, dried over $\mathrm{Na}_{2} \mathrm{SO}_{4}$, filtered, and concentrated under reduced pressure. The crude residue was purified by flash column chromatography $\left(\mathrm{SiO}_{2}\right.$ : ethyl acetate / petroleum ether) to afford $16 \mathrm{~g}$ of $\mathbf{S 4 9}$ as a yellow gum. Yield: $22 \%$. ${ }^{1} \mathrm{HNMR}(300 \mathrm{MHz}$, Chloroform-d) $\delta 7.79(\mathrm{~s}, 1 \mathrm{H}), 7.67(\mathrm{~d}, \mathrm{~J}=8.0 \mathrm{~Hz}, 1 \mathrm{H}), 7.36(\mathrm{dd}, \mathrm{J}=8.4,1.6 \mathrm{~Hz}, 1 \mathrm{H}), 6.32(\mathrm{~s}, 1 \mathrm{H})$, $4.23(\mathrm{dd}, \mathrm{J}=5.2,11.2 \mathrm{~Hz}, 2 \mathrm{H}), 4.06(\mathrm{~s}, 2 \mathrm{H}), 4.04-3.98(\mathrm{~m}, 2 \mathrm{H}), 2.27-2.21(\mathrm{~m}, 1 \mathrm{H}), 1.48-1.38$ $(\mathrm{m}, 1 \mathrm{H}), 1.38(\mathrm{~s}, 6 \mathrm{H}), 1.32(\mathrm{~s}, 9 \mathrm{H})$. MS [ES-MS] $(\mathrm{ESI}+) \mathrm{m} / \mathrm{z}$ found $\mathrm{MH}^{+} 318, \mathrm{C}_{19} \mathrm{H}_{28} \mathrm{NO}_{3}$ requires 318.

Step 4: 2-(4-(tert-Butyl)-2-(1,3-dioxan-2-yl)-6-fluorophenyl)-4,4-dimethyl-4,5-dihydrooxazole S50

To a solution of 2-(4-(tert-butyl)-2-(1,3-dioxan-2-yl)phenyl)-4,4-dimethyl-4,5dihydrooxazole $\mathbf{S 4 9}(20 \mathrm{~g}, 63 \mathrm{mmol})$ in anhydrous THF $(400 \mathrm{~mL})$ was added $n$-BuLi $(65 \mathrm{~mL}$, $157 \mathrm{mmol}, 2.5$ equiv., $2.4 \mathrm{M}$ in hexane) at $-78^{\circ} \mathrm{C}$ under $\mathrm{N}_{2}$. The clear yellow solution was stirred at $-17{ }^{\circ} \mathrm{C}$ for $3 \mathrm{~h}$. The deep red-orange color reaction solution was re-cooled to $-78^{\circ} \mathrm{C}$, and a solution of NFSI (29 g, $92 \mathrm{mmol})$ in anhydrous THF (100 mL) was added dropwise over $10 \mathrm{~min}$. The reaction mixture was stirred at $-78^{\circ} \mathrm{C}$ for $5 \mathrm{~min},-20^{\circ} \mathrm{C}$ for $30 \mathrm{~min}$, then at room temperature for $1 \mathrm{~h}$. The reaction mixture was quenched with $50 \%$ aq. $\mathrm{NH}_{4} \mathrm{CI}$ solution $(150 \mathrm{~mL})$ and extracted EtOAc $(300 \mathrm{~mL})$. The organic layer was washed with water $(150 \mathrm{~mL})$ and brine $(150 \mathrm{~mL})$, dried over $\mathrm{Na}_{2} \mathrm{SO}_{4}$, filtered, and concentrated under reduced pressure. The crude residue was purified by flash column chromatography $\left(\mathrm{SiO}_{2}\right.$ : ethyl acetate / DCM) to afford $7 \mathrm{~g}$ of $\mathbf{S 5 0}$ as yellow solid. Yield: 33\%. ${ }^{1} \mathrm{HNMR}(300 \mathrm{MHz}$, Chloroform- $d$ ) $\delta 7.53(\mathrm{~d}, \mathrm{~J}=1.6 \mathrm{~Hz}, 1 \mathrm{H}), 7.08(\mathrm{dd}, \mathrm{J}=$ 12.0, 2.0 Hz, 1 H), $5.90(\mathrm{~s}, 1 \mathrm{H}), 4.24$ (dd, J = 10.8. 5.2 Hz, 2H), 4.06 (s, 2H), 3.98 - 3.91 (m, 2H), $2.262 .19(\mathrm{~m}, 1 \mathrm{H}), 1.45-1.42(\mathrm{~m}, 1 \mathrm{H}), 1.42(\mathrm{~s}, 6 \mathrm{H}), 1.30(\mathrm{~s}, 9 \mathrm{H}) . \mathrm{MS}$ [ES-MS] (ESI+) m/z found $\mathrm{MH}^{+} 336, \mathrm{C}_{19} \mathrm{H}_{27} \mathrm{FNO}_{3}$ requires 336 .

Step 5: 5-(tert-Butyl)-7-fluoro-3-methoxyisobenzofuran-1(3H)-one S51

A stirred mixture of 2-(4-(tert-butyl)-2-(1,3-dioxan-2-yl)-6-fluorophenyl)-4,4-dimethyl-4,5dihydrooxazole S50 (68.8 g, $205.4 \mathrm{mmol})$ in $\mathrm{MeOH}(1.34 \mathrm{~L})$ and 50\% aq. $\mathrm{H}_{2} \mathrm{SO}_{4}(881 \mathrm{~mL})$ was stirred at reflux overnight. The reaction mixture was diluted with water $(400 \mathrm{~mL})$ and extracted with DCM $(3 \times 1 L)$. The combined organic layers were washed with brine $(400 \mathrm{~mL})$, dried over 
$\mathrm{Na}_{2} \mathrm{SO}_{4}$, filtered, and concentrated under reduced pressure to provide $43 \mathrm{~g}$ of $\mathbf{S 5 1}$ as an off-white solid which was used in the next step without further purification.

Step 6: 6-tert-Butyl-8-fluorophthalazin-1(2H)-one $\mathbf{S 2 6}$

To a stirred solution of 5-(tert-butyl)-7-fluoro-3-methoxyisobenzofuran-1(3H)-one S51 (40 g, $168 \mathrm{mmol})$ in glacial acetic acid $(360 \mathrm{~mL})$ was added hydrazine monohydrate $(240 \mathrm{~mL})$ at $0{ }^{\circ} \mathrm{C}$ under $\mathrm{N}_{2}$. The resulting slurry was stirred under at $50^{\circ} \mathrm{C}$ for $1.5 \mathrm{~h}$. The reaction mixture was diluted with water $(300 \mathrm{~mL})$, and the aqueous layer was extracted with DCM $(2 \times 500 \mathrm{~mL})$. The combined organic layers was dried over $\mathrm{Na}_{2} \mathrm{SO}_{4}$, filtered, and concentrated under reduced pressure. The crude residue was recrystallized from $\mathrm{DMC}$ and $\mathrm{Et}_{2} \mathrm{O}$ to provide $17 \mathrm{~g}$ of $\mathbf{S 2 6}$ as an off-white solid. Yield: $38 \%$ over 2 steps. ${ }^{1} \mathrm{HNMR}(300 \mathrm{MHz}$, Chloroform- $d$ ) $\delta 8.11(\mathrm{~d}, \mathrm{~J}=2.7 \mathrm{~Hz}, 1 \mathrm{H}), 7.52-$ $7.41(\mathrm{~m}, 2 \mathrm{H}), 1.39(\mathrm{~s}, 9 \mathrm{H}), \mathrm{NH}$ not seen. MS [ES-MS] (ESI+) m/z found $\mathrm{MH}^{+} 221, \mathrm{C}_{12} \mathrm{H}_{14} \mathrm{FN}_{2} \mathrm{O}$ requires 221.

Step 7: 2-(6-(tert-Butyl)-8-fluoro-1-oxophthalazin-2(1H)-yl)-4-chloronicotinaldehyde $\mathbf{S 8}$

To a stirred mixture of 6-tert-butyl-8-fluorophthalazin-1(2H)-one $\mathbf{S 2 6}$ (300 mg, $1.36 \mathrm{mmol}$ ) and 2-bromo-4-chloronicotinaldehyde $\mathbf{S 5 2}$ (446 $\mathrm{mg}, 2.05 \mathrm{mmol}, 1.5$ equiv.) in dioxane (50 $\mathrm{mL}$ ) was added KOAc (267 mg, $2.72 \mathrm{mmol}, 2.0$ equiv.), $\mathrm{Cul}$ (259 mg, $1.36 \mathrm{mmol}, 1.0$ equiv.), and 4,7dimethoxy-1,10-phenanthroline (327 mg, $1.36 \mathrm{mmol}, 1.0$ equiv.). Nitrogen was bubbled through the reaction mixture for $30 \mathrm{~min}$, and the mixture was stirred at $90{ }^{\circ} \mathrm{C}$ for $10 \mathrm{~h}$. Water $(100 \mathrm{~mL})$ was added to the cooled reaction, and the aqueous layer was extracted with EtOAc $(2 \times 200 \mathrm{~mL})$. The combined organic layers were washed with brine $(100 \mathrm{~mL})$ and dried over $\mathrm{Na}_{2} \mathrm{SO}_{4}$, filtered, and concentrated under reduced pressure. The crude residue was purified by flash column chromatography ( $\mathrm{SiO}_{2}$ : ethyl acetate / petroleum ether) to afford $120 \mathrm{mg}$ of S8. Yield: $25 \%$. ${ }^{1} \mathrm{HNMR}(500 \mathrm{MHz}$, Chloroform- $d$ ) $\delta 10.36(\mathrm{~s}, 1 \mathrm{H}), 8.69(\mathrm{~d}, \mathrm{~J}=5.5 \mathrm{~Hz}, 1 \mathrm{H}), 8.28(\mathrm{~d}, \mathrm{~J}=2.0 \mathrm{~Hz}$, 1H), $7.28-7.56(\mathrm{~m}, 3 \mathrm{H}), 1.49$ (s, 9H). MS [ES-MS] (ESI+) m/z found $\mathrm{MH}^{+} 360, \mathrm{C}_{18} \mathrm{H}_{16} \mathrm{ClFN}_{3} \mathrm{O}_{2}$ requires 360 .

6-(tert-Butyl)-2-(4-chloro-3-(hydroxymethyl)pyridin-2-yl)-8-fluorophthalazin-1(2H)-one $\mathbf{S 4 3}$

To a solution of 2-(6-(tert-butyl)-8-fluoro-1-oxophthalazin-2(1H)-yl)-4-chloronicotinaldehyde S8 (2.0 g, $5.5 \mathrm{mmol})$ in $\mathrm{MeOH}(30 \mathrm{~mL})$ was added $\mathrm{NaBH}_{4}(700 \mathrm{mg}, 16.5 \mathrm{mmol}, 3.0$ equiv.) at room temperature. The reaction mixture was stirred for $1 \mathrm{~h}$ and quenched with water $(30 \mathrm{~mL})$. Volatile solvent was removed under reduced pressure, and the aqueous phase was extracted with DCM $(3 \times 30 \mathrm{~mL})$. The combined organic layers were dried over anhydrous $\mathrm{Na}_{2} \mathrm{SO}_{4}$, filtered, and 
evaporated under reduced pressure to afford $1.8 \mathrm{~g}$ of $\mathbf{S 4 3}$ as a white solid. Yield: $90 \%$. MS [ESMS] (ESI+) $\mathrm{m} / \mathrm{z}$ found $\mathrm{MH}^{+} 362, \mathrm{C}_{18} \mathrm{H}_{18} \mathrm{ClFN}_{3} \mathrm{O}_{2}$ requires 362 .

Scheme S11. Preparation of S15. ${ }^{a}$
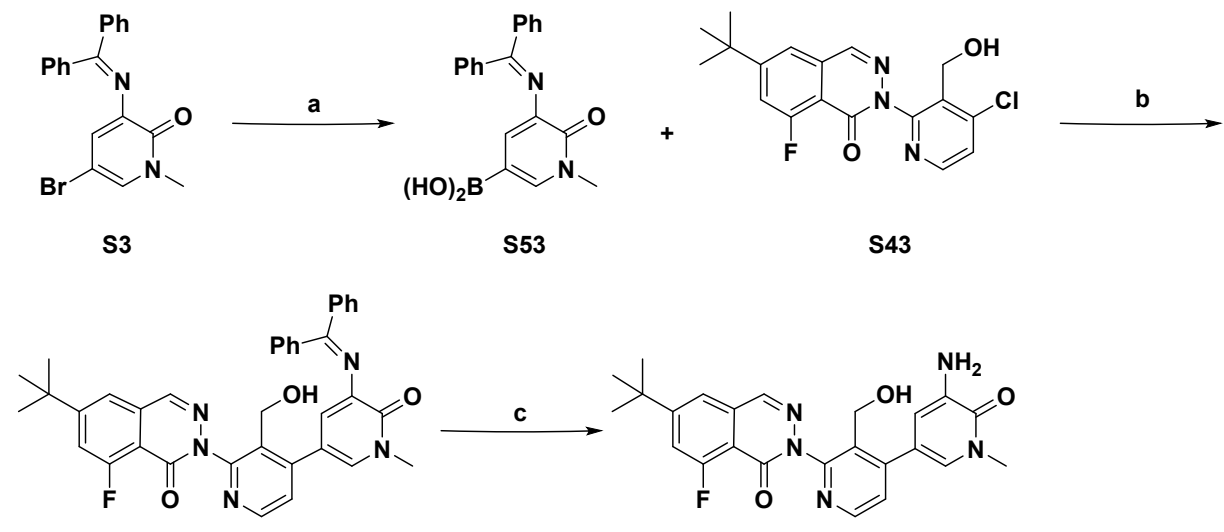

S54

S15

${ }^{a}$ Reagents and conditions: (a) $\operatorname{Pin}_{2} \mathrm{~B}_{2}$, KOAc, XPhos, $\operatorname{Pd}_{2}(\mathrm{dba})_{3}$, dioxane, $60^{\circ} \mathrm{C}, 3 \mathrm{~h}, 93 \%$ yield;

(b) $\mathrm{Pd}(\mathrm{dppf}) \mathrm{Cl}_{2}, \mathrm{~K}_{3} \mathrm{PO}_{4}, \mathrm{NaOAc}, \mathrm{ACN}, \mathrm{H}_{2} \mathrm{O}, 100{ }^{\circ} \mathrm{C}, 2 \mathrm{~h}, 40 \%$ yield; (c) $4 \mathrm{M} \mathrm{HCl}$ in dioxane, 25

${ }^{\circ} \mathrm{C}, 1 \mathrm{~h}, 50 \%$ yield.

2-(5-Amino-3'-(hydroxymethyl)-1-methyl-6-oxo-1,6-dihydro-[3,4'-bipyridin]-2'-yl)-6-(tertbutyl)-8-fluorophthalazin-1(2H)-one $\mathbf{S 1 5}$

Step 1: (5-((Diphenylmethylene)amino)-1-methyl-6-oxo-1,6-dihydropyridin-3-yl)boronic acid S53

A 100-mL round-bottomed flask equipped with a reflux condenser was charged with 5-bromo3-((diphenylmethylene)amino)-1-methylpyridin-2(1H)-one (3.0 g, $8.0 \mathrm{mmol}), \mathrm{Pin}_{2} \mathrm{~B}_{2}(6.1 \mathrm{~g}, 24.0$ mmol, 3.0 equiv.), $\mathrm{Pd}_{2}(\mathrm{dba})_{3}$ (290 mg, $0.40 \mathrm{mmol}, 0.05$ equiv.), XPhos (385 mg, $0.80 \mathrm{mmol}, 0.1$ equiv.), KOAc (1.6 g, $16.0 \mathrm{mmol}, 2.0$ equiv.), and 1,4-dioxane (30 mL). After three cycles of vacuum/argon flush, the mixture was stirred at $60^{\circ} \mathrm{C}$ for $3 \mathrm{~h}$. The reaction was cooled and filtered, and the filtrate was evaporated under reduced pressure. The crude residue was washed with PE to afford $2.5 \mathrm{~g}$ of S53 as brown oil, which was used directly without further purification. Yield: 93\%. MS [ES-MS] $(\mathrm{ESI}+) \mathrm{m} / \mathrm{z}$ found $\mathrm{MH}^{+} 333, \mathrm{C}_{19} \mathrm{H}_{18} \mathrm{BN}_{2} \mathrm{O}_{2}$ requires 333.

Step 2: 6-(tert-Butyl)-2-(5-((diphenylmethylene)amino)-3'-(hydroxymethyl)-1-methyl-6-oxo-1,6dihydro-[3,4'-bipyridin]-2'-yl)-8-fluorophthalazin-1(2H)-one $\mathbf{S 5 4}$ 
A 50-mL round-bottomed flask equipped with a reflux condenser was charged with (5((diphenylmethylene)amino)-1-methyl-6-oxo-1,6-dihydropyridin-3-yl)boronic acid S53 (2.0 g, $6.0 \mathrm{mmol}), 6$-(tert-butyl)-2-(4-chloro-3-(hydroxymethyl)pyridin-2-yl)-8-fluorophthalazin-1(2H)one $\mathbf{S 4 3}$ (2.17 g, 6.0 mmol, 1.0 equiv.), $\mathrm{K}_{3} \mathrm{PO}_{4}(2.54 \mathrm{~g}, 12.0 \mathrm{mmol}, 2.0$ equiv,), $\mathrm{NaOAc}$ (1.0 g, 12.0 mmol, 2.0 equiv.), $\mathrm{Pd}(\mathrm{dppf}) \mathrm{Cl}_{2}$ (245 mg, $0.3 \mathrm{mmol}, 0.05$ equiv.), $\mathrm{ACN}$ (15 mL), and $\mathrm{H}_{2} \mathrm{O}$ (12 $\mathrm{mL}$ ). After three cycles of vacuum/argon flush, the reaction mixture was stirred at $100^{\circ} \mathrm{C}$ under $\mathrm{N}_{2}$ for $2 \mathrm{~h}$.. The reaction was cooled to room temperature and filtered. The filtrate was concentrated under reduced pressure. The residue was diluted with DCM $(20 \mathrm{~mL})$ and water $(10 \mathrm{~mL})$. The aqueous layer was extracted with DCM $(2 \times 10 \mathrm{~mL})$. The combined organic layers were dried over $\mathrm{Na}_{2} \mathrm{SO}_{4}$, filtered, and concentrated under reduced pressure. The crude residue was purified by flash column chromatography $\left(\mathrm{SiO}_{2}: \mathrm{MeOH} / \mathrm{DCM}\right)$ to afford $1.6 \mathrm{~g}$ of $\mathbf{S 5 4}$ as yellow solid. Yield: 40\%. MS [ES-MS] (ESI+) m/z found $\mathrm{MH}^{+} 614, \mathrm{C}_{37} \mathrm{H}_{33} \mathrm{FN}_{5} \mathrm{O}_{3}$ requires 614.

Step 3: 2-(5-Amino-3'-(hydroxymethyl)-1-methyl-6-oxo-1,6-dihydro-[3,4'-bipyridin]-2'-yl)-6(tert-butyl)-8-fluorophthalazin-1(2H)-one $\mathbf{S 1 5}$

A mixture of 6-(tert-butyl)-2-(5-((diphenylmethylene)amino)-3'-(hydroxymethyl)-1-methyl-6oxo-1,6-dihydro-[3,4'-bipyridin]-2'-yl)-8-fluorophthalazin-1(2H)-one S54 (1.6 g, 2.6 mmol) in 4M $\mathrm{HCl}$ in dioxane $(10 \mathrm{~mL})$ was stirred at $25{ }^{\circ} \mathrm{C}$ for $1 \mathrm{~h}$. The mixture was evaporated under reduced pressure, and the crude residue was purified by reverse-phase prep-HPLC to afford $580 \mathrm{mg}$ of S15 as a pale yellow solid. Yield: 50\%. ${ }^{1} \mathrm{H}$ NMR (500 MHz, DMSO-d 6 ) $\delta 8.53-8.52(\mathrm{~m}, 2 \mathrm{H}), 7.90$ $(\mathrm{d}, \mathrm{J}=1.0 \mathrm{~Hz}, 1 \mathrm{H}), 7.79-7.76(\mathrm{~m}, 1 \mathrm{H}), 7.45(\mathrm{~d}, \mathrm{~J}=5.0 \mathrm{~Hz}, 1 \mathrm{H}), 7.24(\mathrm{~d}, \mathrm{~J}=2.5 \mathrm{~Hz}, 1 \mathrm{H}), 6.65$ $(\mathrm{d}, \mathrm{J}=2.0 \mathrm{~Hz}, 1 \mathrm{H}), 5.33$ (s, 2H), $4.95-4.93$ (m, 1H), 4.39 (s, 2H), 3.52 (s, 3H), 1.38 (s, 9H). MS [ES-MS] $(\mathrm{ESI}+) \mathrm{m} / \mathrm{z}$ found $\mathrm{MH}^{+} 450, \mathrm{C}_{24} \mathrm{H}_{25} \mathrm{FN}_{5} \mathrm{O}_{3}$ requires 450.

Scheme S12. Preparation of S35. ${ }^{a}$

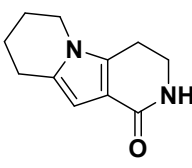

S55

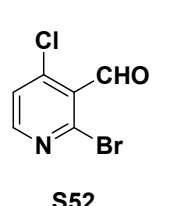

S52
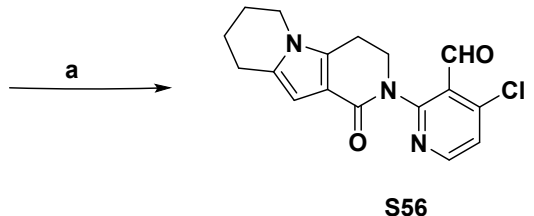

S56

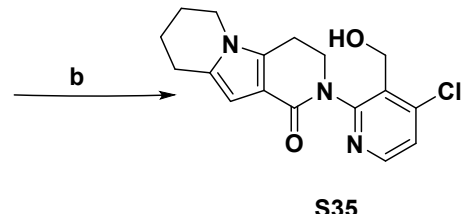

S35

${ }^{a}$ Reagents and conditions: (a) $\mathrm{Pd}_{2}(\mathrm{dba})_{3}$, XantPhos, $\mathrm{K}_{2} \mathrm{CO}_{3}$, dioxane, $80{ }^{\circ} \mathrm{C}$, overnight, $50 \%$ yield; (b) $\mathrm{NaBH}_{4}, \mathrm{MeOH}, 30^{\circ} \mathrm{C}, 1 \mathrm{~h}, 92 \%$ yield. 
2-(4-Chloro-3-(hydroxymethyl)pyridin-2-yl)-3,4,6,7,8,9-hexahydropyrido[3,4-b]indolizin-1(2H)one S35

Step 1: 4-Chloro-2-(1-oxo-3,4,6,7,8,9-hexahydropyrido[3,4-b]indolizin-2(1H)-yl)nicotinaldehyde S56

A 250-mL single-neck round-bottomed flask equipped with a magnetic stirrer and reflux condenser was charged with 1,4-dioxane $(50 \mathrm{~mL}), 3,4,6,7,8,9$-hexahydropyrido[3,4-b]indolizin1(2H)-one S55 (0.6 g, 3.2 mmol), 2-bromo-4-chloronicotin-aldehyde S52 (1.4 g, 6.4 mmol, 2.0 equiv.), $\mathrm{Pd}_{2}(\mathrm{dba})_{3}(293 \mathrm{mg}, 0.32 \mathrm{mmol}, 0.1$ equiv.), XantPhos (370 mg, $0.64 \mathrm{mmol}, 0.2$ equiv.), and potassium carbonate ( $627 \mathrm{mg}, 6.4 \mathrm{mmol}, 2.0$ equiv.). After three cycles of vacuum/argon flush, the mixture was stirred at $80{ }^{\circ} \mathrm{C}$ overnight. The reaction was cooled to room temperature and filtered, and the filtrate was evaporated under reduced pressure. The crude residue was purified by flash column chromatography $\left(\mathrm{SiO}_{2}: \mathrm{MeOH} / \mathrm{DCM}\right)$ to afford $528 \mathrm{mg}$ of $\mathbf{S 5 6}$ as a yellow solid. Yield: 50\%. ${ }^{1} \mathrm{H}$ NMR (500 MHz, Chloroform- $d$ ) $\delta 10.09(\mathrm{~s}, 1 \mathrm{H}), 8.37$ (d, J = 5.5 Hz, 1H), $7.16(\mathrm{~d}$, $\mathrm{J}=5.5 \mathrm{~Hz}, 1 \mathrm{H}), 6.25(\mathrm{~s}, 1 \mathrm{H}), 4.29-4.32(\mathrm{~m}, 2 \mathrm{H}), 3.83-3.86(\mathrm{~m}, 2 \mathrm{H}), 2.96-2.99(\mathrm{~m}, 2 \mathrm{H}), 2.75$ $-2.78(\mathrm{~m}, 2 \mathrm{H}), 2.00-2.07(\mathrm{~m}, 2 \mathrm{H}), 1.82-1.85(\mathrm{~m}, 2 \mathrm{H}) . \mathrm{MS}$ [ES-MS] (ESI+) $\mathrm{m} / \mathrm{z}$ found $\mathrm{MH}^{+}$ $330, \mathrm{C}_{17} \mathrm{H}_{17} \mathrm{ClN}_{3} \mathrm{O}_{2}$ requires 330 .

Step 2: 2-(4-Chloro-3-(hydroxymethyl)pyridin-2-yl)-3,4,6,7,8,9-hexahydropyrido[3,4b]indolizin-1 (2H)-one $\mathbf{S 3 5}$

To a solution of 4-chloro-2-(1-oxo-3,4,6,7,8,9-hexahydropyrido[3,4-b]indolizin-2(1H)yl)nicotinaldehyde $\mathbf{S 5 6}(1.0 \mathrm{~g}, 3.0 \mathrm{mmol})$ in $\mathrm{MeOH}(30 \mathrm{~mL})$ was added $\mathrm{NaBH}_{4}(380 \mathrm{mg}, 9.0 \mathrm{mmol}$, 3.0 equiv.). The reaction mixture was stirred at $30^{\circ} \mathrm{C}$ for $1 \mathrm{~h}$ and then quenched with water $(10$ $\mathrm{mL}$ ). Volatile solvent was concentrated under reduced pressure, and the crude was extracted with DCM $(3 \times 20 \mathrm{~mL})$. The combined organic layers were dried over anhydrous $\mathrm{Na}_{2} \mathrm{SO}_{4}$, filtered, and evaporated under reduced pressure to afford $920 \mathrm{mg}$ of a yellow solid, which was used as is in the next reaction step. Yield: $92 \%$. MS [ES-MS] (ESI+) $\mathrm{m} / \mathrm{z}$ found $\mathrm{MH}^{+} 332, \mathrm{C}_{17} \mathrm{H}_{19} \mathrm{ClN}_{3} \mathrm{O}_{2}$ requires 332. 


\section{IN VITRO PHARMACOLOGY}

Btk assays.

Btk kinase activity and inhibition was assessed using a peptide phosphorylation assay as previously described (1). The inhibitor concentration at $50 \%$ inhibition $\left(\mathrm{IC}_{50}\right)$ values were calculated from inhibitor titration data by plotting the \% of Control Btk activity against test article concentration and fitting the data to a standard 4-parameter sigmoidal inhibition equation using Prism v5 software (GraphPad Software LLC; San Diego, CA, USA).

In vitro whole blood $\mathrm{pBTK}$ assay.

Heparinized human whole blood was treated with test article for $1 \mathrm{~h}$ at $37^{\circ} \mathrm{C}(0.4 \% \mathrm{DMSO}$ final concentration). Blood was lysed with $2 \mathrm{X}$ lysis buffer (Cell Signaling Technology) containing protease (Roche Applied Science) and phosphatase inhibitors (cocktail II and III) (Sigma). Phosphorylation of Btk at the Y223 residue was evaluated using Meso Scale Discovery (MSD) technology. Mouse anti-total Btk Ab (BD Bioscience) and rabbit anti-pBtk-Y223 mAbs (Epitomics) followed by a SULFO-TAG anti-rabbit Ab (MSD) were used for detection.

Human whole blood CD69 assay.

Heparinized human whole blood was incubated with test article for $1 \mathrm{~h}$ at $37^{\circ} \mathrm{C}$ (11-point titration, with 3-fold dilution with a top concentration of $4.76 \mu \mathrm{M}$ ) or $0.4 \%$ DMSO vehicle control. Blood was then stimulated with $50 \mu \mathrm{g} / \mathrm{mL}$ of goat anti-IgM F(ab')2 (Southern Biotech) for $18 \mathrm{~h}$. After incubation, B cells were stained with anti-mouse CD19 PerCP (BD Biosciences, clone SJ25C1), anti-mouse CD27 FITC (BD Biosciences, clone L128) and anti-mouse CD69 PE (BD Biosciences, clone FN50) or Isotype IgG1 PE antibodies for $30 \mathrm{~min}$ at room temperature followed by RBC lysis using 1X BD lysis buffer. Cells were washed with FACS buffer and fixed with 2\% paraformaldehyde. Samples were acquired on BD LSR II and analyzed using BD FACSDiva software. B cells were gated as CD19+CD27- and B cell activation was assessed based on CD69 PE mean fluorescence intensity (MFI).

Measure of error / number of replicates for CD69 and pBtk HWB assays

Mean $\mathrm{IC}_{50}+/-\mathrm{SD}(\mathrm{n}=$ determinations $)$

Cmpd 6: $\mathrm{CD} 69=8.5+/-5.6 \mathrm{nM}(\mathrm{n}=6) ; \mathrm{pBTK}=11+/-4.2 \mathrm{nM}(\mathrm{n}=6)$

Cmpd 25: $\operatorname{CD} 69=78+/-57 \mathrm{nM}(\mathrm{n}=3) ; \mathrm{pBTK}=79+/-13 \mathrm{nM}(\mathrm{n}=7)$ 
Liver Microsome Metabolic Stability Assays

Metabolic stability of test compounds was evaluated in pooled human, mouse, and rat liver microsomes (BD Biosciences, San Jose, CA). The final incubations contained: $1 \mu \mathrm{M}$ of the tested compound, $1 \mathrm{mM} \mathrm{NADPH}, 0.5 \mathrm{mg} / \mathrm{mL}$ microsomal protein in $0.1 \mathrm{M}$ potassium phosphate buffer (pH 7.4). Following a 5-minute pre-incubation period, the enzymatic reactions were initiated by the addition of NADPH and test compound to the microsomes diluted in phosphate buffered saline. The mixtures were incubated at $37^{\circ} \mathrm{C}$ for $0,20,40$, and $60 \mathrm{~min}$. Compound concentrations were assessed by LCMS/MS. Intrinsic clearance based upon microsomal stability data was determined using a substrate depletion method and scaled to hepatic clearance using the well-stirred model. ${ }^{2}$

Hepatocyte Metabolic Stability Assays

Metabolic stability assays of test compounds were carried out using cryopreserved pooled donor mouse, rat, dog, cynomolgus monkey, and human hepatocytes (CellzDirect; Durham, NC). Membrane integrity of the cells was assessed by trypan blue exclusion. Test compounds ( $1 \mu \mathrm{M}$ with $0.1 \%$ DMSO $)$ were incubated with cells $(0.5$ million cells $/ \mathrm{mL})$ at $37{ }^{\circ} \mathrm{C}$ in a $95 \%$ air $/ 5 \% \mathrm{CO}_{2}$ atmosphere for $0,20,40$, or $60 \mathrm{~min}$. Concentrations of test compounds in hepatocyte incubations were determined by LC-MS/MS. Intrinsic clearance was determined using a substrate depletion method and scaled to hepatic clearance using the well-stirred model (vide supra).

In Vitro Permeability Assay in MDCK (Madin-Darby Canine Kidney) Cells

The permeability of test compounds was determined in MDCK cells (American Type Culture Collection; Manassas, VA). Four days prior to use, MDCK cells were seeded at a density of $2.5 \times 105$ cells $/ \mathrm{mL}$ in 24 well plates. Compounds were dissolved in transport buffer consisting of Hank's Balanced Salt Solution with 10 mM HEPES (Invitrogen Corporation, Grand Island, NY) at a concentration of $10 \mu \mathrm{M}$, and permeability was assessed in the apical to basolateral (A-B) and basolateral to apical (B-A) directions following a 3 hour incubation. Lucifer Yellow (Sigma Aldrich, St. Louis, MO) was used as the cell monolayer integrity marker. Test compound concentrations in the donor and receiving compartments were determined by LC-MS/MS. The apparent permeability (Papp) of test compounds was determined as follows:

$$
\mathrm{P}_{\mathrm{app}}=(\mathrm{dQ} / \mathrm{dt})^{*}\left(1 / \mathrm{AC}_{0}\right)
$$


Where $\mathrm{dQ} / \mathrm{dt}$ is the rate of compound appearance in the receiver compartment, $\mathrm{Q}$ is the quantity of compound), $\mathrm{C} 0$ is the concentration in the donor compartment and $\mathrm{A}$ is the surface area of the insert. Efflux ratio was calculated as $\mathrm{P}_{\text {app, B-A}} /$ Papp, A-B.

In Vitro Plasma Protein Binding

In vitro plasma protein binding $(\mathrm{n}=2)$ was determined in pooled mouse, rat, and human plasma (Bioreclamation, Inc., Hicksville, NY) by equilibrium dialysis using a Rapid Equilibrium Dialysis (RED) device (Pierce Biotechnology / Thermo Fisher Scientific; Rockford, IL) with a molecular weight cut-off of 8000 Daltons. Test compounds were added to plasma. Plasma samples were equilibrated with phosphate-buffered saline at $37{ }^{\circ} \mathrm{C}$ for 4 hours. Compound concentrations in post-dialysis plasma and buffer samples were measured by LC-MS/MS. The percent unbound fraction in plasma for each compound was calculated by dividing the compound concentration in the post-dialysis buffer by that measured in the post-dialysis plasma and multiplying by $100 \%$.

Reversible CYP and Inhibition Studies in Human Liver Microsomes ${ }^{3}$

Compound 25 was incubated with human liver microsomes (150 donor pool, BD Biosciences, San Jose, CA) fortified with NADPH and isoform-specific probe substrates. Reactions were stopped by the addition of cold acetonitrile/formic acid ( $94: 6 \mathrm{v} / \mathrm{v})$ containing internal standard. Five concentrations of each compound were tested $(10,5,1$, and $0.1 \mu \mathrm{M}$ as well as a solvent control) $\mathrm{S} 30$ to generate $\mathrm{IC}_{50}$ values.

\section{Aqueous Solubility Determinations}

Compounds were dissolved in DMSO to a concentration of $10 \mathrm{mM}$. These solutions were diluted into PBS buffer ( $\mathrm{pH} 7.2$, composed with $\mathrm{NaCl}, \mathrm{KCl}, \mathrm{Na}_{2} \mathrm{HPO}_{4}$, and $\mathrm{KH}_{2} \mathrm{PO}_{4}$ ) to a final compound concentration of $100 \mu \mathrm{M}$, DMSO concentration of $2 \%$, at $\mathrm{pH}$ 7.4. The samples were shaken for 24 hours at room temperature followed by filtration. LC/CLND was used to determine compound concentration in the filtrate, with the concentration calculated by a caffeine calibration curve and the sample's nitrogen content. An internal standard compound was spiked into each sample for accurate quantification. 


\section{hERG Automatic Patch Clamp Assay}

The in vitro effects of test articles on hERG potassium channel current expressed in mammalian cells were evaluated at room temperature by using automated patch-clamp technique, the QPatch HT (Sophion Bioscience A/S, Denmark) or QPatch HTX (Sophion Bioscience) at Chantest (Cleveland, OH) or Wuxi AppTec (Shanghai, China), respectively. $\mathrm{IC}_{50 \mathrm{~s}}$ of 24, 25, 33, and 34 were determined based on the data from five concentrations tested $(0.1,0.3,1,3$, and $10 \mu \mathrm{M})$.

\section{Induced Pluripotent Stem Cell (iPSC)-derived Cardiomyocyte Multi-electrode Array Assay}

iPSC-derived cardiomyocytes (icell ${ }^{4}$ cardiomyocytes, Fujifilm Cellular Dynamics, Madison, WI) were thawed and plated on 96-well multi-electrode array (MEA) plates (Axion Biosystems, Atlanta, GA) according to manufacturer directions. Briefly, cells were spotted in $5 \mu \mathrm{L}$ droplets over electrodes at a density of 60k/well on fibronectin (Roche, Pleasanton, CA) and maintained for 7 days. A $100 \%$ media change was performed one day prior to compound treatment. Compounds were initially diluted in DMSO, and added to wells at 10x target concentration in media for a final DMSO concentration of $0.1 \%$. A single dose per well scheme was utilized with 4 replicates per condition, and time matched controls included untreated (media only), vehicle, cisapride (hERG channel blocker, Sigma Aldrich, St Louis, MO), and nifedipine (calcium channel blocker, Sigma Aldrich). On the day of the experiment, plates were moved from the incubator to the MEA device (Maestro, Axion Biosystems) with environmental controls $\left(37^{\circ} \mathrm{C}\right.$ and $\left.5 \% \mathrm{CO}_{2}\right)$ and allowed to equilibrate for 5 minutes prior to recording a baseline measurement. Dosing was performed manually in a biosafety cabinet in under 10 minutes, after which plates were returned to the MEA platform for post-dose recordings. All recordings were at least 5 minutes in length and analyzed using instrument specific software with semi-automated analysis of field potential signals. Endpoints included sodium spike amplitude and field potential duration, which was corrected for beat rate using the Fridericia correction (2). Values were normalized first to baseline, then vehicle. Additionally, beat waveforms were inspected for arrhythmic events and drug-induced beat cessation (quiescence). 


\section{Pharmacokinetic (PK) study protocols.}

\section{Rat pharmacokinetic study.}

Nine male Sprague Dawley rats (275-300g) obtained from Charles River Laboratories (Hollister, CA) were divided evenly into three dose groups ( $\mathrm{n}=3$ rats/group). Animals in Group 1 were given a single IV dose of $1 \mathrm{mg} / \mathrm{kg}$ compound 25 in $60 \%$ polyethylene glycol 400 (PEG400)/15\% EtOH/50mM NaCitrate, $\mathrm{pH} 4.2$ at $1 \mathrm{~mL} / \mathrm{kg}$. Animals in Group 2 were given 5 $\mathrm{mg} / \mathrm{kg}$ PO dose of $\mathbf{2 5}$ in 0.5\% hydroxypropyl methyl cellulose (HPMC) $/ 50 \mathrm{mM}$ sodium citrate (NaCitrate), pH 3.0, as an amorphous solid dispersion (ASD) suspension at $2 \mathrm{~mL} / \mathrm{kg}$, and animals in Group 3 were given $5 \mathrm{mg} / \mathrm{kg}$ PO dose of 25 in 1\% HPMC/0.2\% polysorbate 80 (Tween 80 ) /50 $\mathrm{mM} \mathrm{NaCitrate,} \mathrm{pH} 3.0$, as crystalline suspension at $2 \mathrm{~mL} / \mathrm{kg}$. The blood samples were collected at $0.033,0.167,0.5,1,2,4,6$ and 8 hours after IV administration. For PO administration, the blood samples were collected at $0.083,0.25,0.5,1,2,4,6$, and 8 hours post dose. Blood was centrifuged to harvest plasma. Concentration of $\mathbf{2 5}$ in each plasma sample was determined by a non-validated liquid chromatography tandem mass spectrometry assay at Genentech, Inc. Pharmacokinetic (PK) analysis was performed using non-compartmental methods and the IV bolus input model (Model 201) or extravascular (Model 200), WinNonlin-Enterprise ${ }^{\circledR}$, version 5.2.1. Following PO administration (Groups 2 and 3), percent bioavailability (\% F) was determined for each animal by dividing the dose-normalized area under the plasma concentration-time curve extrapolated to infinity (AUCinf) obtained following each PO dose by the mean dose-normalized AUCinf of the animals dosed by IV injection (Group 1). 


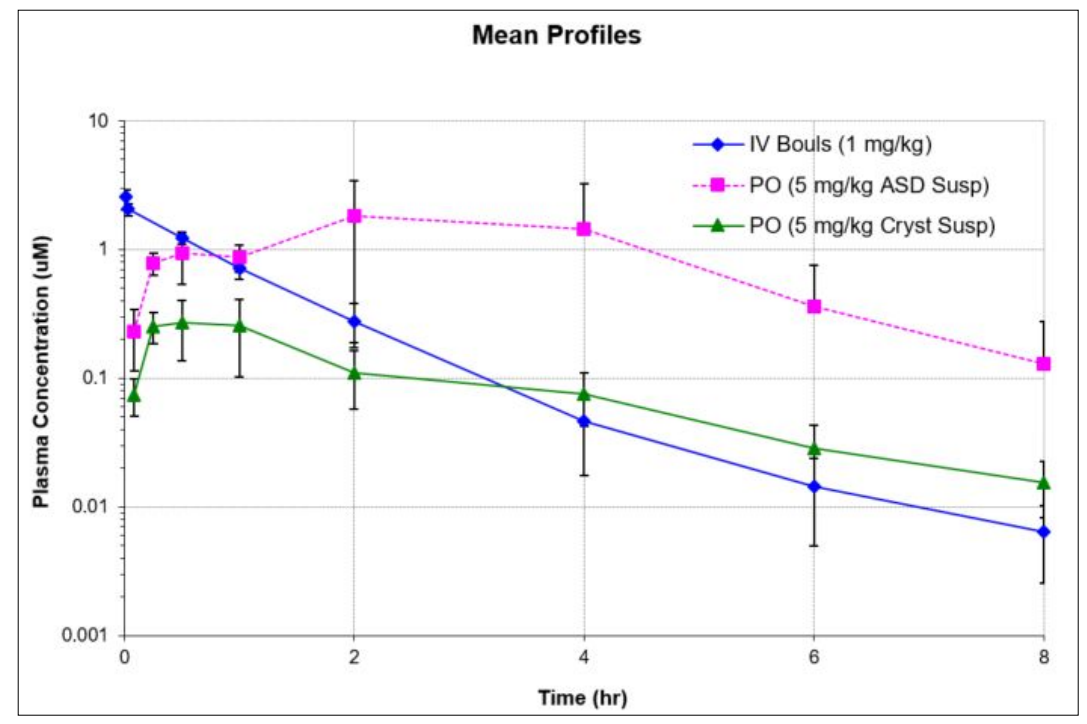

Figure S1. Mean total plasma concentration vs. time profiles of compound 25 after an IV bolus dose of $1 \mathrm{mg} / \mathrm{kg}$ and a PO dose of $5 \mathrm{mg} / \mathrm{kg}$ (ASD suspension) and a PO dose of $\mathrm{mg} / \mathrm{kg}$ (Crystalline suspension) in male Sprague-Dawley rats, $\mathrm{n}=3$, mean $\pm \mathrm{SD}$.

\section{Dog pharmacokinetic study.}

Six male beagle dogs (7-12 kg) obtained from Marshall Bioresources (Beijing, China) were divided evenly into two dose groups ( $\mathrm{n}=3$ dogs/group). Animals in Group 1 were given a single IV dose of $1 \mathrm{mg} / \mathrm{kg}$ compound 25 in 60\% PEG400/15\% EtOH/50mM NaCitrate, pH 4.2 at 1 $\mathrm{mL} / \mathrm{kg}$. Animals in Group 2 were given $5 \mathrm{mg} / \mathrm{kg}$ PO dose of 25 in $0.5 \% \mathrm{HPMC} / 50 \mathrm{mM}$ NaCitrate, $\mathrm{pH} 3.0$, as a suspension at $2 \mathrm{~mL} / \mathrm{kg}$. The blood samples were collected at $0.033,0.083,0.25,0.5$, 1, 3, 6, 9 and 24 after IV and PO administration. Blood was centrifuged to harvest plasma. Concentration of $\mathbf{2 5}$ in each plasma sample was determined by a non-validated liquid chromatography tandem mass spectrometry assay at WuXi AppTec. Pharmacokinetic (PK) analysis was performed at Genentech, Inc., using non-compartmental methods and the IV bolus input model (Model 201) or extravascular (Model 200), WinNonlin-Enterprise ${ }^{\circledR}$, version 5.2.1. Following PO administration (Group 2), percent bioavailability (\% F) was determined for each animal by dividing the dose-normalized area under the plasma concentration-time curve extrapolated to infinity (AUCinf) obtained following each PO dose by the mean dose-normalized AUCinf of the animals dosed by IV injection (Group 1). 


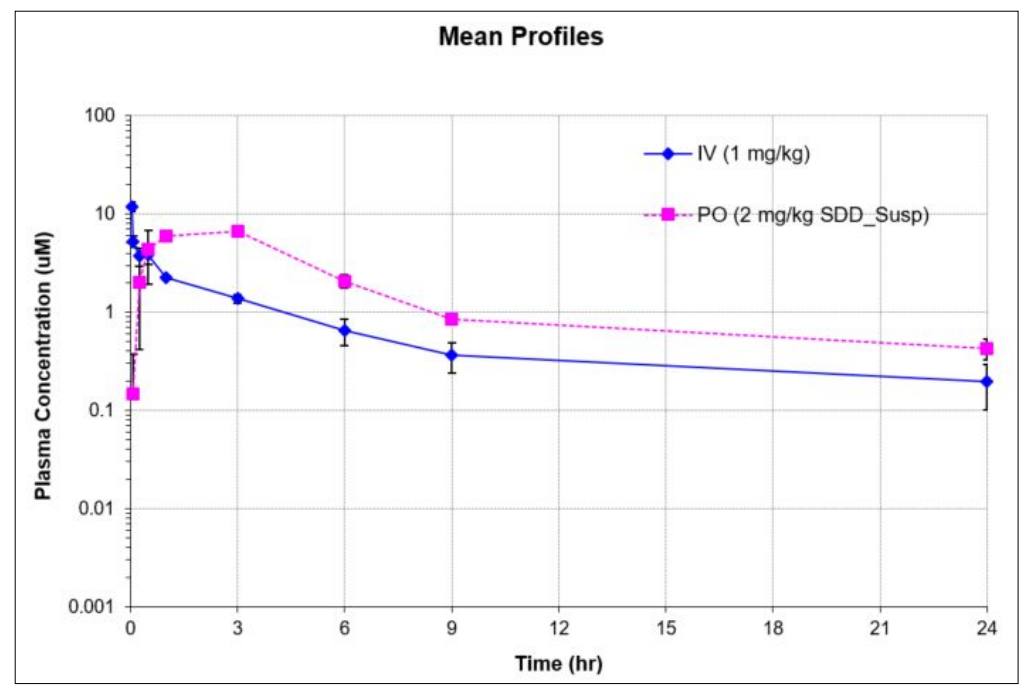

Figure S2. Mean total plasma concentration vs. time profiles of compound $\mathbf{2 5}$ after an IV dose of $1 \mathrm{mg} / \mathrm{kg}$ and a PO dose of $5 \mathrm{mg} / \mathrm{kg}$ (selective decontamination of the digestive tract [SSD] suspension) in male Beagle dogs, $\mathrm{n}=3$, mean $\pm \mathrm{SD}$.

\section{Animal Care:}

Animals were pair-housed in cages that are in accordance with applicable animal welfare laws and regulations during acclimation period.

The room was controlled and monitored for humidity (targeted mean range $40 \%$ to $70 \%$, and any excursion from this range for more than 3 hours will be documented as a deviation) and temperature (targeted mean range $18^{\circ}$ to $26^{\circ} \mathrm{C}$, and any excursion from this range will be documented as a deviation) with 10 to 20 air changes/hour. The room was on a 12-hour light/dark cycle except when interruptions are necessitated by study activities.

The dogs were individually housed in cages during experiment. The animals were fed twice daily. Stock dogs were fed approximately 220 grams of Certified Dog Diet daily (Beijing Vital Keao Feed Co., Ltd. Beijing, P. R. China). These amounts were adjusted as necessary based on food consumption of the group or an individual, body weight changes of the group or an individual and/or changes in the certified diet.

For fasted group (PO dose group), animals were fed the afternoon (at 3:30 to 4:00 pm) prior to the day of oral dosing and the remaining food were removed at about 8:00 pm. Food were withheld until 4-hour post-dose unless specified in this protocol. Fasted animals were fed once on the day of dosing, with the amount of approximately $220 \mathrm{~g}$. 
Fresh drinking water were available to all animals, ad libitum. Feed and water analyses were maintained.

\section{KINASE SELECTIVITY}

Table S1. Selectivity of 6 and 25 tested in duplicate at $1 \mu \mathrm{M}$ in the SelectScreen kinase assay panel (ThermoFisher Scientific; Madison, WI); the mean percent inhibition is shown. The [ATP] column indicates the concentration of ATP used in each assay: Km app means the ATP concentration was within 2-fold of the experimentally determined apparent $\mathrm{Km}$ in the assay; NA (Not Applicable) denotes these were binding assays and no ATP was present; and 10 or 100 are micromolar concentrations of ATP. Gray cells indicate the kinase was not tested. 

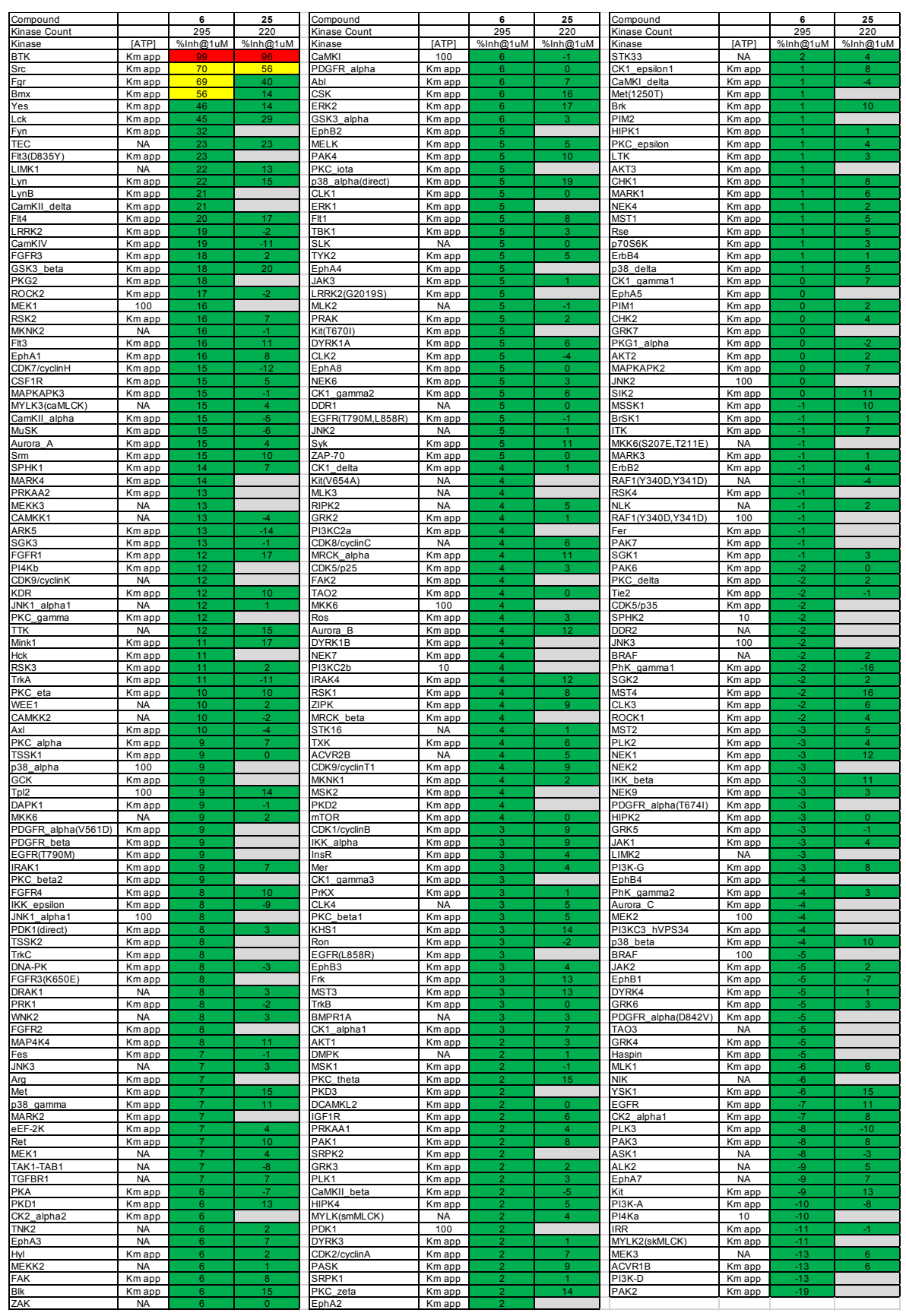

Table S2. Comparison of kinome selectivity of $\mathbf{2 5}$ vs. 6 against the top hits in the SelectScreen kinase assay panel (ThermoFisher Scientific; Madison, WI).

\begin{tabular}{|c|c|c|}
\hline & $\mathbf{2 5}$ & $\mathbf{6}$ \\
\hline Kinases & \%Inh $\boldsymbol{a} \mathbf{1} \mathbf{M}\left(\mathbf{I C}_{\mathbf{5 0}}\right)$ & \%Inh $\boldsymbol{a} \mathbf{1} \boldsymbol{M}\left(\mathbf{I C}_{\mathbf{5 0}}\right)$ \\
\hline Btk & $96(2.4 \mathrm{nM})$ & $99(2.3 \mathrm{nM})$ \\
\hline Src & $56(1330 \mathrm{nM})$ & $70(302 \mathrm{nM})$ \\
\hline
\end{tabular}




\begin{tabular}{|c|c|c|}
\cline { 2 - 3 } Fgr & 40 & $69(387 \mathrm{nM})$ \\
\hline $\operatorname{Bmx}$ & 14 & $56(351 \mathrm{nM})$ \\
\hline
\end{tabular}




\section{CRYSTALLOGRAPHY}

Btk kinase domain protein was expressed in insect cells, purified, and crystallized as previously described $^{3}$. Diffraction data for the complex of Btk and 25 were collected at beamline 21-IDF of the Advanced Photon Source, and the data were integrated and scaled in HKL2000 ${ }^{5}$. The structure was determined by molecular replacement in space group P6 1 with PHASER ${ }^{6}$, and with unit cell dimensions $\mathrm{a}=\mathrm{b}=108.3 \AA, \mathrm{c}=42.2 \AA, \alpha=\beta=90^{\circ}$, and $\gamma=120^{\circ}$, with one protein molecule in the asymmetric unit. Clear electron density of the inhibitor (Figure S3) was observed in all protein molecules. The structure was refined in PHENIX ${ }^{7}$ (Table S3).
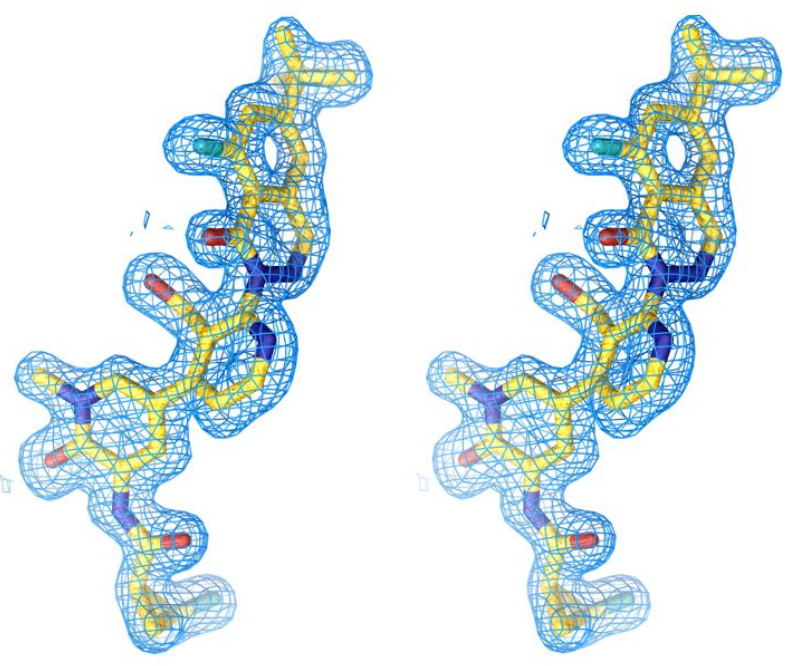

Figure S3: Electron density map of inhibitor 25 in complex with Btk. Divergent eye stereo diagram of the simulated annealing composite omit difference electron density map, $\left(2 \mathrm{~m}\left|\mathrm{~F}_{\mathrm{o}}\right|-\mathrm{D}\left|\mathrm{F}_{\mathrm{c}}\right|\right) \exp \left(i \alpha_{\mathrm{c}}\right)$, of the Btk inhibitor $\mathbf{2 5}$, contoured at $1 \sigma$. 
Table S3: Btk crystallographic data collection and refinement statistics.

\begin{tabular}{lc}
\hline PDB code & 6XE4 \\
Compound \# & $\mathbf{2 5}$ \\
\hline Beamline & APS 21-IDF \\
Wavelength $(\AA)$ & 0.97872 \\
Space group & P6 1 \\
Kinase molecules in ASU & 1 \\
Resolution range $(\AA)$ & $35.0-1.60$ \\
Highest resolution bin $(\AA)$ & $1.63-1.60$ \\
Redundancy & $7.6(6.0)$ \\
Completeness $(\%)$ & $98.8(93.9)$ \\
Mean $\mathrm{I} / \sigma_{\mathrm{I}}$ & $13.8(2.4)$ \\
$\mathrm{R}_{\text {merge }}(\%)$ & $8.5(80.2)$ \\
CC $1 / 2$ highest bin & 0.54 \\
\hline
\end{tabular}

\section{Refinement}

Resolution range $(\AA)$

$33.3-1.60$

No. reflections $\left(\mathrm{R}_{\text {free }} \mathrm{set}\right)$

$37,117(1,912)$

$\mathrm{R}_{\text {work }}, \mathrm{R}_{\text {free }}(\%)$

$18.0,15.6$

No. non-hydrogen atoms in ASU

2,498

No. water molecules in ASU

276

Rmsd bond lengths $(\AA)$

0.005

Rmsd bond angles $\left(^{\circ}\right)$

0.792

Molprobity clash score

0.69

Ramachandran most favored region

$98.1 \%$

Ramachandran outlier region

$0 \%$

Values in parentheses represent data from the highest resolution shell. 


\section{SI REFERENCES}

(1) Crawford, J. J.; Johnson, A. R.; Misner, D. L.; Belmont, L. D.; Castanedo, G.; Choy, R.; Coraggio, M.; Dong, L.; Eigenbrot, C.; Erickson, R.; Ghilardi, N.; Hau, J.; Katewa, A.; Kohli, P. B.; Lee, W.; Lubach, J. W.; McKenzie, B. S.; Ortwine, D. F.; Schutt, L.; Tay, S.; Wei, B.; Reif, K.; Liu, L.; Wong, H.; Young, W. B. Discovery of GDC-0853: A Potent, Selective, and Noncovalent Bruton's Tyrosine Kinase Inhibitor in Early Clinical Development. Journal of Medicinal Chemistry 2018, 61 (6), 2227-2245. (See also, Supporting Information).

(2) Obach, R. S.; Baxter, J. G.; Liston, T. E.; Silber, B. M.; Jones, B. C.; MacIntyre, F.; Rance, D. J.; Wastall, P. The prediction of human pharmacokinetic parameters from preclinical and in vitro metabolism data. J. Pharmacol. Exp. Ther. 1997, 283 (1), 46-58.

(3) Halladay, J. S.; Delarosa, E. M.; Tran, D.; Wang, L.; Wong, S.; Khojasteh, S. C. Highthroughput, 384-well, LC-MS/MS CYP inhibition assay using automation, cassette-analysis technique, and streamlined data analysis. Drug. Metab. Lett. 2011, 5 (3), 220-30.

(4) Fridericia, L. S. The duration of systole in the electrocardiogram of normal subjects and of patients with heart disease. Acta Medica Scandinavica 1920, 53, 469-486.

(5) Otwinowski, Z.; Minor, W., [20] Processing of X-ray diffraction data collected in oscillation mode. In Methods in Enzymology, Academic Press: 1997, 276, 307-326.

(6) McCoy, A. J.; Oeffner, R. D.; Wrobel, A. G.; Ojala, J. R. M.; Tryggvason, K.; Lohkamp, B.; Read, R. J., Ab initio solution of macromolecular crystal structures without direct methods. Proc. Natl. Acad. Sci. U. S. A. 2017, 114 (14), 3637-3641.

(7) Adams, P. D.; Afonine, P. V.; Bunkoczi, G.; Chen, V. B.; Davis, I. W.; Echols, N.; Headd, J. J.; Hung, L.-W.; Kapral, G. J.; Grosse-Kunstleve, R. W.; McCoy, A. J.; Moriarty, N. W.; Oeffner, R.; Read, R. J.; Richardson, D. C.; Richardson, J. S.; Terwilliger, T. C.; Zwart, P. H., PHENIX: a comprehensive Python-based system for macromolecular structure solution. Acta Cryst. D 2010, 66 (2), 213-221 